Universidade de São Paulo

Instituto de Física

\title{
Estudo da Cristalinidade de Filmes Finos de Nitreto de Índio e simulado pelo pacote de programas Wien $2 \mathrm{k}$
}

\author{
Yocefu Hattori
}

Orientador: Prof. Dr. José Fernando Diniz Chubaci

Dissertação de mestrado apresentada ao Instituto de Física para a obtenção do título de Mestre em Ciências

Banca Examinadora:

Prof. Dr. José Fernando Diniz Chubaci (IFUSP)

Profa. Dra. Lucy V. C. Assali (IFUSP)

Prof. Dr. João Francisco Justo Filho (POLI-USP) 
"Physics isn't the most important thing. Love is."

Richard Feynman 


\section{Agradecimentos}

Ao meu amigo e orientador, professor José Fernando Diniz Chubaci pela oportunidade e o apoio para conclusão desse trabalho, sem contar o grande estímulo para continuação dos estudos durante a graduação e o mestrado.

Ao professor Masao Matsuoka, que me acompanhou e guiou durante todas as deposições dos filmes finos, além de ter auxiliado a resolver todos os problemas técnicos decorrentes. O seu imenso e minucioso conhecimento técnico a respeito do IBAD foi e é essencial para as deposições de filmes.

Ao professor Antônio Ferreira da Silva, por ter me recebido na UFBa (Universidade Federal da Bahia) por um mês para o estudo de programas computacionais de estrutura eletrônica.

Aos técnicos do Departamento de Física Nuclear e da Mecânica, pelo imenso suporte técnico.

À minha família, pela grande ajuda financeira e constante suporte durante todos os anos de graduação e mestrado.

Aos meus amigos, por principalmente me ajudarem em momentos difíceis.

À Nicolle Dantas Gusmão pelo seu valioso carinho e amor.

À CNPq e CAPES pelo apoio financeiro. 


\section{RESUMO}

Neste trabalho, foi utilizado o método de deposição assistida por feixe de íons (IBAD na sigla em inglês) para produção de filmes finos de nitreto de índio em substratos de silício (111) e safira (001). Variando as condições de deposição e utlilizando a técnica de difração de raios-X, investigou-se com o intuito de obter os parâmetros que resultam em filmes finos com melhor grau de cristalinidade. Os filmes produzidos a $380^{\circ} \mathrm{C}$ apresentaram alta cristalinidade, superior àqueles a $250{ }^{\circ} \mathrm{C}$. Temperaturas muito superiores a $380^{\circ} \mathrm{C}$ não ocasionam a formação de filme cristalino de $\mathrm{InN}$, como foi observado ao utilizar a temperatura de $480^{\circ} \mathrm{C}$; o mesmo se observa ao utilizar temperatura ambiente. Na temperatura considerada adequada , de $380^{\circ} \mathrm{C}$, obteve-se que a utilização de $R_{a}$, ou seja, a razão de fluxo de partículas entre o nitrogênio e índio, em torno de 2,3 permite obter um melhor grau de cristalinização, o qual decresce conforme se diverge desse valor. A comparação entre difratogramas de amostras produzidas com e sem a evaporação prévia de titânio, o qual é possível observar um deslocamento dos picos do InN, indicam que o efeito Gettering permite a redução de impurezas no filme, principalmente de oxigênio. Utilizou-se a técnica de Retroespalhamento de Rutherford para obtenção da composição dos elementos e o perfil de profundidade. Notou-se uma forte mistura dos elementos do substrato de silício e safira com o nitreto de índio mesmo próximos a superfície.

A presença indesejável de impurezas, principalmente o oxigênio, durante a deposição de filmes finos é praticamente inevitável. Desta forma, cálculos ab initio baseados na Teoria do Funcional da Densidade foram realizados para investigar defeitos isolados e complexos de oxigênio no nitreto de índio e a sua influência nas propriedades óticas. Considerou-se diferentes concentrações de oxigênio $(\mathrm{x}=2,76,8,32,11,11$ e 22,22\%) aplicando-se o método PBEsolGGA e TB-mBJ para o tratamento da energia e potencial de troca e correlação. Obteve-se que é energeticamente favorável o oxigênio existir principalmente como defeito carregado e isolado. Os resultados utilizando a aproximação de TB-mBJ indicam um estreitamento do bandgap conforme a concentração de oxigênio aumenta. Entretanto, a alta contribuição do efeito de Moss-Burstein resulta num efetivo alargamento do band gap, gerando valores de band gap ótico maiores que no do bulk de nitreto de índio. 


\begin{abstract}
In the present work, the ion beam assisted deposition (IBAD) method was used for the production of thin films of indium nitride in silicon (111) and sapphire (001) substrates. Through variation of deposition conditions and by using X-ray diffraction technique, the parameters which resulted in thin films with the best crystallinity were investigated. The film produced at $380^{\circ} \mathrm{C}$ showed good crystallinity, which was better than the one produced at $250^{\circ} \mathrm{C}$. Temperatures much higher than $380^{\circ} \mathrm{C}$ doesn't lead to the formation of crystalline films of InN; the same is observed by using room temperature. In the temperature of $380^{\circ} \mathrm{C}$ considered as adequate, it was obtained that using $R_{a}$, that is, the flux ratio of nitrogen and indium, around 2.3 allows getting a better crystallinity, which decreases as deviates from this value. The comparison between diffractograms of samples produced with and without the previous titanium evaporation, where a dislocation of indium nitride peak was observed, indicates that the Gettering effect reduces the impurities on the films, especially oxygen. The Rutherford Backscattering technique was applied in order to obtain the elements composition and the depth profile. It was noticed a strong mixture between substrates elements with the indium nitride even close to the surface.

The presence of unintentional impurities, mainly oxygen, are almost inevitable during thin films deposition. Thus, Density Functional Theory based on ab initio calculations was employed to investigate single and complex defects of oxygen in Indium Nitride and their influence on the optical properties. Different oxygen contents ( $x=2.76,8.32,11.11$ and 22.22\%) were considered in our study by using PBEsolGGA and TB-mBJ for the treatment of exchange-correlation energy and potential. It was found that oxygen is energetically favorable to exist mainly as singly charged isolated defect. The results using TB-mBJ approximation predicts a narrowing of the bandgap as oxygen content increases. Nevertheless, the larger contribution of the Moss-Burstein effect leads to an effective band-gap increase, yielding absorption edge values larger than that of the intrinsic bulk indium nitride.
\end{abstract}




\section{Sumário}

Agradecimentos

Resumo

iv

Abstract

vi

Lista de Figuras

$\mathbf{x}$

Lista de Tabelas

xiv

Lista de Abreviaturas e Siglas

XV

1 Introdução

1.1 Nitreto de Índio: Uma Visão Geral . . . . . . . . . . . . . . . . . 1

1.2 Uma breve introdução dos métodos de deposição . . . . . . . . . 2

$1.3 a b$ initio, DFT e o WIEN2k . . . . . . . . . . . . . . . . 4

1.4 Motivações e Objetivos . . . . . . . . . . . . . . 5

2 O sistema IBAD e os processos físicos envolvidos $\quad 6$

2.1 Modelo Fenomenológico . . . . . . . . . . . . . 6

2.2 Especificações Técnicas . . . . . . . . . . . . . . . . . . 11 
2.3 Fonte de Íons . . . . . . . . . . . . . . . . . . . . . . 13

3 Metodologia Experimental $\quad \mathbf{1 6}$

3.1 Substratos: Silício (111) e Safira-C . . . . . . . . . . 16

3.2 Evaporação Prévia do Titânio na limpeza do ambiente da câmara. . 18

3.3 Filmes Finos Produzidos . . . . . . . . . . . . . . . 19

3.4 Difração de Raios-X . . . . . . . . . . . . . . . 20

3.5 Retroespalhamento Rutherford ................ 22

4 Base teórica da Teoria do Funcional da Densidade 24

4.1 Teoria do Funcional da Densidade e o programa Wien2k . . . . . . . 24

4.1.1 Aproximação de Born-Oppenheimer . . . . . . . . . . 25

4.1.2 Teoria do Funcional da Densidade . . . . . . . . . . 25

4.1.3 As equações de Kohn-Sham . . . . . . . . . . . . . 26

4.1.4 O funcional de troca e correlação . . . . . . . . . . . . 29

4.1.5 O programa Wien2k ................ 30

4.1.5.1 O método APW ................. 31

4.1.5.2 O método APW + lo............. 33

4.1.6 O método TB-mBJ para a investigação das propriedades óticas 34

4.1 .7 O Laboratório Virtual . . . . . . . . . . . . . . 37

5 Estudo $a b$ initio dos defeitos pontuais 39

5.1 Introdução . . . . . . . . . . . . . . . . . 39

5.2 Termodinâmica da estabilidade dos defeitos . . . . . . . . . . 40 
5.3 Correções na dopagem de supercélulas . . . . . . . . . . . . . 41

5.4 Defeitos complexos ....................... 43

6 Resultados Experimentais $\quad 44$

6.1 Cristalinidade dos filmes finos . . . . . . . . . . . . . 44

6.1.1 Substrato de Safira-C e Silício (111) . . . . . . . . . . 44

6.1.2 Temperatura do substrato e o parâmetro $R_{a} \ldots$. . . . 46

6.1.3 Efeito Gettering . . . . . . . . . . . . 52

6.2 Perfil dos filmes formados. . . . . . . . . . . . . . . 54

7 Resultados Teóricos: $\operatorname{InN}$ e $\operatorname{InO}_{x} \mathrm{~N}_{1-x} \quad 57$

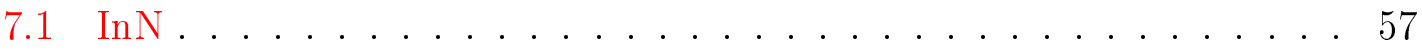

7.1 .1 Otimização da estrutura . . . . . . . . . . . . . 59

7.1.2 Propriedades óticas e inclusão do método TB-mBJ . . . . . 61

$7.2 \mathrm{InO}_{x} \mathrm{~N}_{1-x} \ldots \ldots \ldots \ldots \ldots \ldots \ldots \ldots \ldots$

7.2.1 Defeito de um único oxigênio . . . . . . . . . . . . . . 64

7.2 .2 Defeitos complexos ................ 65

7.2 .3 Propriedades óticas . . . . . . . . . . . . . . 68

8 Conclusões 


\section{Lista de Figuras}

2.1 Esquema com os processos físicos envolvidos no sistema IBAD. . 7

2.2 Gráfico extraído do trabalho de D. Van Vechten et al. . . . . . . . . . 10

$2.3 \quad$ Esquema do IBAD ...................... 12

2.4 Imagem da parte externa da câmara de descarga (a) e do anodo

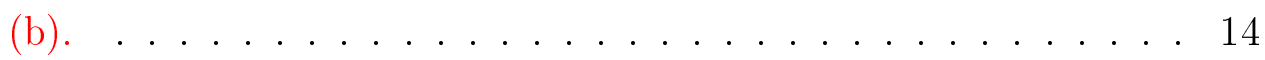

$2.5 \quad$ Imagem das grades de molibdênio. . . . . . . . . . . . . . 14

Esquema dos componentes da fonte de íons. . . . . . . . 15

3.1 Imagem do porta amostras com os substratos fixos. . . . . . . 17

3.2 Imagens do substrato sem (a) e com (b) limpeza ampliado 500x. . 17

3.3 Cálculos realizados com o programa SRIM. . . . . . . . 18

3.4 Variação da pressão em função do tempo e da corrente de evaporação para duas ocasiões diferentes. . . . . . . . . . . . . 19

3.5 Efeito da distorção da rede no formato e posicionamento dos picos. 22

4.1 Fluxograma com as etapas do ciclo autoconsistente. . . . . . 29

4.2 Divisão da célula unitária para um caso com dois átomos. . . . . 32

4.3 Gráfico extraído do trabalho de F. Tran e P. Blaha comparando cálculos teóricos com resultados experimentais. . . . . . . . 36 
4.4 Esquema ilustrativo da configuração do cluster montado. . . . . . 38

5.1 Esquema ilustrativo em duas dimensões onde a figura do lado esquerdo representa as imagens periódicas das supercélulas e a figura do lado direito mostra o que se pretende obter através das correções. . . . . . . . . . . . . . . . . . . 4 42

$6.1 \quad$ Difratograma da amostra F-saf de InN. . . . . . . . . . . 45

6.2 Difratograma da amostra C-si de InN . . . . . . . . . . 45

6.3 Difratogramas de amostras produzidas a $380^{\circ} \mathrm{C}$ e a $253^{\circ} \mathrm{C}$ com valores próximos de $R_{a}$. . . . . . . . . . . 47

6.4 Difratograma da amostra G-saf produzida a $480^{\circ} \mathrm{C}$. Não houve a formação de pico referente ao InN. . . . . . . . . . . . . 47

6.5 Difratogramas de amostras produzidas a $380^{\circ} \mathrm{C}$ com diferentes valores de $R_{a} \ldots \ldots \ldots \ldots \ldots \ldots$

6.6 Ajuste de Lorentz no pico de InN para diferentes valores de $R_{a}$ (a) e gráfico de $R_{a}(\mathrm{~N} / \mathrm{In})$ por FHWM (b), onde o dado com o símbolo quadrado se refere a amostra A-saf com condições de produção levemente diferente das outras.

6.7 Ajustes realizados para obtenção dos parâmetros $c$ (figura A) e $a$ (figura B e C). .................... 50

6.8 Gráfico com parâmetros de rede obtidos pelo nosso grupo e por outros trabalhos listados na tabela $6.1 \ldots \ldots . \ldots . . . . . .52$

6.9 Difratrogramas comparando as amostras E-saf e F-saf, onde foram produzidas sem e com evaporação prévia de titânio, respectiva-

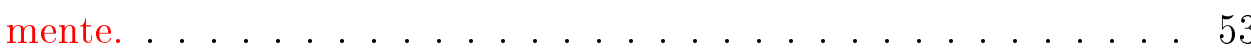

6.10 Dados experimentais obtidos por RBS e a curva teórica ajustada das amostras C-saf (a), D-saf (b) e D-si (c). . . . . . . . 55 
6.11 Perfil de composição em função da profundidade estimada da amostra B-saf. .................... 55

6.12 Perfil de composição em função da profundidade estimada da amostra D-saf. ................... 56

6.13 Perfil de composição em função da profundidade estimada da amostra D-si. .................... 56

$7.1 \quad$ Célula unitária da estrutura Wurtzita do InN. . . . . . . . . 58

7.2 Gráficos de energia em função do número de pontos k (a) e energia em função do valor de $R_{m t} \cdot K_{\max }(\mathrm{b}) \ldots \ldots \ldots \ldots \ldots \ldots$

7.3 Ajuste polinomial de ordem 3 da energia total em função do volume (\%) e c/a(\%) utilizando o funcional LDA (a) e PbesolGGA (b).

7.4 Densidade de estados comparando com a implementação do método TB-mBJ. .................... 62

7.5 Densidade de estados com a contribuição de cada orbital do InN. 62

7.6 Estrutura de banda com e sem a implementação do método TB-

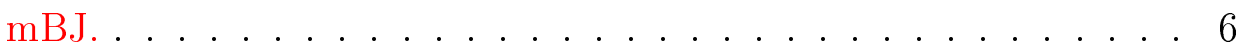

7.7 Gráficos de absorção por energia com e sem inserção do método TB-mBJ (a) e estimativa do valor do band gap ótico (b), utilizando a equação $4.29 . \ldots$. . . . . . . . . . . . 63

$7.8 \quad$ Supercélula com 72 átomos $(36$ N e 36 In). . . . . . . . . 64

7.9 Energia de Formação por nível de Fermi de um oxigênio isolado utilizando condições "rico" e "pobre" de N. ......... 65

7.10 Tipos de distribuição para uma supercélula (linhas pontilhadas representam as fronteiras) de 72 átomos e 4 (a,b,c), 8 (d,e) e 12 (f,g) oxigênios substitucionais. Alguns átomos foram omitidos para facilitar a compreensão. . . . . . 6 
7.11 Determinação do band gap ótico do $\mathrm{InO}_{x} \mathrm{~N}_{1-x}$ utilizando o método TB-mBJ. ..................... 70

7.12 MBC e MBV do $\operatorname{InO}_{x} \mathrm{~N}_{1-x}$ calculado a partir do método TB-mBJ. 71

7.13 Curva teórica da variação do band gap ótico em função de transportadores de carga. . . . . . . . . . . . . . 71 


\section{Lista de Tabelas}

1.1 Exemplo de técnicas de deposição de filmes e suas classificações. 3

2.1 Valores dos parâmetros utilizados na equação 2.14. . . . . . . 11

3.1 Tabela com o nome e informações das amostras produzidas. . . . 20

6.1 Parâmetros de rede obtidos do InN, comparando com outros tra-

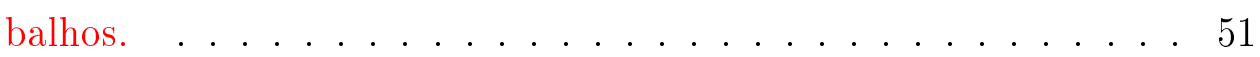

7.1 Valores dos parâmetros de rede otimizados para cada método e resultados de outros trabalhos. . . . . . . . . . . . 59

7.2 Energia da supercélula para cada tipo de distribuição atômica. . . . . . . 68

7.3 Energia de ligação para cada estado de carga do defeito complexo. 68

7.4 Valores de $E_{g}^{o p t}$ e $\triangle E_{M B C-M B V}$ extraídos dafigura 7.11 and 7.12, respectivamente. . . . . . . . . . . . . . 69 


\title{
Lista de Abreviaturas e Siglas
}

\author{
CPU Central Processing Unit \\ CVD Chemical Vapor Deposition \\ DFT Density Functional Theory \\ FWHM Full Width at Half Maximum \\ GGA Generalized Gradient Approximation \\ IBAD Ion Beam Assisted Deposition \\ LAPW +lo Linearized Augmented Plane Waves + Local Orbitals \\ LDA Local Density Approximation \\ LED Light-emitting diode \\ MBC Mínimo da Banda de Condução \\ MBE Molecular Beam Epitaxy \\ MBV Mínimo da Bande de Valência \\ MISFET Metal insulator semiconductor field-effect transistor \\ MOCVD Metal-Organic Chemical Vapour Deposition \\ MPI Message Passing Interface \\ PW Plane Waves \\ RBS Rutherford Backscattering \\ RF Radio Frequency \\ saf Safira (substrato) \\ si Silício (substrato) \\ SRIM Stopping and Range of Ions in Matter
}

xiv 
TB-mBJ

u.a.

XRD

Trans Blaha - modified Becke-Johnson

Unidades atômicas

X-Ray Diffraction 


\section{Capítulo 1}

\section{Introdução}

\subsection{Nitreto de Índio: Uma Visão Geral}

O primeiro resultado sobre a produção de nitreto de índio foi divulgado em 1938 para análise da difração de raios-X [1]. Desde esse ano até 1992, a pesquisa sobre o InN foi esporádica. Em 1972, foi produzido o primeiro material com alta mobilidade eletrônica com valor de $250 \pm 50 \mathrm{~cm}^{2} / V$ e concentração de $5-8 \times$ $10^{18} \mathrm{~cm}^{-3}$ utilizando a técnica RF-Sputtering. Já em 1984, Tansley e Foley [2] obtiveram um valor de mobilidade eletrônica de $2700 \mathrm{~cm}^{2} / V$ utilizando uma técnica similar. Tais resultados, indicaram um alto potencial para produção de transistores de alta mobilidade eletrônica. Porém, foi apenas em 1993, com o sucesso dos LED (light-emitting diode) de GaN e GaInN, que houve um real interesse no InN, devido a necessidade do desenvolvimento da importante liga, principalmente do ponto de vista comercial.

O estágio que se encontra a compreensão física e aplicação entre o GaN e InN é enorme. Não é de se surpreender que o GaN é o segundo material semicondutor mais importante atualmente, depois do silício. Os diodos baseados em GaN são amplamente utilizados e estão muito presentes em nosso cotidiano, como as telas digitais, semáforos, discos Blu-ray, dispositivos HD-DVD (DVD de alta densidade), smartphones, etc. Por outro lado, o InN se encontra num estágio ainda pioneiro, apesar de já haver alguns protótipos de dispositivos sendo divulgados como: dispo- 


\subsection{UMA BREVE INTRODUÇÃO DOS MÉTODOS DE DEPOSIÇÃO}

sitivos MISFET [3], sensores líquidos/gás [4], anodos para baterias de filmes finos de íons de Li [5], entre outros. Apesar de o InN ter inicialmente atraído uma maior atenção da comunidade científica devido ao desenvolvimento do LED, a sua forte candidatura para, principalmente, criação de dispositivos de alta potência e alta frequência, fez continuar ativa a pesquisa desse material. Originalmente, o valor do band gap do InN era considerado ser de $\sim 1,9 \mathrm{eV}$ [2, 6]. Foi apenas em 2002 quando Wu et al. [7] produziram amostras utilizando a técnica MBE em um ambiente de ultra alto vácuo divulgando um valor de band gap de 0,7 a 0,8 eV. Desde então, o valor de $\sim 0,7 \mathrm{eV}$ tem sido estabelecido como o valor correto do InN. Devido a isso, há um grande potencial em aplicações em dispositivos baseados em InGaN de células solares que podem absorver praticamente todo o espectro de luz.

Entretanto, como é de se esperar devido aos recentes estudos, falta uma compreensão física bem estabelecida do InN. Por exemplo, não há um consenso do motivo que leva a diferenças de band gap obtidos, apesar de haver inúmeros indícios como: efeito de Moss-Burstein [8],[9], presença de impurezas, defeitos, etc. A dificuldade de produzir material de alta qualidade somada a inúmeras diferentes técnicas de produção de materiais presentes, acabam também por dificultar a separação das causas da variação do band gap. Isso não se limita apenas sobre a questão do bandp gap, mas também a outros valores das propriedades do InN. Assim, apesar do grande potencial apresentado por esse material, ainda há várias questões a serem esclarecidas e sua extensa aplicação depende fortemente disso.

\subsection{Uma breve introdução dos métodos de deposição}

A tecnologia de deposição é a principal maneira para criação de dispositivos, tais como componentes de computadores, uma vez que a microeletrônica é totalmente baseada em estruturas de materiais formados por deposição de filmes finos. A contínua alta demanda por dispositivos eletrônicos mais sofisticados, impulsionou o desenvolvimento das técnicas de produção, que existem em dezenas de variedades.

Basicamente, a tecnologia de deposição de filme fino é, ou puramente física, 


\subsection{UMA BREVE INTRODUÇÃO DOS MÉTODOS DE DEPOSIÇÃO}

Tabela 1.1: Exemplo de técnicas de deposição de filmes e suas classificações.

\begin{tabular}{c|l}
\multicolumn{1}{c|}{ Métodos por evaporação } & $\begin{array}{l}\text { Epitaxia de Feixe Molecular (MBE) } \\
\text { Evaporação por elétron-beam }\end{array}$ \\
\hline \multirow{2}{*}{ Métodos por descarga incandesc. } & $\begin{array}{l}\text { Sputtering Reativo } \\
\text { Magnetron Sputtering } \\
\text { Deposição por feixe de íons }\end{array}$ \\
\hline \multirow{2}{*}{ Métodos quím. na fase gasosa } & $\begin{array}{l}\text { CVD em pressão atmosférica (APCVD) } \\
\text { CVD organometálico (MOCVD) }\end{array}$ \\
& CVD foto-aumentado (PHCVD) \\
\hline Métodos quím. na fase líquida & $\begin{array}{l}\text { Eletro-platinação } \\
\text { Platinação por redução química } \\
\text { Pirólise por spray }\end{array}$
\end{tabular}

tais como métodos envolvendo evaporação, ou puramente química, a qual envolve processos químicos na fase líquida ou gasosa. Há também um número considerável de sistemas que são baseados em descargas incandescentes ou sputtering reativo que envolvem os dois processos. A tabela 1.1 mostra de forma categorizada uma parte das variadas técnicas de produção existentes.

É preciso dar uma atenção especial a dois métodos de deposição, pois ambos são mais utilizadas na produção de filmes finos de InN de alta qualidade: MBE (Molecular Beam Epitaxy) e MOCVD (Metal-Organic Chemical Vapour Deposition). As técnicas de sputtering por outro lado, normalmente resultam em materiais amorfos ou policristalinos, além da indesejável alta concentração de impurezas. O primeiro é um sofisticado método de alto controle que permite o crescimento de filmes monocristalinos em um ambiente de alto vácuo de $10^{-11}$ Torr. Nesse sistema, os materiais são colocados em células de efusão e então evaporados. Um sistema eletrônico de controle de potência e sensor é utilizado para manter a temperatura constante que possibilita o controle de fluxo de evaporação. Um obturador mecânico permite que o feixe seja interrompido, permitindo o crescimento de camadas alternadas de diferentes materiais com interfaces bem definidas. No caso da utilização de 
um gás de nitrogênio, por exemplo, as moléculas são dissociadas por radiofrequência (RF-MBE) para obtenção de nitrogênio atômico reativo.

Assim como no MBE, o método de deposição química MOCVD também permite o crescimento epitaxial, porém a partir de reação química de compostos orgânicos ou organometálicos. A reação química e a formação da camada epitaxial ocorrem na superfície do substrato. No caso do InN, o filme pode ser crescido sobre um substrato em um reator, geralmente usando $\left(\mathrm{CH}_{3}\right)_{3} \mathrm{In}$ como fonte de In e gás de amônia $\mathrm{NH}_{3}$.

Nesse trabalho, utilizou-se o método de deposição assistida por feixe de íons (IBAD). A principal diferença entre as técnicas apresentadas é a utilização de feixes de íons energéticos, variando entre 100 a $1000 \mathrm{eV}$, direcionados ao substrato. Concomitantemente, evapora-se um outro material através de um feixe de elétrons num ambiente de vácuo. Maiores detalhes sobre o funcionamento do sistema serão discutidos no capítulo seguinte.

\section{3 ab initio, DFT e o WIEN2k}

Simulações baseados em modelos de primeiros princípios (ab initio) têm se tornado fundamental para compreenssão das propriedades físicas de sólidos devido a capacidade em prever suas propriedades, tornando-se essencial para o desenvolvimento e design de novos materiais. Numa primeira etapa, um sólido cristalino pode ser idealizado e estudado como átomos numa célula unitária a qual se repete periodicamente a temperatura zero. Nessa escala atômica, a mecânica quântica governa a estrutura eletrônica, cuja configuração é responsável pelas propriedades óticas, ligações químicas, transição de fases, comportamentos elétricos e magnéticos, etc. Os cálculos correspondentes de primeiros princípios são realizados tendo como base a Teoria do Funcional da Densidade (DFT), onde o problema de muitos corpos compostos de elétrons e núcleo atômicos é mapeado numa série de equações de elétrons individuais, também denominado de equações de Kohm-Sham (KS). Para solucionar essas equações, vários métodos foram desenvolvidos, sendo o método da Função de 
Onda Aumentada e Linearizada (LAPW) o mais preciso. Um programa de computador amplamente utilizado e que trabalha com essa metodologia é o Wien $2 \mathrm{k}^{1}$. Os fundamentos teóricos e a metodologia envolvidos neste esquema serão aprofundados posteriormente.

\subsection{Motivações e Objetivos}

Até onde se tem conhecimento, não houve divulgação de outros trabalhos experimentais com a utilização do método IBAD para produção de filmes finos de InN. Além disso, é pequena a presença de publicações envolvendo tal técnica de produção se comparado com outros métodos como MBE e MOCVD. Assim, o processo de controle da formação de um determinado filme fino e suas propriedades físicas são normalmemnte um longo e complexo trajeto. Com essa situação como pano de fundo, pretende-se primeiramente estudar o funcionamento do sistema de deposição utilizado e como o ajuste nos parâmetros das condições de produção podem produzir um filme fino de InN altamente cristalino. Serão utilizadas técnicas como XRD e RBS para investigação da cristalinidade e o perfil de profundidade.

Como será discutido posteriormente, o InN é um material ainda recente do ponto de vista de compreensão e aplicação, assim ainda resta um longo caminho para um entendimento e consenso bem estabelecido pela comunidade científica a respeito das propriedades físicas desse material. Neste trabalho, realizando simulações ab initio, pretende-se investigar as propriedades óticas do $\mathrm{InN}$ e a influência do oxigênio nesse composto, o qual é fonte de muitas discussões ainda hoje.

Em suma, este trabalho tem duas principais frentes, sendo a primeira experimental, envolvendo a produção e caracterização dos filmes finos, e a outra com um enfoque mais teórico, utilizando intensivamente simulações computacionais.

\footnotetext{
${ }^{1}$ link: http://www.wien2k.at
} 


\section{Capítulo 2}

\section{O sistema IBAD e os processos físicos envolvidos}

\subsection{Modelo Fenomenológico}

O processo de formação de filmes finos pelo sistema IBAD pode ser descrito de forma simplificada através do modelo ilustrado na figura 2.1. Uma parte importante do processo ocorre na fonte iônica, onde moléculas e átomos de nitrogênio são ionizados e, então, acelerados em direção ao alvo onde podem ser refletidos com um coeficiente de reflexão $r$. Como resultado do bombardeio iônico no alvo, alguns átomos constituintes são removidos da superfície com um coeficiente de sputtering $S$, além disso, moléculas de gás podem ser formadas e dessorvidas, assim como moléculas do ambiente eventualmente podem ser adsorvidas. Concomitantemente a emissão do feixe, o índio é evaporado e chega a superfície com energia cinética praticamente nula se comparada com o feixe de íons, onde estes estão sujeitos a processos de neutralização durante sua trajetória para o substrato.

Com o intuito de estreitar a compreensão física dos processos físicos envolvidos é possível elaborar um modelo fenomenológico simplificado onde três critérios são adotados para sua aplicabilidade: 1) baixa incorporação das moléculas do ambiente, 2) os íons são implantados obedecendo a relação $(1-r)$ e 3$)$ não há efeitos de 


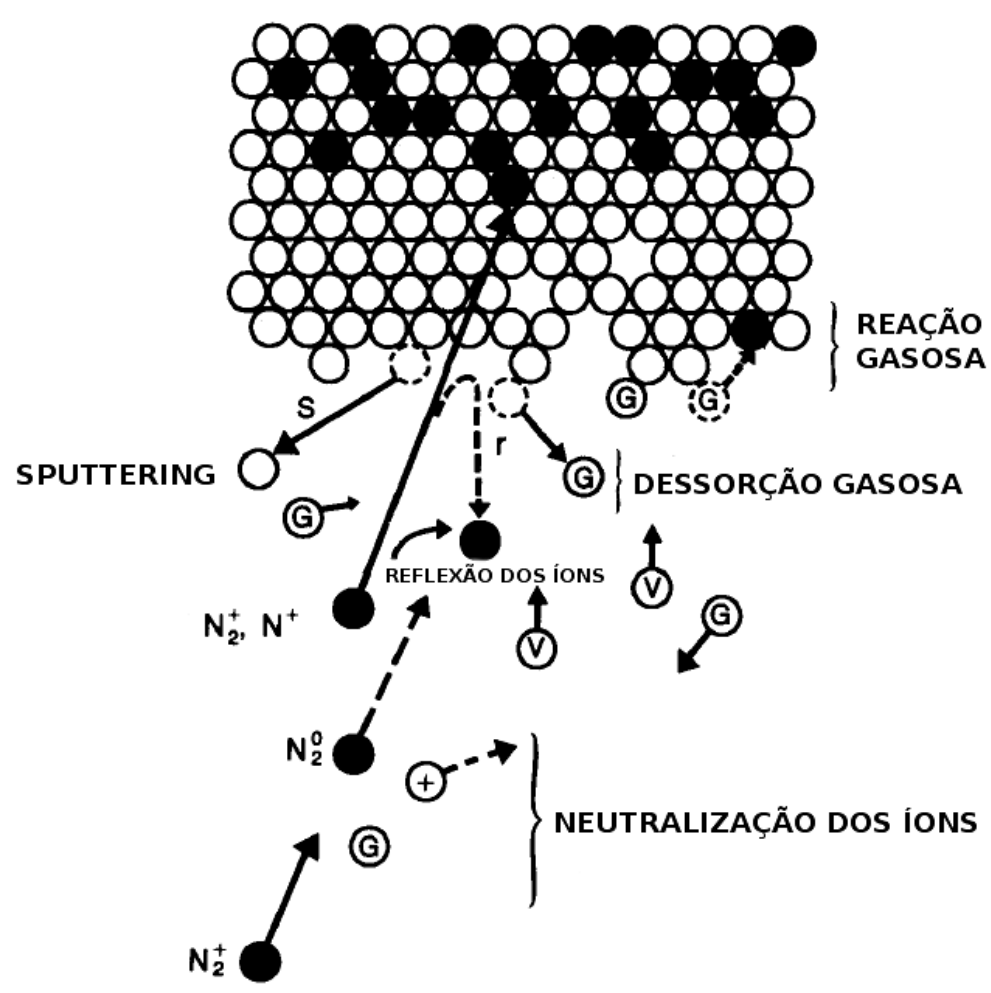

Figura 2.1: Esquema com os processos físicos envolvidos no sistema IBAD.

difusão após os íons pararem no filme. No trabalho de Van Vechten et al. [10] os autores mostraram que energias acima de $500 \mathrm{eV}$ e temperaturas abaixo de $100^{\circ} \mathrm{C}$ são suficientes para satisfazerem os critérios 2 e 3.

Seja $F_{N}$ o fluxo do nitrogênio e $F_{I n}$ o fluxo incidente do índio evaporado então a razão dos fluxos é definido como:

$$
R_{a}=\frac{F_{N}}{F_{I n}}
$$

Tal que:

$$
F_{\text {In }}=Q N_{\text {In }} \gamma_{e}
$$

onde $Q$ é a taxa de deposição medida pelo cristal de quartzo acoplado no interior da câmara, $N_{I n}$ é a densidade atômica do índio e $\gamma_{e}$ é um fator adimensional para correção devido a diferença do posicionamento do medidor de quartzo e o substrato. 
Na ausência da troca de carga de íons, o seu fluxo pode ser definido como:

$$
F_{N}=\frac{J_{0}}{e} \sum_{i} n_{i} \epsilon_{i} \gamma_{i}
$$

$J_{0}$ é a densidade de corrente, $\epsilon_{i}$ é o número de átomos por íon e $n_{i}$ a fração dos componentes em relação ao íon. Nesse caso, os íons são majoritariamente $N^{+}$ou $N_{2}^{+}$ e $\gamma_{i}$ é um fator adimensional para corrigir a diferença entre a densidade da corrente do feixe medido no copo de Faraday e no filme. A natureza estatística do processo que afeta a corrente iônica é similar ao da absorção da luz $J=J_{0} \exp (-\alpha d)$, onde $\alpha$ é o coeficiente de absorção e $d$ a distância [11]. Se o sistema está a uma pressão $p$ e temperatura $T$, o valor da densidade de corrente medido $J_{F}$ é relacionado a $J_{0}$ por:

$$
J_{0}=J_{F} \exp \left[\left(a p \gamma_{p} / k_{\beta} T\right) l\right]
$$

Onde então, o coeficiente de absorção é substituído por $a p \gamma_{p} / k_{\beta} T$. Na equação 2.4, $a$ é a seção de choque da transferência de carga, $l$ é a distância da fonte de íons ao copo de Faraday e $k_{B}$ a constante de Boltzmann. O parâmetro $\gamma_{p}$ é um fator adimensional que leva em conta a diferença da pressão na fonte de íons externa e a pressão na câmara. Reescrevendo $1+\beta=\exp \left[\left(a p \gamma_{p} / k_{\beta} T\right) l\right]$ por conveniência, então ter-se-á $J_{0}=J_{F}(1+\beta)$. A expressão 2.3 então fica:

$$
F_{N}=\frac{J_{F}}{e} \sum_{i} n_{i} \epsilon_{i} \gamma_{i}\left(1+\beta_{i}\right)
$$

Até o momento, têm-se duas importantes expressões $F_{N}$ e $F_{I n}$, tais que possuem correções das informações dadas pelos copo de Faraday e pelo cristal de quartzo, permitindo obter, a princípio, o real valor do fluxo de íons e dos átomos evaporados que chegam no substrato.

O fluxo de íons que são incorporados no filme $F_{N}^{f}$ é obtido ao inserir o termo $(1-r)$ na expressão 2.5 , portanto: 


$$
F_{N}^{f}=\frac{J_{F}}{e} \sum_{i} n_{i} \epsilon_{i} \gamma_{i}\left(1+\beta_{i}\right)\left[1-r_{i}\right]
$$

enquanto que a do fluxo de índio incorporado é:

$$
F_{\text {In }}^{f}=F_{\text {In }}-\frac{J_{F}}{e} \sum_{i} n_{i} \epsilon_{i} \gamma_{i}\left(1+\beta_{i}\right) S_{i}
$$

Definindo outra variável como $\langle\delta\rangle=\sum_{i} n_{i} \epsilon_{i}$ e assumindo que $\gamma_{i}$ e $\beta_{i}$ são iguais para todos os tipos de íons de nitrogênio, então a expressão do fluxo de nitrogênio pode ser simplificado como:

$$
F_{N}^{f}=\frac{J_{F}}{e}<\delta>\gamma(1+\beta)[1-<r>]=F_{N}(1-<r>)
$$

onde $\langle r\rangle$ é a média ponderada do coeficiente de reflexão:

$$
<r>=\frac{\sum_{i} n_{i} \epsilon_{i} r_{i}}{\sum_{i} n_{i} \epsilon_{i}}
$$

De forma análoga, têm-se:

$$
F_{\text {In }}^{f}=F_{\text {In }}-\frac{J_{F}}{e}<\delta>\gamma(1+\beta)<S>=F_{\text {In }}-F_{N}<S>
$$

onde $<S>$ é a média ponderada do coeficiente de sputtering:

$$
<S>=\frac{\sum_{i} n_{i} \epsilon_{i} S_{i}}{\sum_{i} n_{i} \epsilon_{i}}
$$

Finalmente, através das equações 2.1, 2.10 e 2.8 a razão do nitrogênio e índio incorporado $R_{f}$ é dado por:

$$
R_{f}=\frac{F_{N}^{f}}{F_{I n}^{f}}=\frac{F_{N}(1-<r>)}{F_{I n}-F_{N}<S>}=\frac{R_{a}(1-<r>)}{1-R_{a}<S>}
$$

A expressão que define a composição $x$ do nitrogênio no filme será então: 


$$
x=\frac{R_{a}}{R_{a}+\left(1-R_{a}<S>\right) /(1-<r>)}=\frac{R_{f}}{1+R_{f}}
$$

Para obtenção dos parâmetros mencionados acima é necessário realizar uma extensa calibração do equipamento. Uma vez realizada [10][12], é possível obter a curva teórica dada pela equação 2.13, o qual possui uma ótima concordância com os dados experimentais [13] (ver figura 2.2). Isso reforça a aplicabilidade do modelo, servindo também como uma forte ferramenta para a compreensão física dos processos envolvidos na deposição de filmes finos pelo sistema IBAD.

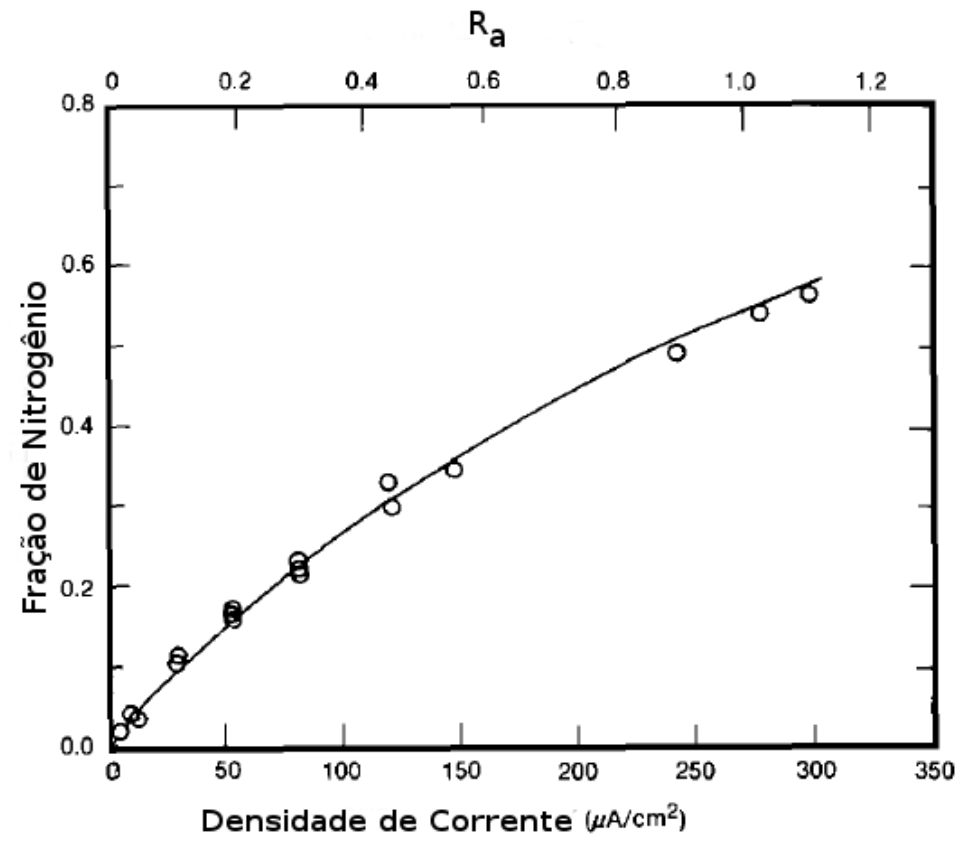

Figura 2.2: Gráfico extraído do trabalho de D. Van Vechten et al.

Uma atenção especial deve ser dada a equação 2.1, pois será amplamente utilizada nesse trabalho para investigação de sua relação com a cristalinidade do filme. Reescrevendo-a explicitamente, tem-se:

$$
R_{a}=\frac{<\delta>(1+\beta) \gamma}{e N_{\text {In }} \gamma_{e}} \frac{J_{F}}{Q}
$$

Entretanto, ainda resta saber os parâmetros dessa equação. No trabalho de Hubler et al. [10] obteve-se, através de um sistema magnético separador acoplado, 
que numa fonte também do tipo Kaufman, o feixe é composto por $11 \%$ de $N^{+}$e $89 \%$ de $N_{2}^{+}$para uma tensão de descarga de $V_{D}=50 \mathrm{~V}$. Como a tensão de descarga $V_{D}$ utilizada nesse trabalho é próximo desse valor, cerca de $V_{D}=55 \mathrm{~V}$ na maioria dos casos, adotou-se então $\langle\delta\rangle=1,89$. O medidor de quartzo utilizado possui $\gamma_{e}=1,1$, e adotou-se o fator admensinal de correção para a fonte de feixe de íons como sendo $\gamma=1$, devido ao posicionamento do copo de Faraday ser de poucos centímetros em relação ao substrato. Como foi mostrado anteriormente, reescreveuse um termo da corrente de íons, tal que $1+\beta=\exp \left[\left(a p \gamma_{p} / k_{\beta} T\right) l\right]$. Definiu-se $\gamma_{p}=1$, $l=41 \mathrm{~cm}, a=27 \AA^{2}[14]$ (para energias próximas de $150 \mathrm{eV}$ ), $p=1,2 \times 10^{-4}$ Torr (pressão durante a deposição) na temperatura ambiente, possibilitando obter o valor de $\beta=0,53$. Com esses parâmetros em mãos, é possível calcular $R_{a}$ com as medições da densidade de corrente no copo de Faraday $J_{F}$, cuja área é de $A=19,63 \mathrm{~cm}^{2}$, e a taxa de deposição acusado pelo medidor de quartzo $Q$. Todos esses dados apresentados estão dispostos na tabela 2.1. Para a produção dos filmes finos com o sistema IBAD, utilizou-se $R_{a}$ entre 1,48 e 3,16 .

Tabela 2.1: Valores dos parâmetros utilizados na equação 2.14.

\begin{tabular}{c|c}
$<\delta>$ & 1,89 \\
\hline$\gamma_{e}$ & 1,1 \\
\hline$\gamma_{p}$ & 1 \\
\hline$\gamma$ & 1 \\
\hline Área & $19,63 \mathrm{~cm}^{2}$ \\
\hline $\mathrm{l}$ & $41 \mathrm{~cm}$ \\
\hline $\mathrm{a}$ & $27 \AA^{2}$ \\
\hline $\mathrm{p}$ & $1,2 \times 10^{-4}$ Torr \\
\hline$\beta$ & 0,53
\end{tabular}

\subsection{Especificações Técnicas}

O sistema IBAD (da sigla em inglês Ion Beam Assisted Deposition) é um método de produção de filmes finos que consiste principalmente de um evaporador por feixe 
de elétrons e uma fonte de feixe de íons do tipo Kaufman. Os principais componentes desse sistema estão ilustrados na figura 2.3:

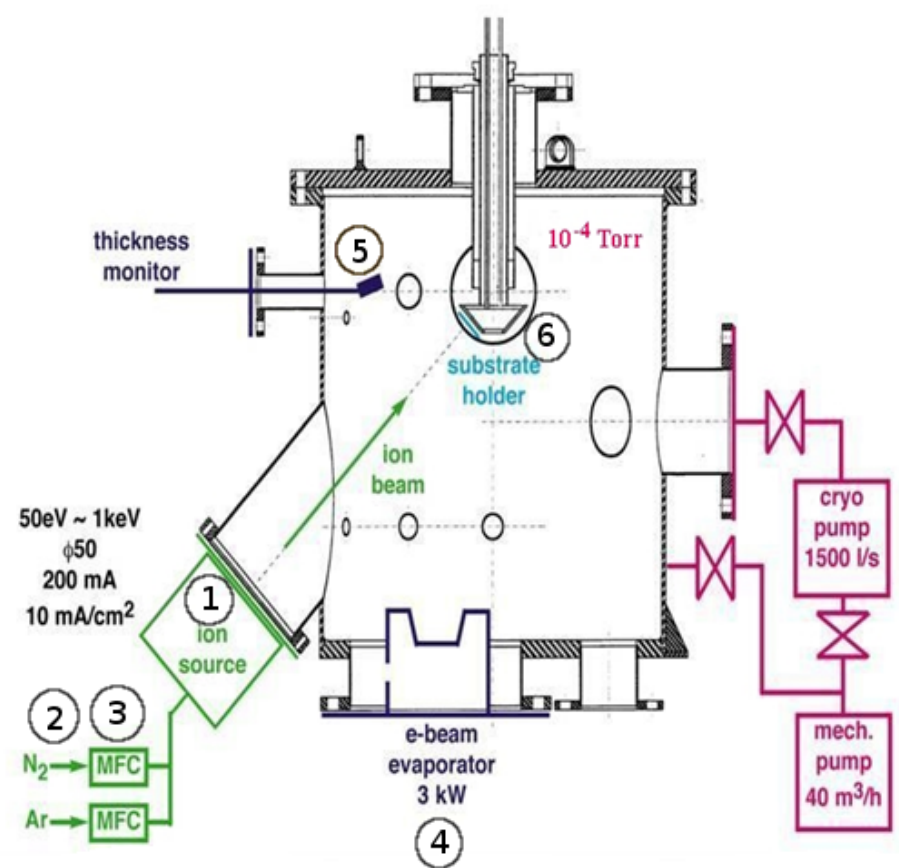

Figura 2.3: Esquema do IBAD

A fonte de íons (1) utilizada foi a do tipo Kaufman (MPS-3000, Ion Tech) com diâmetro de feixe de $5 \mathrm{~cm}$ na saída, cuja energia varia entre $50 \mathrm{a} 1200 \mathrm{eV}$. À fonte são acoplados duas linhas de gás, uma de nitrogênio e outra de argônio (2), onde são ionizados para formação do plasma; a alimentação é controlada através do controlador de fluxo de massa (3) (mass flow controller (MFC) 1179A, MKS). O evaporador por feixe de elétrons (4) (EB3, Edwards) trabalha numa potência de $3 \mathrm{~kW}$, onde estes são incididos em um porta amostra para quatro cadinhos; o material evaporado incide no substrato com um ângulo de aproximadamente $45^{\circ}$. Para o controle da taxa de evaporação é utilizado um sensor de quartzo (5) (XTC/2, Leybold), enquanto que o fluxo do feixe de íons é monitorado através do Copo de Faraday de aço inoxidável de $2 "$. O substrato é fixado num suporte (6) com aquecedor de até $550^{\circ} \mathrm{C}$ e um termopar tipo K. Para evacuação da câmara utiliza-se inicialmente um bomba mecânica com taxa de bombeamento de $40 \mathrm{~m}^{3}$ seguida de uma bomba criogênica, atingindo até $7 \times 10^{-7}$ Torr 


\subsection{Fonte de Íons}

O componente mais importante do sistema IBAD e o que o diferencia de outras técnicas de deposição é a fonte de feixe de íons. Originalmente, a tecnologia de feixe de íons possuia um outro propósito. A tecnologia foi desenvolvida pela Agência Espacial Norte Americana (NASA da sigla em inglês) em 1960 para propulsão de aeronaves. A fonte de feixe de íons também possui inúmeras outras aplicações, onde nas últimas décadas ela foi utilizada para deposição de óxidos, nitretos, carbono tipo diamante e outros revestimentos em equipamentos mecânicos, além de extenso uso na área de telecomunicação, com a criação de filmes óticos.

A função da fonte de feixe de íons é a produção de íons e aceleração para altas velocidades direcionados numa determinada região externa à ela. Os íons acelerados formam um feixe mono-energético com velocidades na ordem de $\mathrm{km} / \mathrm{s}$. A constituição da fonte é definida por 3 elementos chaves: Câmara de descarga, fonte de elétrons e a grade feito de molibdênio (figura 2.5). Basicamente, a fonte é operada inicialmente inserindo o gás na câmara de descarga (figure 2.4a). Um fio de tungstênio faz o papel da fonte de elétrons, ou catodo, que ioniza o gás, estabelecendo então um plasma, na qual é mantido em um potencial positivo. Os elétrons excedentes são coletados pelo anodo (figura 2.4b). Em seguida, os íons criados na câmara de descarga são acelerados e desacelerados em direção ao alvo através do sistema de grades. 


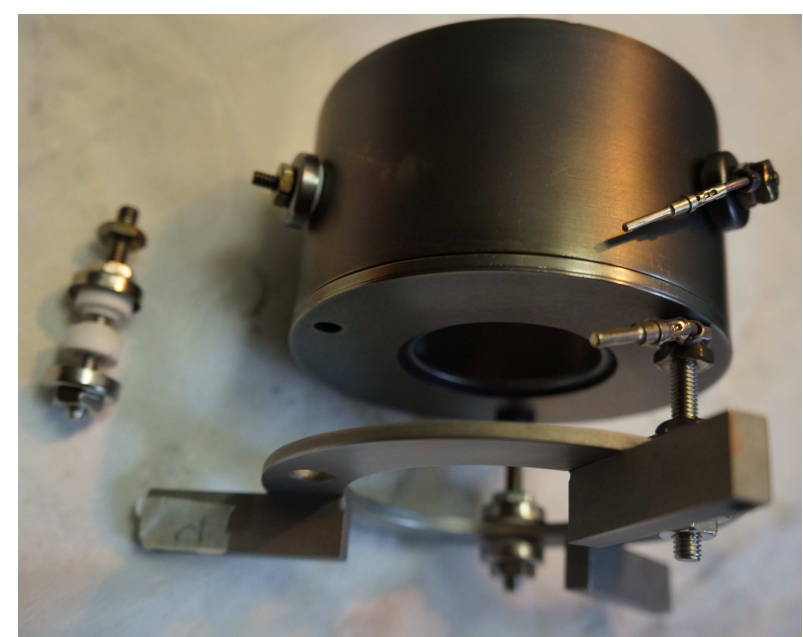

(a)

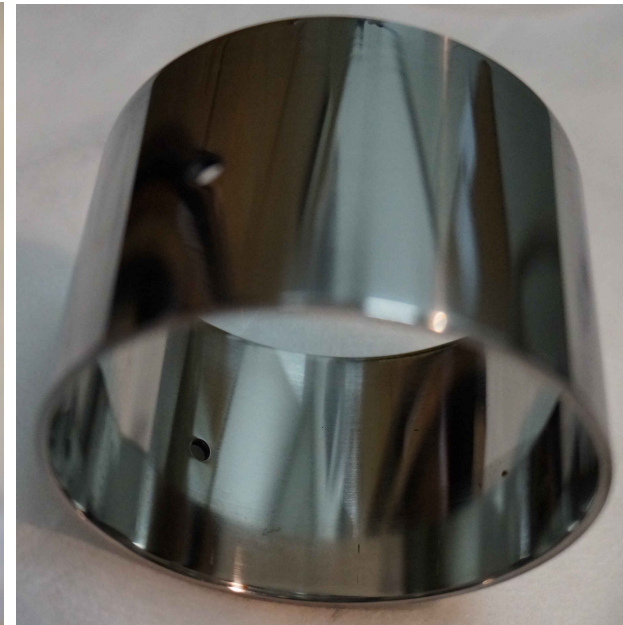

(b)

Figura 2.4: Imagem da parte externa da câmara de descarga (a) e do anodo (b).

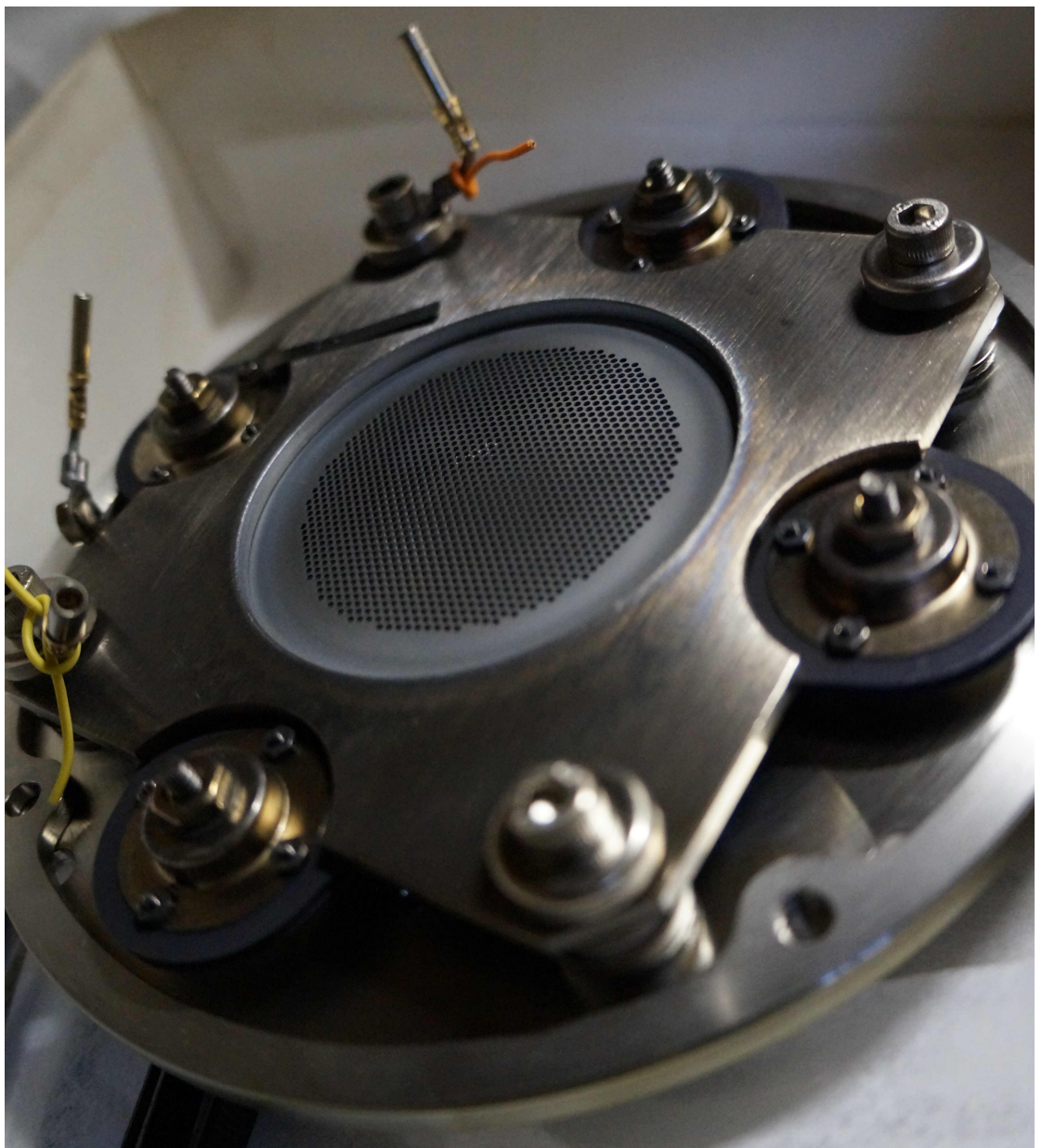

Figura 2.5: Imagem das grades de molibdênio. 


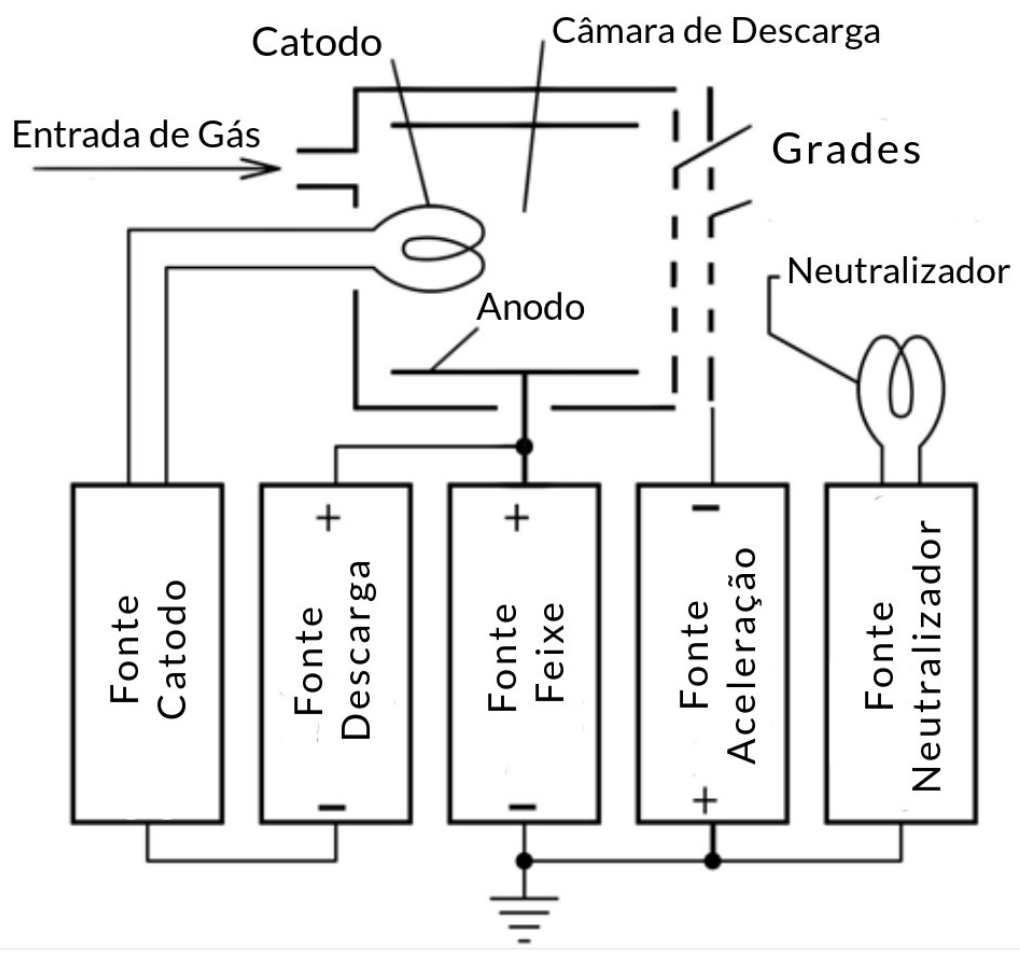

Figura 2.6: Esquema dos componentes da fonte de íons.

A figura 2.6 ilustra o esquema com os principais componentes. Há dois tipos principais de fonte de íons, a fonte CC (corrente contínua) ou a fonte de rádio frequência, onde nesse trabalho foi utlizada a primeira. Na câmara de descarga, também denominada de corpo, existem dois ímãs permanentes produzindo campo magnético para controlar o movimento dos elétrons de forma a aumentar o número de colisões com o gás antes de serem coletados pelo anodo. As grades são eletrodos separados e alinhados um do outro por poucos milímetros, também denominados de ótica dos íons. Como o nome sugere, a primeira grade tem o papel principal de alinhamento de feixe. Os íons mais alinhados serão então acelerados e desacelerados em direção ao substrato, voltando a ter o potencial inicial aplicado pelo anodo. Esse processo de acelerar e desacelerar tem como principal intuito aumentar a corrente do feixe de íons e evitar que elétrons do neutralizador entrem no sistema de aceleração, ocasianando uma falsa indicação da corrente de íons. Porém, neste trabalho não foi utilizado o neutralizador para possiblitar a medição do fluxo de íons através do copo de Faraday. 


\section{Capítulo 3}

\section{Metodologia Experimental}

\subsection{Substratos: Silício (111) e Safira-C}

Todos os filmes finos produzidos foram depositados sobre o substrato de silício (111) e Safira-C, ou seja, $\mathrm{Al}_{2} \mathrm{O}_{3}$ (001) com o eixo c da estrutura perpendicular a superfície. Antes de posicionar o substrato no porta amostras (figura 3.1), estes foram devidamente limpos utilizando acetona, álcool isopropílico e água deionizada. O procedimento consistiu em imergir o substrato primeiramente na acetona, depois é imediatamente inserido no álcool isopropílico e em seguida na água desionizada; por fim, a superfície do substrato é varrida utilizando um jato de gás de nitrogênio de alta pureza. Um exemplo comparando substratos com e sem a limpeza estão apresentados na figura 3.2, onde se observa a diminuição de manchas na superfície através de um microscópio ótico.

É amplamente conhecido pela comunidade científica que o substrato desempenha um importantíssimo papel na formação do filme fino. O principal fator está relacionado com o grau de desacordo entre os parâmetros de rede do material a ser formado e o substrato. No substrato de silício (111) o desacordo entre $\mathrm{InN}-\mathrm{h}(001) / \mathrm{Si}(111)$ é de aproximadamente $8 \%$, enquanto que $\operatorname{InN}-\mathrm{h}(001) /$ Safira(001) é de cerca de $25 \%$ no parâmetro de rede $a$. Tendo como base apenas estes fatos, é de se esperar que o InN seja melhor formado sobre o substrato de silício, porém outros fatores devem ser considerados. A nitridação não intencional no silício causa uma fina camada de 


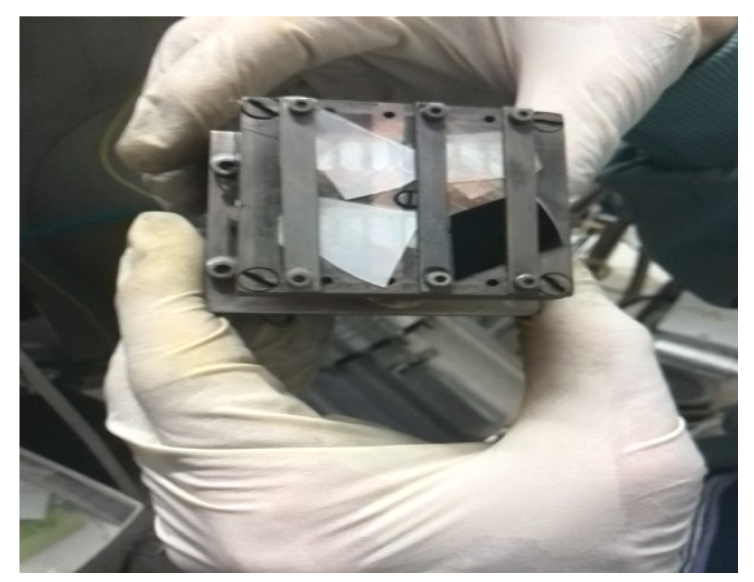

Figura 3.1: Imagem do porta amostras com os substratos fixos.
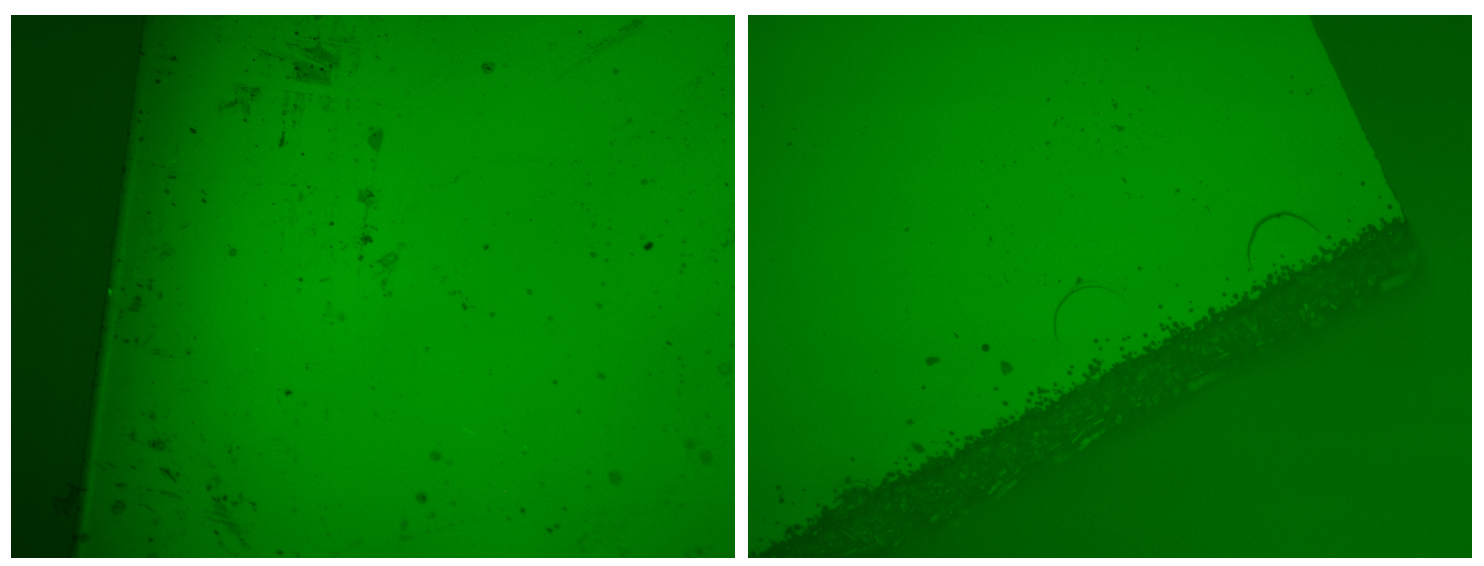

Figura 3.2: Imagens do substrato sem (a) e com (b) limpeza ampliado 500x.

$S i_{x} N_{y}$ [15], causando um abrupto desacordo com a geometria da estrutura do InN. Já no caso da safira, a formação de uma camada intermediária de AlN (hexagonal) pode favorecer o crescimento de InN devido ao menor desacordo no parâmetro de rede, de aproximadamente 11\%. No trabalho de F. Agulló-Rueda [16], o grupo reportou filmes finos de InN de alta cristalinidade utilizando substrato de silício, com uma camada intermediária de AlN. O segundo fator a se considerar é a diferença fundamental da técnica de deposição do IBAD com as outras, que é o uso de feixes energéticos. Assim, o efeito do bombardeamento deve ser considerado. 


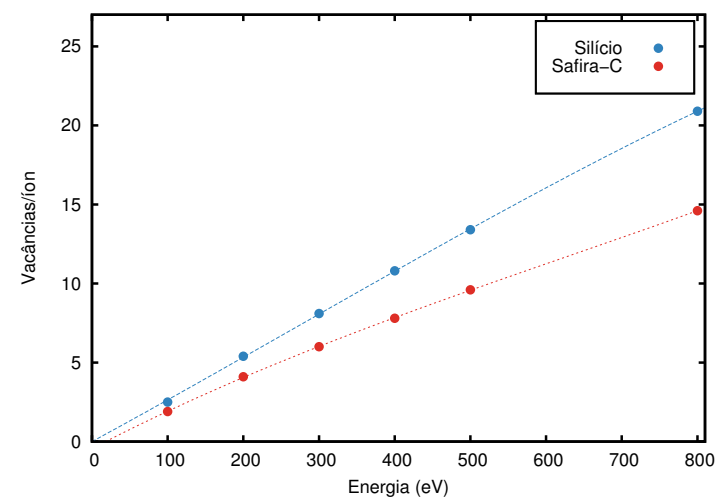

(a) Variação do número de vacâncias/íon em função da energia do feixe.

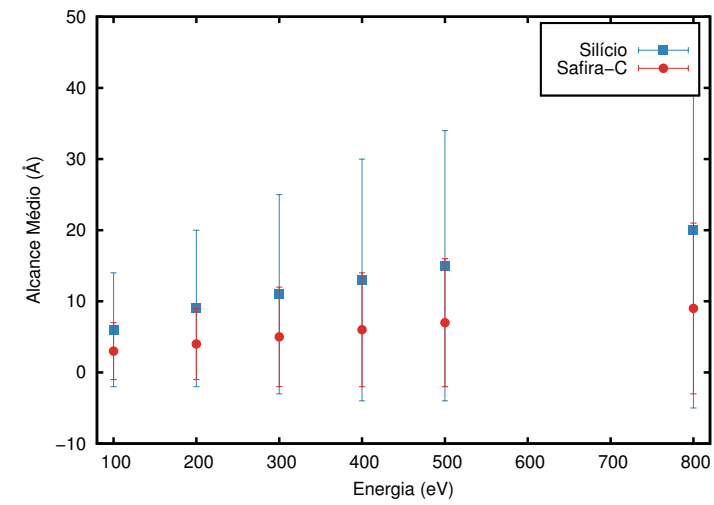

(b) Variação do alcance médio do feixe em função da energia do feixe.

Figura 3.3: Cálculos realizados com o programa SRIM.

A figura 3.3, mostra resultados provenientes de cálculos computacionais de MonteCarlo utilizando o programa SRIM (Stopping and Range of Ions in Matter) ${ }^{1}$, onde compara-se a produção de vacâncias por íon e o seu alcance dentro do substrato. Nota-se que no substrato de silício há um maior dano causado, com maior número de vacâncias produzidas e em uma região mais ampla. Portanto, devido a isso esperase obter melhores filmes utilizando o substrato de Safira-C, além do fato de que a camada intermediária de AlN favorece o crescimento cristalino de InN.

\subsection{Evaporação Prévia do Titânio na limpeza do ambiente da câmara.}

É comum em técnicas de deposição de materiais o uso de bombas de sublimação de titânio com o objetivo de reduzir impurezas no ambiente de vácuo. O titânio faz parte do grupo denominado "Getter Materials", o qual este em específico possui a característica de ser altamente reagente principalmente com o oxigênio e hidrogênio [15]. O efeito Gettering é definido como o efeito tal qual certos elementos tem de reagir quimicamente com os gases residuais, como $\mathrm{CO}_{2}, \mathrm{CO}, \mathrm{H}_{2}, \mathrm{H}_{2} \mathrm{O}$ e $\mathrm{N}_{2}$, num ambiente de maneira a melhorar o vácuo.

\footnotetext{
${ }^{1}$ link: http://www.srim.org
} 
Seria adequado o uso de bombas especificamente projetadas com esse intuito, porém nesse trabalho optou-se por evaporar o titânio com o uso do elétron-beam. O procedimento para obter um melhor ambiente de vácuo consistiu em primeiramente emitir um feixe de elétrons na superfície do índio metálico para evaporar eventuais impurezas retidas na superfície e só em seguida evaporar o titânio de alta pureza (99.999\%). As figuras 3.4a e 3.4b mostram a variação da pressão em função do tempo e da corrente do elétron-beam irradiado em duas ocasiões.

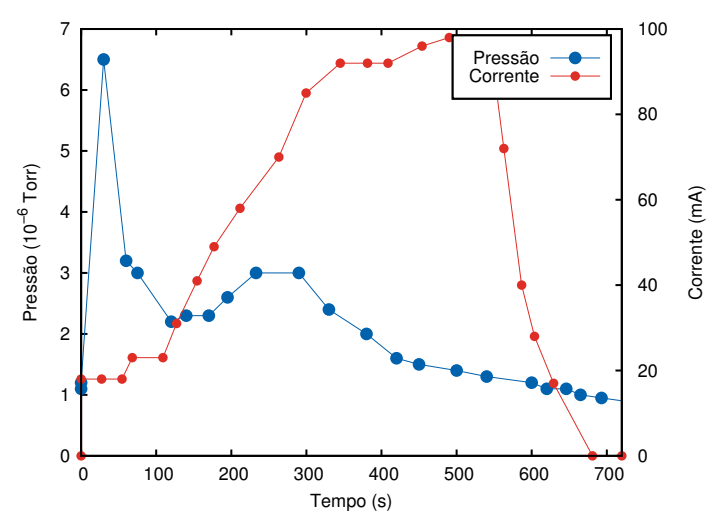

(a)

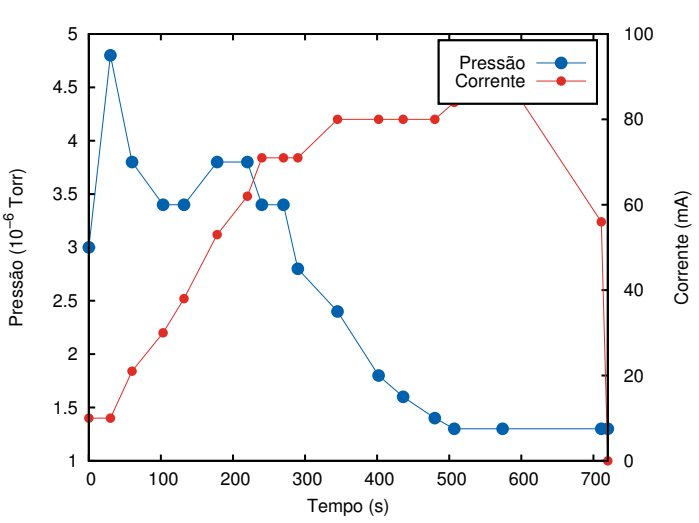

(b)

Figura 3.4: Variação da pressão em função do tempo e da corrente de evaporação para duas ocasiões diferentes.

O tempo definido como zero é o momento do início da irradiação do feixe. O importante a notar nesses gráficos são a pressão inicial, ou seja, a pressão estável onde não há nenhum processo ocorrendo dentro da câmara, e a pressão final. Observou-se em geral, uma pequena variação onde na figura $3.4 \mathrm{~b}$ foi de $P_{\text {inicial }}=3 \times 10^{-6}$ para $P_{\text {final }}=1,3 \times 10^{-6}$ Torr , enquanto que da figura 3.4 a foi $P_{\text {inicial }}=1,1 \times 10^{-6}$ para $P_{\text {final }}=7,5 \times 10^{-7}$ Torr.

\subsection{Filmes Finos Produzidos}

Na tabela 3.1 está apresentado o nome e outras informações dos filmes depositados, de maneira que "saf"e "si"se referem ao filme fino depositado sobre a Safira-C e silício (111), respectivamente. Os filmes foram depositados até que o medidor de quartzo, o qual mede a espesssura de índio evaporado, acusasse $900 \AA$. Da tabela, 
também pode-se observar que em todos os casos foram evaporados previamente o titânio, exceto a amostra E, com o intuito de justamente verificar o seu efeito causado na formação do filme.

Tabela 3.1: Tabela com o nome e informações das amostras produzidas.

\begin{tabular}{c|c|c|c|c} 
& $\bar{T}\left({ }^{\circ} \mathrm{C}\right)$ & E. feixe $(\mathrm{eV})$ & $R_{a}(\mathrm{~N} / \mathrm{In})$ & Evap. Titânio \\
\hline A-saf / A-si & 351 & 120 & 1,48 & Sim \\
\hline B-saf / B-si & 380 & 150 & 2,26 & Sim \\
\hline C-saf / C-si & 380 & 150 & 3,16 & Sim \\
\hline D-saf / D-si & 252 & 150 & 2,26 & Sim \\
\hline E-saf / E-si & 380 & 150 & 2,03 & Não \\
\hline F-saf / F-si & 380 & 150 & 2,03 & Sim \\
\hline G-saf /G-si & 480 & 150 & 2,26 & Sim
\end{tabular}

\subsection{Difração de Raios-X}

Para realizar a análise estrutural e composicional dos filmes finos formados foi utilizada a técnica de difração de raios-X (XRD) através do difratrômetro Rint 2100, Rigaku com radiação $C u-K_{\alpha}$ do Laboratório de Cristalografia do Instituto de Física da USP. Num cristal, os centros espalhadores são formados por átomos contidos nos planos virtuais, os quais são denominados planos cristalográficos e indexados através dos índices de Miller, $h k l$, separados por uma distância $d$. W.L. Bragg formulou uma equação possibilitando obter a distância interplanar, sabendo-se o ângulo de incidência e o comprimento de onda do feixe incidente através de relações geométricas entre o feixe incidente e o feixe difratrado pelos planos. Esta relação leva a famosa equação conhecida como Lei de Bragg:

$$
2 d \operatorname{sen} \theta=n \lambda
$$

onde $\theta$ é o ângulo entre a direção do feixe incidente e o plano cristalográfico, $\lambda$ o comprimento de onda da radiação e $n$ um número inteiro referente à ordem de 
difração (usualmente considera-se $n=1$ ). Por outro lado, $d$ também está relacionado com a estrutura geométrica que os átomos estão arranjados, onde os índices de Miller definem quais planos estão sendo considerados. Portanto, tal parâmetro permite a obtenção dos parâmetros de rede. No caso de um sistema hexagonal, a relação é a seguinte:

$$
\frac{1}{d_{h k l}^{2}}=\frac{4}{3 a^{2}}\left(h^{2}+h k+k^{2}\right)+\frac{l^{2}}{c^{2}}
$$

onde $a$ e $c$ são os parâmetros de rede. Voltando a equação 3.1 é importante notar a dependência $\operatorname{com} \operatorname{sen} \theta$. A precisão dependerá da função $\operatorname{sen} \theta$ e não de $\theta$, de forma que esta dependência ocorre de maneira "lenta" com $\theta$. Por exemplo, um erro em $1^{\circ}$ gera um erro de $1,7 \%$ em $\operatorname{sen} \theta$ em $\theta=45^{\circ}$ mas apenas $0,15 \%$ se $\theta=85^{\circ}$. Então, a maneira mais adequada para obtenção dos parâmetros de rede seria através de medidas dos picos próximos de $\theta=90^{\circ}$ ou $2 \theta=180^{\circ}$, onde é comum de se observar a obtenção dos parâmetros de rede extrapolando para esse ângulo. Nesse trabalho optou-se apenas em obter o parâmetro de rede utilizando o pico referente ao de maior ângulo, devido ao baixo número de picos referente a um plano virtual.

Um conceito importante na análise da difração de raios-X é o termo denominado cristalito, o qual compreende o número de células agrupadas para formar um domínio de difração coerente. Partículas inferiores a cerca de $0.1 \mu m$ já apresentam difrações com pequenas variações em torno do ângulo de Bragg, causando um alargamento do pico difratado. Há a expressão formulada por Scherrer [17] para quantificar as dimensões do cristalito, entretanto, anterior ao seu cálculo é importante a discussão das fontes que causam o alargamento do pico. O próprio instrumento também tem um peso, porém a sua obtenção é imediata uma vez que é característico do tipo do equipamento. Já as contribuições para o alargamento devido a amostra, incluem principalmente o tamanho do cristalito e a tensão, ou de forma mais correta, a tensão não homogênea. A figura 3.5 ilustra o efeito da distorção da rede cristalina no formato e posicionamento dos picos. 

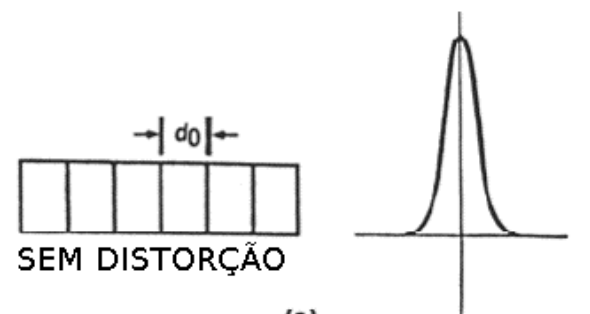

(a)

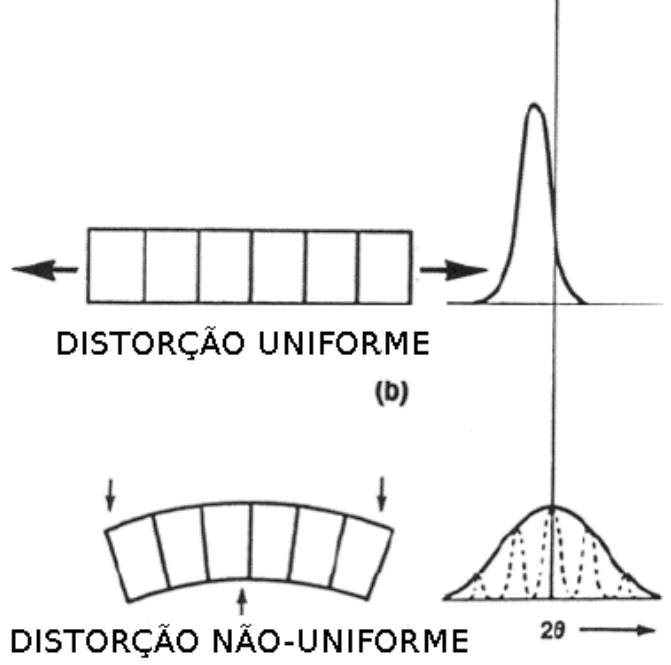

(c)

Figura 3.5: Efeito da distorção da rede no formato e posicionamento dos picos.

Como ferramenta para quantificar o perfil dos picos, utilizou-se a função de Lorentz:

$$
\Gamma(2 \theta)=\frac{2 C_{1} w}{\pi\left[w^{2}+4\left(2 \theta-2 \theta_{0}\right)^{2}\right]}+C_{2}
$$

onde $w$ representará a largura total da altura máxima (FWHM da sigla em inglês) do pico na posição $2 \theta_{0}$ e $C_{1}$ e $C_{2}$ são parâmetros ajustáveis.

\subsection{Retroespalhamento Rutherford}

A técnica de Espectrometria de Retroespalhamento Rutherford (RBS da sigla em inglês) é um método de análise de materiais por feixe iônico que permite obter informações sobre a composição elementar de um material. Em 1911 o físico neoze- 
landês Ernest Rutherford mostrou que o átomo possui um núcleo positivo e maciço, com elétrons orbitando ao seu redor a grandes distâncias em relação ao tamanho do núcleo. Devido a isso, esta técnica recebeu o seu nome.

A técnica consiste em medir a energia das partículas do feixe que colidiram com a amostra e foram retroespalhadas. Durante a colisão, os íons do feixe perdem energia e tal redução depende da razão das massas da partícula incidente e da partícula do alvo. Correções no valor da energia são aplicadas para camadas mais internas, uma vez que o feixe perde energia à medida que penetra na amostra (principalmente por desvios causados pelos elétrons).

Para as medições das amostras desse tabalho, utilizou-se o feixe de $\mathrm{He}^{+}$com energia de 2,2 MeV, acelerado pelo Pelletron-Tandem 5SDH, construído pela National Electrostatic Corporarion e mantido atualmente pelo Laboratório de Análises de Materiais por Feixes Iônicos, localizado no instuto de Física da Universidade de São Paulo. 


\section{Capítulo 4}

\section{Base teórica da Teoria do Funcional da Densidade}

\subsection{Teoria do Funcional da Densidade e o programa Wien2k}

A Teoria do Funcional da Densidade (DFT) se tornou um dos métodos mais utilizados, atualmente, para investigação da estrutura eletrônica de um sistema de muitos corpos. Porém, ainda há muito espaço para o desenvolvimento com o intuito de melhorar a precisão do modelo. Antes de iniciar o estudo da DFT, convém contextualizá-la brevemente.

Um sólido nada mais é que uma coleção de prótons e elétrons. Se tivermos $\mathrm{N}$ prótons, estaremos lidando com um problema de $N+Z N$ partículas carregadas interagindo eletromagneticamente. Devido a pequena massa delas, o sistema se torna um problema quântico de muitos corpos. A definição da hamiltoniana completa é imediata:

$$
\begin{array}{r}
\hat{H}=-\frac{\hbar^{2}}{2} \sum_{i} \frac{\nabla_{\vec{R}_{i}^{2}}}{M_{i}}-\frac{\hbar^{2}}{2} \sum_{i} \frac{\nabla_{\vec{r}_{i}^{2}}}{m_{e}}-\frac{1}{4 \pi \epsilon_{0}} \sum_{i, j} \frac{e^{2} Z_{i}}{\left|\vec{R}_{i}-\vec{r}_{j}\right|}+ \\
+\frac{1}{8 \pi \epsilon_{0}} \sum_{i \neq j} \frac{e^{2}}{\left|\vec{r}_{i}-\vec{r}_{j}\right|}+\frac{1}{8 \pi \epsilon_{0}} \sum_{i \neq j} \frac{e^{2} Z_{i} Z_{j}}{\left|\vec{R}_{i}-\vec{R}_{j}\right|}
\end{array}
$$

A massa do núcleo na posição $\vec{R}_{i}$ é definido como $M_{i}$ e o elétron na posição $\vec{r}_{i}$ como $m_{e}$. Os dois primeiros termos da hamiltoniana são os operadores cinéticos 
dos núcleos e elétrons. Os últimos três termos correspondem a interação entre os elétrons e núcleos, entre os próprios elétrons e entre os prótons, respectivamente. Obviamente que é impossível resolver esse problema de forma exata, mesmo com a atual capacidade computacional que tem-se disponível. Como é comum ao se deparar com modelos muito complexos, aproximações serão realizadas a fim de facilitar o cálculo dos auto-estados eletrônicos desse tipo de sistema.

\subsubsection{Aproximação de Born-Oppenheimer}

Uma aproximação muito conhecida na física do estado sólido e na física molecular é a de Born-Oppenheimer. O método se baseia em fixar os núcleos e assumir que os elétrons estão em equilíbrio instantâneo com eles. Dessa maneira é possível abstrair a interação dos elétrons com os núcleos através de um correspondente potencial externo. Vizualizando novamente a equação 4.1, o primeiro se torna nulo e o último é reduzido a uma constante. Portanto, tem-se:

$$
\hat{H}=\hat{T}_{e}+\hat{V}_{e e}+\hat{V}_{e x t}
$$

É interessante notar um ponto: a característica dos cálculos é universal nos dois primeiros termos e particular no último, onde as informações específicas do sistema, por exemplo de uma molécula de $\mathrm{H}_{2} \mathrm{O}$ ou $\mathrm{CO}_{2}$, estarão contidos em $\hat{V}_{\text {ext }}$.

\subsubsection{Teoria do Funcional da Densidade}

Apesar da grande simplificação do sistema de muitos corpos através da aproximação de Born-Oppenheimer, ainda é muito inviável a sua resolução mesmo com os recursos computacionais existentes atualmente. A Teoria do Funcional da Densidade basicamente reformula o problema de partículas interagentes em termos de um sistema de partículas independentes sujeitas a um potencial efetivo. A teoria foi formalmente estabelecida por Hohenberg e Kohn, na década de 60 através de dois teoremas[18]:

Teorema 1: Há uma correspondência unívoca entre a densidade do estado fundamen- 
tal $\rho(\vec{r})$ de um sistema de muitos elétrons e o potencial externo $V_{\text {ext }}(r)$. Uma consequência imediata é que o valor esperado do estado fundamental de qualquer observável $\hat{O}$ é um funcional único da densidade eletrônica exata do estado fundamental:

$$
<\Psi|\hat{O}| \Psi>=O[\rho]
$$

Teorema 2: Sendo $\hat{O}$ a hamiltoniana $\hat{H}$, o funcional energia total do estado fundamental $H[\rho] \equiv E_{V e x t}[\rho]$ é da forma:

$$
\begin{aligned}
E_{V e x t}[\rho]= & <\Psi|\hat{T}+\hat{V}| \Psi>+<\Psi\left|\hat{V}_{\text {ext }}\right| \Psi> \\
& =F_{H K}[\rho]+\int \rho(\vec{r}) V_{\text {ext }}(\vec{r}) d \vec{r}
\end{aligned}
$$

Onde o funcional densidade de Hohenberg-Kohn $F_{H K}[\rho]$ é universal para qualquer sistema de muitos elétrons. $E_{V e x t}[\rho]$ alcança o valor mínimo para a densidade do estado fundamental exata correspondente ao $V_{\text {ext }}$.

Intuitivamente, é fácil assumir que a densidade eletrônica contém menos informação que a função de onda e portanto não seria possível obter o valor de $V_{\text {ext }}$ apenas como função da densidade. Entretanto, o primeiro teorema nos diz que isso é possível. Todos os observáveis podem ser obtidos de uma forma única através da densidade eletrônica apenas, ou seja, podem ser escritos como funcionais da densidade.

\subsubsection{As equações de Kohn-Sham}

Os teoremas de Hohenberg-Kohn não fornecem uma maneira para encontrar $E_{0}$. Foi então que Kohn e Sham [19] forneceram um procedimento prático para obter a densidade do estado fundamental. O trabalho deles foi basicamente a reformulação da hamiltoniana de muitos corpos da equação 4.1 por um sistema de partículas independentes o qual produz exatamente a mesma densidade do estado fundamental. Em essência, se assume que os elétrons são não-correlacionados exceto por satisfazerem o princípio de exclusão de Pauli. Um pontecial efetivo é então incluído para 
aproximar os efeitos de correlação de muitos corpos, porém não há um termo de interação explícito na hamiltioniana.

O ponto principal aqui é que a densidade do estado fundamental de um sistema de muitos corpos interagentes pode ser gerada através de um sistema de partículas independentes. Todas as interações de muitos corpos podem ser abstraídos num potencial efetivo em que os elétrons estão sujeitos. Assim, desenvolvendo a densidade em termos de uma expansão em uma base de funções $\left\{\phi_{i}\right\}$ e mantendo o vínculo da constância do número de partículas do sistema, chega-se às equações de Kohn e Sham.

$$
\left(-\frac{\hbar^{2}}{2 m} \nabla^{2}+V_{e f f}\right) \phi_{i}=\epsilon_{i} \phi_{i}
$$

Onde $\phi_{i}$ são as funções de onda de partículas independentes. A densidade do sistema é obtida somando a contribuição de cada partícula:

$$
n(\vec{r})=\sum_{i}^{N}\left|\phi_{i}(\vec{r})\right|^{2}
$$

A reformulação comentada anteriormente leva o funcional de energia de Hohenberg e Kohn a ter a seguinte forma de partículas independentes:

$$
E_{K S}[n]=T_{s}[N]+\int d^{3} r v_{e x t}(r) n(r)+E_{H}[n]+E_{X C}[n]
$$

Tal que $T_{s}[n]$ é a energia cinética da partícula independente:

$$
T_{s}[n]=\sum_{i=1}^{N}<\phi_{i}\left|-\frac{\hbar}{2 m} \nabla^{2}\right| \phi_{i}>
$$

A interação de muitos corpos entre os elétrons é separada em um termo coulombiano clássico auto-interagente ou também conhecido como energia de Hartree $E_{H}[n]:$

$$
E_{H}[n]=\frac{1}{2} \int d^{3} r d^{3} r^{\prime} \frac{n(r) n\left(r^{\prime}\right)}{\left|r-r^{\prime}\right|}
$$


e por um outro termo que leva em conta as interações de troca e correlação $E_{X C}$. Através de substituições da equação 4.8 e 4.5, ela pode se reescrita como:

$$
E_{X C}[n]=\left(T_{e}[n]-T_{s}[n]\right)+\left(E_{e e}[n]-E_{H}[n]\right)
$$

destacando então que $E_{X C}$ representa o resíduo da energia cinética e potencial entre um sistema de muitos corpos interagentes e não interagentes. Esse termo é o único desconhecido no método de Kohn e Sham.

Recapitulando, esse último método permite reescrever o funcional energia de Hohenber e Kohn, separando em um termo de energia cinética não interagente, energia de Hartree e a contribuição restante dado por $E_{X C}$ que pode ser razoavelmente aproximado como um funcional local ou semi-local. Entretanto, tanto o termo de Hartree $E_{H}$ e $E_{X C}$ dependem da densidade eletrônica, que por sua vez depende dos orbitais. Isto significa lidar com um problema auto-consistente: as soluções $\phi_{i}$ determinam $E_{H}$ e $E_{X C}$, assim a equação de Schrodinger não pode ser escrita sem antes conhecer a solução. A saída consiste num método iterativo, é assumido um valor inicial para $n_{0}(r)$ e constrói-se a hamiltoniana; o problema de autovalores é resolvido e os auto-estados são determinados, então um novo valor de $n_{1}(r)$ é obtido e comparado com o inicial. Esse ciclo é repetido até que satisfaça um critério de convergência entre as densidades eletrônicas de uma etapa com a anterior. Uma vez satisfeito o critério, afirma-se que a densidade eletrônica é consistente com as equações de Kohn-Sham. Esse esquema está ilustrado na figura 4.2. 


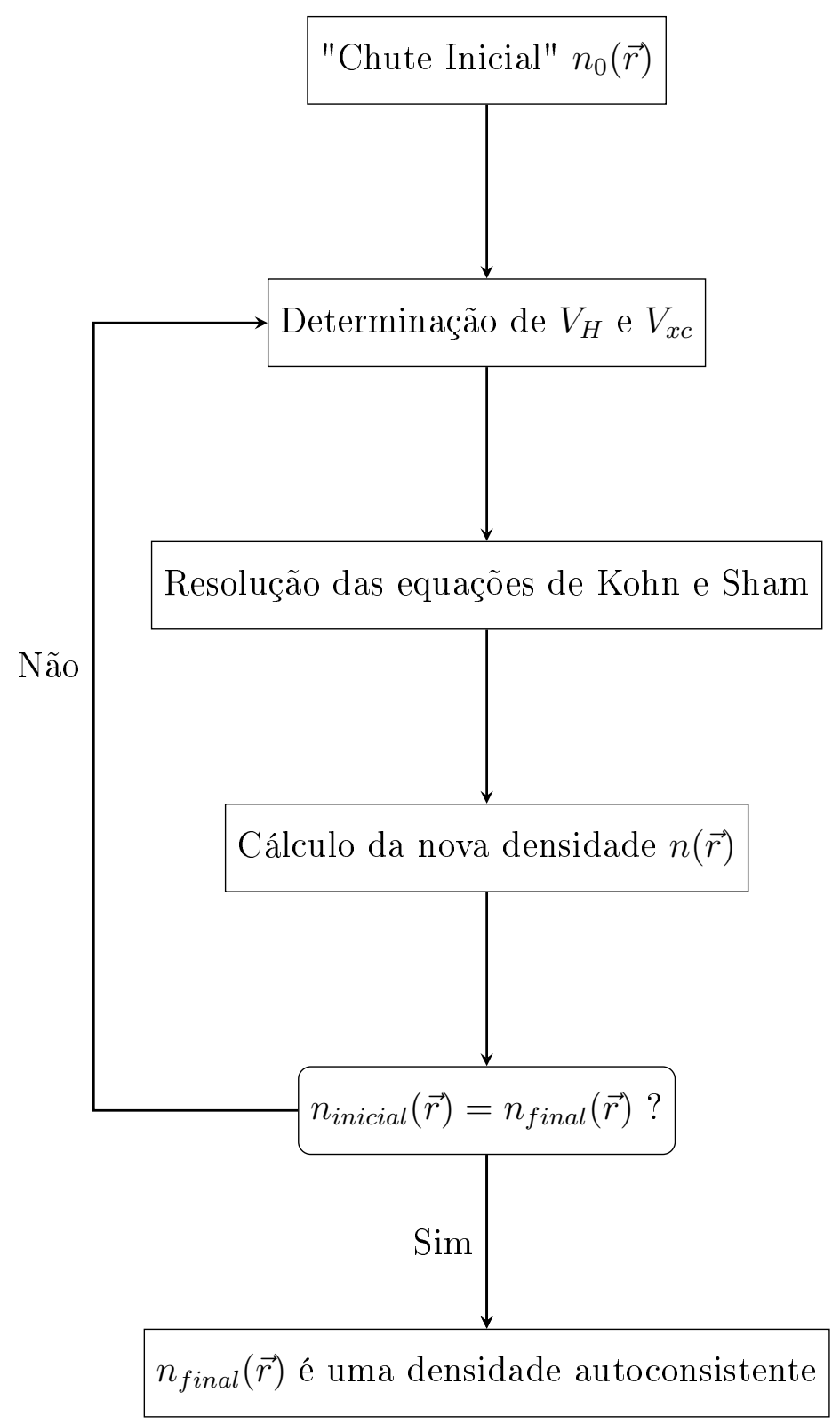

Figura 4.1: Fluxograma com as etapas do ciclo autoconsistente.

\subsubsection{O funcional de troca e correlação}

Como foi discutido anteriormente, a menos da aproximação Born-Oppenheimer, as equações de Kohn e Sham são exatas, porém não se tem o conhecimento do termo de troca e correlação. Uma aproximação amplamente utilizada é a Aproximação da Densidade Local (LDA), tal que possui a forma: 


$$
E_{X C}^{L D A}=\int n(\vec{r}) \epsilon_{x c}(n(\vec{r}) d \vec{r}
$$

onde o termo $\epsilon_{x c}$ é numericamente conhecido. A expressão acima basicamente divide o material em volumes infinitesimais com uma densidade constante. Esses volumes contribuem para a energia total de troca e correlação por uma quantidade equivalente a de um volume preenchido por um gás de elétrons. Por construção, espera-se que a aproximação tenha resultado preciso apenas para sistemas com pequena variação de densidade. Mas surpreendemente, ela também permite obter ótimos resultados para vários outros sistemas realistas.

Outro tipo de aproximação que vai além da aproximação LDA foi desenvolvida adicionando-se a contribuição para a energia de troca e correlação não só dependente de cada volume infinitesimal mas também sobre a densidade em volumes vizinhos, em outras palavras, o gradiente da densidade é utilizado. Tal aproximação é conhecida como Aproximação do Gradiente Generalizado (GGA). Há uma certa liberdade em como incorporar o gradiente da densidade e portanto, há várias versões de GGA. Para os cálculos desse trabalho, utilizou-se o funcional PBEsol-GGA [20], do qual obteve-se os resultados do parâmetro de rede mais próximos do experimental se comparados com o funcional LDA e PBE-GGA.

\subsubsection{O programa Wien2k}

Existem várias maneiras de se resolver a equação 4.6. A resolução consiste primeiramente na escolha de um conjunto de base de funções $\phi_{p}^{b}$ e a obtenção dos coeficientes $c_{p}^{i}$ das funções de onda $\phi_{i}$

$$
\phi_{i}=\sum_{p=1}^{P} c_{p}^{i} \phi_{p}^{b}
$$

Uma escolha adequada para o conjunto base é extremamente importante, uma vez que refletirá principalmente no custo computacional. Dois critérios são adotados para a definição de uma boa escolha da base: ser eficiente e não ser tendenciosa ou imparcial. O primeiro é importante para diminuir a quantidade de funções de base 
e descrever com precisão as funções de onda. Entretanto, tal critério vai contra o segundo, pois manter a precisão implica em saber o comportamento prévio da função de onda. A arte da teoria da física da matéria condensada consiste em encontrar um conjunto de funções de base que seja simultaneamente eficiente e não tendencioso. Alguns exemplos de funções de base bastante conhecidos que tentam alcançar esse objetivo são as ondas planas (PW), ondas planas aumentadas (APW) e ondas planas aumentadas e linearizadas (LAPW).

O programa Wien2k utiliza a base de ondas planas aumentadas e linearizadas + orbitais locais ((L)APW+lo), sendo um dos esquemas mais precisos para cálculo da estrutura eletrônica de banda de energia. Outro aspecto desse programa é o tratamento dos orbitais sem o uso de pseudopotenciais, ou seja, os orbitais próximos do núcleo são tratados de forma diferenciada com o uso de combinações de funções atômicas. Devido a isso, o método utilizado no Wien2k também é conhecido como método full-potential.

\subsubsection{O método APW}

Logo de início, é importante enfatizar que o método APW apenas não é mais utilizado. Porém por motivos didáticos é de grande vantagem realizar sua discussão para descrever o método APW + lo, o qual foi amplamente utilizado nesse trabalho.

O teorema de Bloch permite escrever a solução da hamiltoniana periódica da seguinte maneira:

$$
\psi_{\vec{k}}^{n}(\vec{r})=\sum_{\vec{K}} c_{\vec{K}}^{n, \vec{k}} \exp i(\vec{k}+\vec{K}) \cdot \vec{r}
$$

onde comparando com a equação 4.13 , a variável $i$ representa $(n, \vec{k})$ e $p$ o termo $\vec{k}+\vec{K}$. Então uma função da base de $\psi_{\vec{k}}^{n}$ é:

$$
\phi_{\vec{K}}^{\vec{k}}(\vec{r})=\exp i(\vec{k}+\vec{K}) \cdot \vec{r}
$$

sendo $\vec{k}$ o vetor de onda dentro da primeira zona de Brillouin e $\vec{K}$ um vetor da 
rede recíproca.

Próximo do núcleo os elétrons se comportam praticamente como se estivessem em átomos livres e por isso são descritos com funções de onda atômicas. Já para os elétrons mais livres, ou seja, os que estão mais afastados do núcleo, são tratados por ondas planas. O espaço é dividido então em duas regiões (ver figura 4.2), sendo que ao redor do núcleo de cada átomo uma esfera de raio $R_{\alpha}$ é delimitado, cujo espaço será definido por $S_{\alpha}$. O espaço fora da esfera é a zona intersticial denominado por I. Uma onda plana aumentada (APW) é definido como:

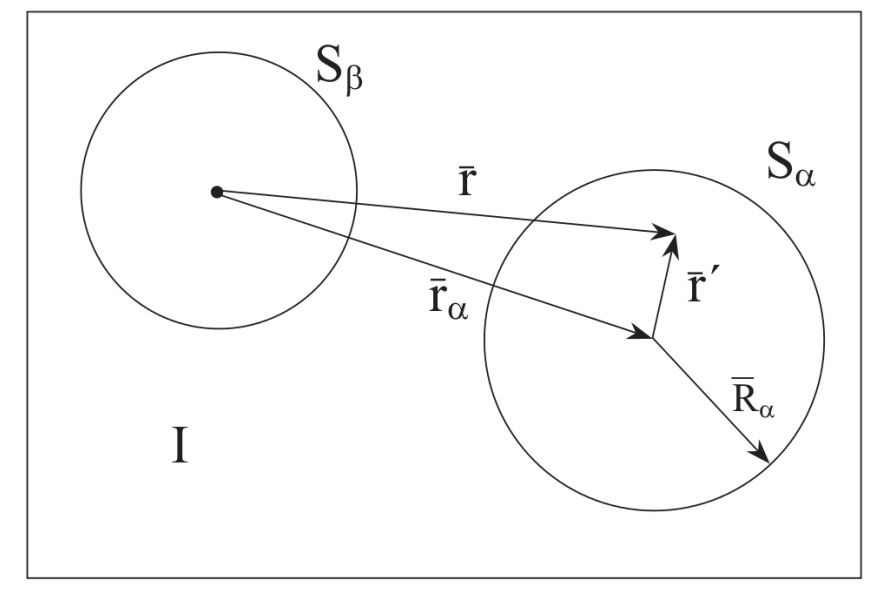

Figura 4.2: Divisão da célula unitária para um caso com dois átomos.

$$
\phi_{\vec{K}}^{\vec{k}}= \begin{cases}\frac{1}{\sqrt{V}} \exp [i(\vec{k}+\vec{K}) \cdot \vec{r}] & \vec{r} \in I \\ \sum_{l, m} A_{l, m}^{\alpha, \vec{k}+\vec{K}} u_{l}^{\alpha}\left(r^{\prime}, E\right) Y_{m}^{l}\left(\hat{r}^{\prime}\right) & \vec{r} \in S_{\alpha}\end{cases}
$$

onde $V$ é volume da célula unitária e $Y_{m}^{l}$ são as funções harmônicos esféricos. $A_{l, m}^{\alpha}$ são os parâmetros ainda não determinados, assim como $E$. $u_{l}^{\alpha}$ são soluções da parte radial da equação de Schrödinger de um átomo livre $\alpha$. Para determinar $A_{l, m}^{\alpha}$, é necessário exigir que as condições de contorno das funções de onda plana com as funções dentro da esfera sejam satisfeitas. Entretanto, para possibilitar isso é preciso expandir as funções de onda planas em harmônicos esféricos:

$$
\frac{1}{\sqrt{V}} \exp [i(\vec{k}+\vec{K}) \cdot \vec{r}]=\frac{4 \pi}{\sqrt{V}} \exp \left[i(\vec{k}+\vec{K}) \cdot \overrightarrow{r_{\alpha}}\right] \sum_{l, m} i^{l} j_{l}(|\vec{k}+\vec{K}||\vec{r}|) Y_{m}^{l *}(\vec{k}+\vec{K}) Y_{m}^{l}\left(\hat{r}^{\prime}\right)
$$


tal que $j_{l}(x)$ é a função de Bessel de ordem $l$. Assim, igualando com a equação 4.16 dentro da esfera resulta em:

$$
A_{l, m}^{\alpha, \vec{k}+\vec{K}}=\frac{4 \pi i^{l} \exp \left[i(\vec{k}+\vec{K}) \cdot \overrightarrow{r_{\alpha}}\right]}{\sqrt{V} u_{l}^{\alpha}\left(\vec{R}_{\alpha}, E\right)} j_{l}\left(|\vec{k}+\vec{K}| R_{\alpha}\right) Y_{m}^{l *}(\vec{k}+\vec{K})
$$

A expressão acima define $A_{l, m}^{\alpha, \vec{k}+\vec{K}}$ a menos do termo $E$. A princípio a equação 4.17 possui infinitos termos, porém obviamente é necessário escolher adequadamente um valor finito $l_{\max }$. Para um dado $l_{\max }, Y_{m}^{l_{\max }}(\theta, \phi)$ pode ter no máximo $2 l_{\max }$ nós ao longo de um círculo $(\theta=0 \rightarrow 2 \pi$ para qualquer $\phi$ fixo) da esfera $\alpha$. Convertendo em nós por unidade de comprimento, obtém-se $2 l_{\max } / 2 \pi R_{\alpha}$. Para que a onda plana satisfaça a condição de contorno, esta deve ter um número similar de número de nós por unidade de comprimento disponível. A onda plana com o menor período terá $K_{\max } / \pi$ nós por unidade de comprimento. $K_{\max }$ e $l_{\max }$ terão valores comparáveis se o número de nós por unidade de comprimento é igual, o que leva a relação de condição $R_{\alpha} K_{\max }=l_{\max }$. Isto permite obter um valor adequado para $l_{\max }$ para um dado $K_{\text {max }}$.

Resumindo, há uma função oscilante percorrendo a célula unitária, e sempre que encontra um átomo o seu comportamento é alterado para uma forma mais complexa dentro do raio determinado por $R_{\alpha}$.

Para a resolução do problema, ainda falta calcular $E$, porém este representa o autovalor que se pretende obter das autofunções. Então será necessário "chutar" um valor inicial $\epsilon_{\vec{k}}^{n}$ e tomá-lo como $E$. Isso possibilitará a resolução da equação secular e $\epsilon_{\vec{k}}^{n}$ deverá ser a raiz, onde normalmente não será o mesmo assumido inicialmente. Portanto, várias etapas serão necessárias.

\subsubsection{O método $A P W+l o$}

Como foi discutido anteriormente, o problema com o método APW era a dependência da energia no conjunto de funções de base. Existe um outro método denominado LAPW $+\mathrm{LO}$ que, por um custo maior do conjunto de base, é possível remover tal dependência. Já no método $\mathrm{APW}+\mathrm{lo}$, o conjunto será independente da 
energia e possuirá o tamanho da base próximo a do APW. Nesse método APW + lo, o conjunto de base é aumentado com um segundo tipo de funções. Estes são orbitais locais, diferente dos utilizados em LAPW $+\mathrm{LO}$ (por isso a diferenciação escrito em minúsculo). Tais orbitais são descritos por:

$$
\phi_{\alpha, l o}^{l m}(\vec{r})= \begin{cases}0 & \vec{r} \notin S_{\alpha} \\ \left(A_{l m}^{\alpha, l o} u_{l}^{\alpha}\left(r^{\prime}, E\right)+B_{l m}^{\alpha, l o} \dot{u}_{l}^{\alpha}\left(r^{\prime}, E\right)\right) Y_{m}^{l}\left(\hat{r}^{\prime}\right) & \vec{r} \in S_{\alpha}\end{cases}
$$

Os coeficientes $A_{l m}^{\alpha, l o}$ e $B_{l m}^{\alpha, l o}$ são determinados através da normalização e exigindo que o orbital local seja nulo na superfície de fronteira entre as duas regiões.

\subsubsection{O método TB-mBJ para a investigação das propriedades óticas}

Como já foi discutido anteriormente, sempre se almeja encontrar métodos para calcular a estrutura eletrônica de um sólido com um custo computacional não muito alto. Existem métodos como LDA + DMFT [21] (teoria dinâmica do campo médio) e GW [22], os quais descrevem com alta precisão as propriedades de um cristal, porém são cálculos muito custosos se comparados com LDA ou GGA. Recentemente, Becke e Johnson [23] propuseram um potencial de troca, o qual descreve com exatidão este potencial em átomos. Tal potencial não possui nenhum parâmetro empírico e é escrito na forma:

$$
v_{x}^{B J}(\mathbf{r})=v_{x}^{B R}(\mathbf{r})+\frac{1}{\pi} \sqrt{\frac{5}{12}} \sqrt{\frac{2 t(\mathbf{r})}{n(\mathbf{r})}}
$$

O termo $t(\mathbf{r})$ contido acima é a densidade da energia cinética:

$$
t(\mathbf{r})=\frac{1}{2} \sum_{i=1}^{N} \nabla \psi_{i}^{*}(\mathbf{r}) . \nabla \psi_{i}(\mathbf{r})
$$

e $v_{x}^{B R}(\mathbf{r})$ é o potencial de Becke-Roussel:

$$
v_{x}^{B R}(\mathbf{r})=-\frac{1}{b(\mathbf{r})}\left(1-\exp [-x(\mathbf{r})]-\frac{1}{2} x(\mathbf{r}) \exp [-x(\mathbf{r})]\right)
$$


onde o termo $b$ é calculado por $b=\left[x^{3} \exp (-x) /(8 \pi n)\right]^{1 / 3}$. No trabalho de [24], é mostrado que o potencial de BJ melhorou moderadamente o cálculo do band gap se comparado com LDA e GGA. Entretanto, em [25], uma simples modificação nesse método foi proposto:

$$
v_{x}^{T B-m B J}(\mathbf{r})=c v_{x}^{B R}(\mathbf{r})+(3 c-2) \frac{1}{\pi} \sqrt{\frac{5}{12}} \sqrt{\frac{2 t(\mathbf{r})}{n(\mathbf{r})}}
$$

tal que o parâmetro $c$ é dado por:

$$
c=A+B \sqrt{\bar{g}}
$$

onde

$$
\bar{g}=\frac{1}{V_{\text {cell }}} \int_{\text {cell }} \frac{1}{2}\left(\frac{\left|\nabla n^{\uparrow}(\mathbf{r})\right|}{n^{\uparrow}(\mathbf{r})}+\frac{\left|\nabla n^{\downarrow}(\mathbf{r})\right|}{n^{\downarrow}(\mathbf{r})}\right)
$$

é a média de $g=|\nabla n| / n$ na célula unitária de volume $V_{\text {cell }}$. Na equação 4.24, $A$ e $B$ são dois parâmetros cujos valores são $A=-0.012$ e $B=1.023 b o h r^{1 / 2}$, obtidos através de um ajuste dos valores experimentais do band gap. Em outros trabalhos $([25,26])$, foi apresentado resultados mostrando que o potencial TB-mBJ é tão preciso quanto o método GW. A figura 4.3 extraída do trabalho de $F$. Tran e P. Blaha [25] ilustra alguns resultados comparativos:

Para a obtenção das propriedades óticas do InN, nesse trabalho foi amplamente utilizado o método TB-mBJ. O ponto principal é analisar a influência da variação do band gap ótico devido a presença do oxigênio, portanto o cálculo do coeficiente de absorção se torna necessário. Tal coeficiente é obtido através da função dielétrica no limite de altos comprimentos de onda $\mathbf{q}=\left|\mathbf{k}^{\prime}-\mathbf{k}\right|=0$ da equação abaixo:

$$
\epsilon_{2}(\mathbf{q}=0, \omega)=\frac{4 \pi^{2} e^{2}}{\Omega^{2} m^{2} \omega^{2}} \sum_{\mathbf{k}, n, \mathbf{k}^{\prime}, n^{\prime}}|<\mathbf{k} n| \mathbf{p}\left|\mathbf{k} n^{\prime}>\right|^{2} f_{\mathbf{k}, n}\left(1-f_{b f k, n}\right) \delta\left(E_{\mathbf{k}, n^{\prime}}-E_{\mathbf{k}, n}-\hbar \omega\right)
$$




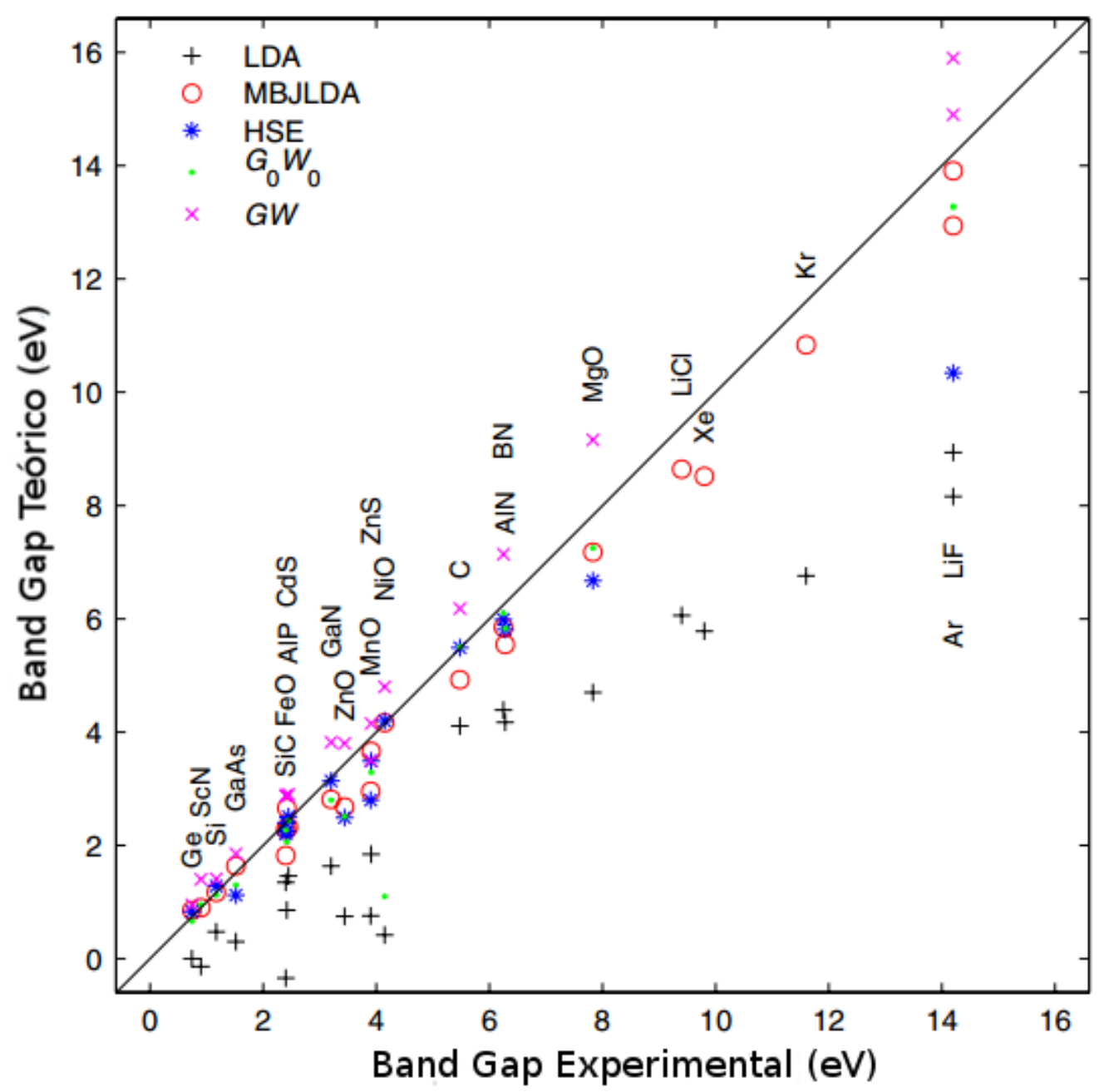

Figura 4.3: Gráfico extraído do trabalho de F. Tran e P. Blaha comparando cálculos teóricos com resultados experimentais.

A parte real $\epsilon_{1}(\mathbf{q}=0, \omega)$ da função dielétrica pode ser obtido através das relações de Kramers-Kronig [27]:

$$
\epsilon_{1}(\mathbf{q}=0, \omega)=1+\frac{1}{2 \pi} \int_{-\infty}^{\infty} d \omega^{\prime} \epsilon_{2}\left(\omega^{\prime}\right)\left(\frac{1}{\omega^{\prime}-\omega}+\frac{1}{\omega^{\prime}+\omega}\right)
$$

Na equação acima, $\Omega$ é o volume do cristal, $f_{\mathbf{k}, n}$ é a distribuição de Fermi e $\mid \mathbf{k}, n>$ corresponde a função de onda do n-ésimo autovalor $E_{\mathbf{k}, n}$. A expressão do coeficiente de absorção $\alpha(\omega)$ é então expresso por: 


$$
\alpha(\omega)=\frac{2 \omega}{c}\left(\frac{-\operatorname{Re}(\epsilon(\omega))+|\epsilon(\omega)|}{2}\right)^{1 / 2}
$$

Finalmente, o band gap ótico é obtido extrapolando linearmente para zero a parte linear do espectro de absorção utilizando o esquema PBEsol-GGA + TB-mBJ:

$$
(\alpha h \nu)^{2}=A\left(h \nu-E_{g}\right)
$$

\subsubsection{O Laboratório Virtual}

Para o cálculo da estrutura eletrônica de qualquer material, primeiramente definese como o espaço recíproco será discretizado. Isso é feito escolhendo o número de pontos k utilizados para a integralização no espaço recíproco. No caso do InN, por exemplo, utilizou-se 700 pontos k. Isso significa que o espaço recíproco foi dividido uniformemente em 700 diferentes regiões discretas. Uma CPU (da sigla em inglês, Central of Processing Unit) com apenas um núcleo, por exemplo, realizaria os cálculos sequencialmente. O uso de várias CPU ou núcleos para o processamento simultâneo denomina-se paralelização e seu uso pode diminuir incrivelmente o tempo de cálculo. O programa Wien2k já está estruturado para realizar cálculos paralelizados e pode atuar de duas maneiras: distribuindo os pontos $\mathrm{k}$ uniformemente para cada núcleo ou CPU, também denominado de paralelização k ou paralelização MPI (da sigla em inglês, Message Passing Interface). Como o parâmetro de rede no espaço recíproco é inversamente proporcional ao do espaço real, para estruturas com muitos átomos são necessários poucos pontos k. Nesse caso, o modo de paralelização MPI se torna fundamental. Este é o principal padrão de paralelismo em memória distribuída (múltiplos processos), onde a principal característica é a comunicação entre os processos. Devido a isso, é possível por exemplo, duas CPUs realizarem cálculos para um único ponto k. Num sistema de 72 átomos, são necessários apenas cerca de 8 pontos k, portanto, no modo paralelização k não haveria uma maior eficiência com o uso acima de 8 CPUs ou núcleos.

O estudo da influência do oxigênio no InN requer criação de supercélulas com 
um grande número de átomos. Nesse trabalho, os estudos com o Wien2k foram realizados numa supercélula com 72 átomos. Para tal, foram necessários recursos computacionais compatíveis com esse propósito, os quais foram disponibilizados pelo Centro de Computação Eletrônica da USP através do projeto Nuvem USP. Assim, os cálculos foram realizados com a utilização de 4 máquinas virtuais (wien3, wien4,wien5 e wien6), cada uma com CPU da Intel(R) Xeon(R) E7-2870 2.40GHz de 8 núcleos e 16GB de memória RAM, mais 2 máquinas virtuais (wien1 e wien2) com 4 núcleos e 8GB de memória RAM cada, e uma última máquina (wien0) apenas para gerenciamento, totalizando 40 núcleos em operação. Todos as CPUs foram configuradas para o funcionamento em paralelização MPI com bibliotecas da Intel(R). O esquema está ilustrado na figura 4.4.

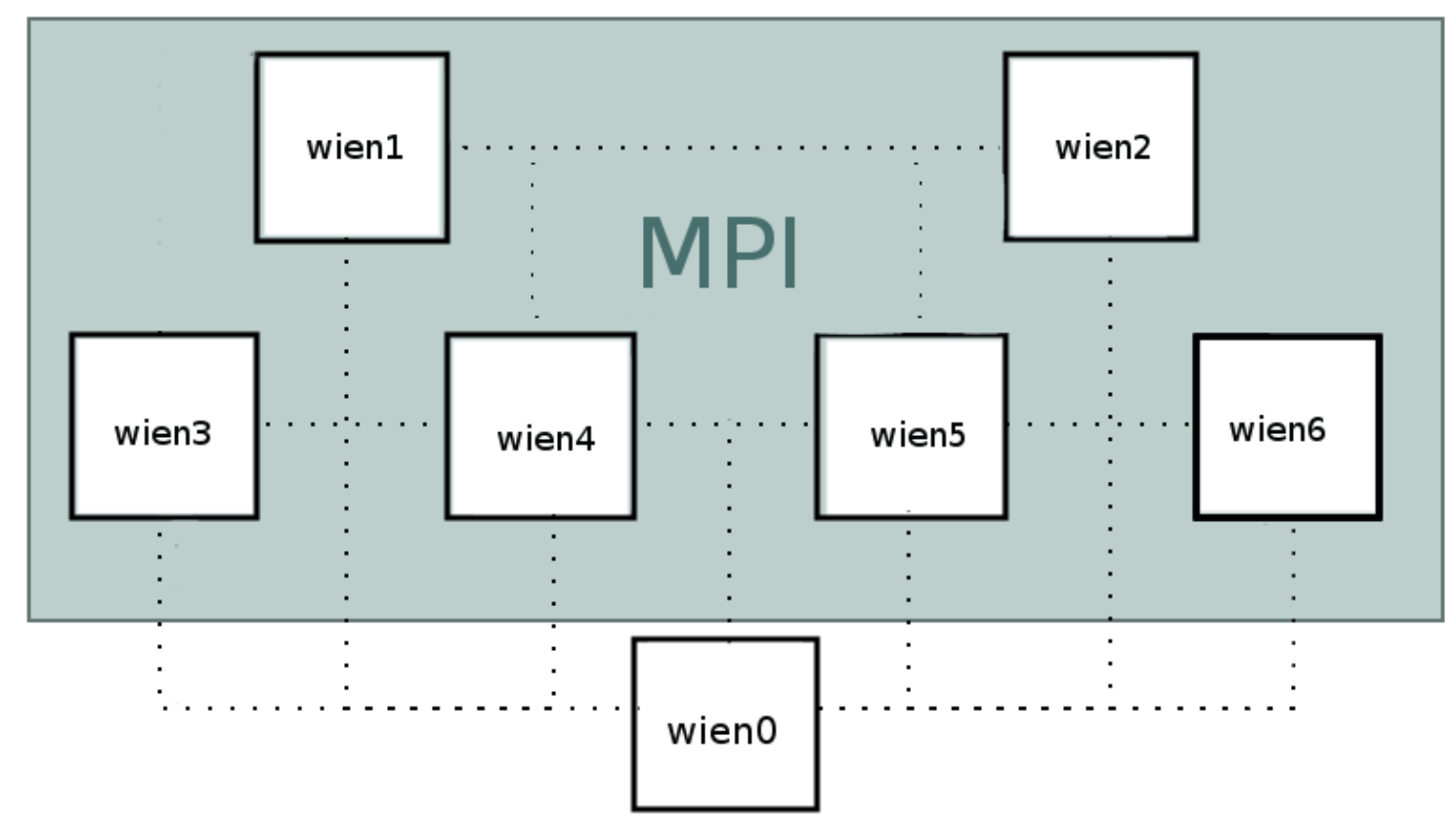

Figura 4.4: Esquema ilustrativo da configuração do cluster montado. 


\section{Capítulo 5}

\section{Estudo ab initio dos defeitos}

\section{pontuais}

\subsection{Introdução}

Seja em qualquer sólido cristalino, a presença de defeitos não podem ser evitados. Mesmo os mais puros substratos de silício estão sujeitos a eles. Os defeitos pontuais podem ser causados pela ausência (vacância), substituição por um outro elemento (dopante ou impureza) ou adição de um átomo que pode se alocar nos interstícios (região entre os átomos). A eletrônica dos semicondutores é praticamente baseada no controle das dopagens, seja para torná-lo do tipo p ou tipo n, ou para alterar a estrutura eletrônica do cristal. Uma simples dopagem de um material isolante pode torná-lo altamente condutor, como por exemplo o silício. Entretanto, é extremamente comum a presença de defeitos pontuais não desejados. Sem um controle eficaz, propriedades novas esperados pela inserção de defeitos podem ser anuladas devido a impurezas não desejadas.

Assim, o estudo dos defeitos pontuais são de grande importância, principalmente no que tange ao desenvolvimento de novas tecnologias. E para tal, o entendimento da termodinâmica da estabilidade dos defeitos se torna primordial para obter o controle desejado durante a produção de um material. 


\subsection{Termodinâmica da estabilidade dos defeitos}

A caracterização de um determinado defeito consiste em saber a probabilidade de sua ocorrência. A probabilidade, que também pode ser entendido como a concentração, é uma quantidade termodinâmica que depende de vários parâmetros intensivos como temperatura, pressão e potencial químico. A quantidade termodinâmica mais adequada para analisar a concentração dos defeitos seria a energia de formação de Gibbs. Porém, os cálculos ab initio são descritos em temperatura e pressão zero. Dessa forma, a quantidade que será utilizado é simplesmente a energia de formação de um defeito $E_{f}$ que, em sua forma geral, é dada por:

$$
E_{f}(D, q)=E_{D, q}-E_{\text {host }}-\sum_{i} \mu_{i} n_{i}+q\left(\epsilon_{V B M}+\epsilon_{F}\right)
$$

$E_{D, q}$ e $E_{\text {host }}$ são a energia total da supercélula contendo o defeito $D$ no estado de carga $q$ e sem defeito, respectivamente. A energia do átomo adicionado $n_{i}=+1$ ou removido $n_{i}=-1$ é tomado como referência o potencial químico do reservatório para diferentes elementos $\mu_{i}$. O potencial químico depende das condições experimentais de produção. No caso da formação de uma vacância de nitrogênio no InN, os potenciais químicos $\mu_{N}$ e $\mu_{\text {In }}$ são parâmetros variáveis, porém se restringem pela relação:

$$
\mu_{\text {InN }}=\mu_{N}+\mu_{\text {In }}=\mu_{\text {InN }}^{0}
$$

Individualmente, $\mathrm{N}$ está limitado por $\mu_{N} \leq 1 / 2 E_{\text {Total }}\left(N_{2}\right)$ e In por $\mu_{\text {In }} \leq \mu_{\text {In }}^{0}$, tal que $\mu_{I n}^{0}=\frac{1}{N} E_{\text {total }}\left(I n_{b u l k}\right)$ onde $\mathrm{N}$ é número de átomos no cristal. Então, é possível escrever a seguinte relação através da equação 5.2 e com as relações de inequação citadas anteriormente:

$$
\mu_{N}=\mu_{I n N}^{0}-\mu_{I n}>\mu_{I n N}^{0}-\mu_{I n}^{0}=\frac{1}{2} E_{\text {Total }}\left(N_{2}\right)+\Delta H_{f}
$$

onde $\Delta H_{f}$ é o calor de formação definido como: 


$$
\begin{aligned}
\Delta H_{f} & =\mu_{\text {InN }}^{0}-\mu_{N}^{0}+\mu_{\text {In }}^{0} \\
& =E_{\text {total }}(\operatorname{InN})-\frac{1}{2} E_{\text {total }}\left(N_{2}\right)-E_{\text {total }}\left(\operatorname{In}_{\text {bulk }}\right)
\end{aligned}
$$

Em suma, tem-se:

$$
\frac{1}{2} E_{\text {Total }}\left(N_{2}\right)+\Delta H_{f}<\mu_{N}<\frac{1}{2} E_{\text {Total }}\left(N_{2}\right)
$$

O limite quando $\mu_{N}$ se aproxima de $1 / 2 E_{\text {Total }}\left(N_{2}\right)$ denomina-se condição termodinâmica nitrogênio-rica. A situação quando $\mu_{N}$ se aproxima de $\frac{1}{2} E_{\text {Total }}\left(N_{2}\right)+\Delta H_{f}$ é denominado condição termodinâmica nitrogênio-pobre. Para os cálculos de InN, utilizou-se o valor experimental $\Delta H_{f}=-0.28 \mathrm{eV}$ [28],[29]. Para o estudo do oxigênio substitucional no nitrogênio $O_{N}$, o seu potencial químico deve ser inserido; este foi calculado como $\mu_{O}=1 / 2 E_{\text {Total }}\left(O_{2}\right)$, onde obteve-se a energia total de $\mathrm{O}_{2}$ pelo programa Wien2k no modo spin polarizado.

De maneira análoga ao potencial químico dos átomos, é preciso considerar os defeitos carregados em equilíbrio com um reservatório de elétrons. O potencial químico dos elétrons é o nível de Fermi no material, limitado entre a região do band gap e denotado por $\epsilon_{F}$. O valor zero de $\epsilon_{F}$ é definido na posição do máximo da banda de valência $\epsilon_{M B V}$, portanto varia entre 0 a $E_{g}$.

\subsection{Correções na dopagem de supercélulas}

O uso de supercélulas na teoria DFT é muito comum no estudo termodinâmico dos defeitos. É importante lembrar que as supercélulas estão sujeitas a condições de contorno periódicas e estão infinitamente repetidas no espaço. Portanto, é preciso ter cautela para evitar efeitos espúrios de interação inter-defeitos. Idealmente, para uma análise local de um defeito seria necessário o seu total isolamento, porém mesmo sistemas com milhares de átomos podem conter uma quantidade razoável de interações espúrias. O estudo de métodos para contornar tais problemas ainda são 
recentes, porém há um intenso trabalho sendo realizado pela comunidade científica para seu aprofundamento. O que se almeja pode ser a grosso modo compreendido pela figura 5.1 abaixo:
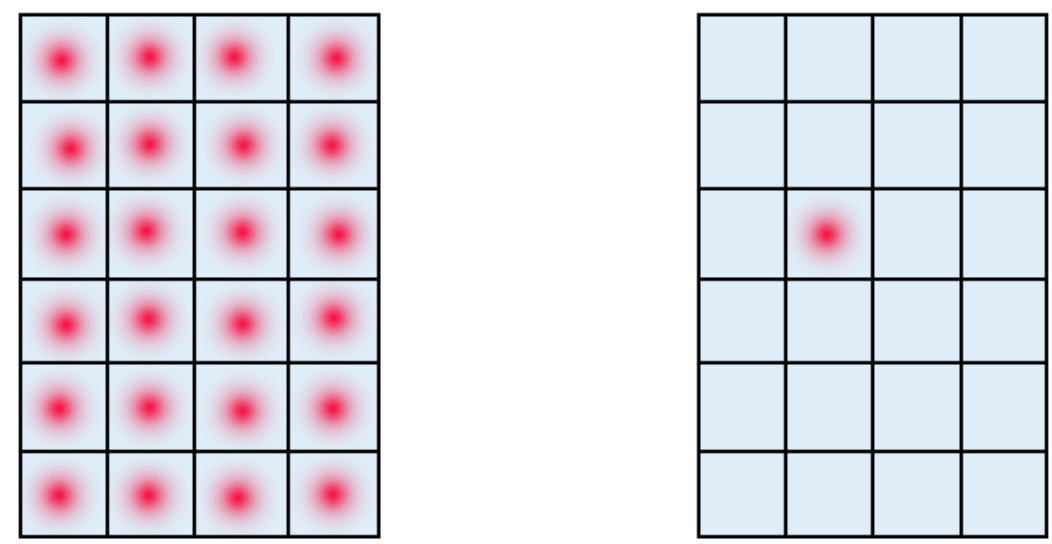

Figura 5.1: Esquema ilustrativo em duas dimensões onde a figura do lado esquerdo representa as imagens periódicas das supercélulas e a figura do lado direito mostra o que se pretende obter através das correções.

O primeiro obstáculo provém do fato que o defeito pode interagir com as imagens periódicas da supercélula através de um potencial Coulombiano de longo alcance $1 / r$. Portanto, haverá uma diferença entre a energia total Coulombiana de um defeito totalmente isolado e entre o defeito repetido periodicamente. Além disso, quando é realizado o cálculo total da energia da supercélula carregada $E_{D, q}$, a posição absoluta dos autovalores são perdidos. Em um sólido períodico, os potenciais eletrostáticos são definidos a menos de uma constante, portanto isso inviabiliza a comparação direta da posição do autovalor na supercélula com defeito carregado com a posição do autovalor na supercélula do bulk. Dessa forma, os autovalores do sistema bulk devem ser alteradso por uma constante na expressão da formação de energia. A expressão final de $E_{f}$ que leva em conta as duas correções mencionadas anteriormente foi formulada por Zhang e Northrup [30]:

$$
E_{f}(D, q)=E_{D, q}-E_{h o s t}+\Delta E_{e l}(q)-\sum_{i} \mu_{i} n_{i}+q\left(\epsilon_{V B M}+\epsilon_{F}+\Delta V\right)
$$


Onde $E_{e l}(q)$ é denominado correção eletrostática, proposto por Leslie e Gillian [31], cuja expressão é representada por:

$$
\Delta E_{e l}=\frac{\alpha_{M} q^{2}}{2 \epsilon \Omega^{1 / 3}}
$$

tal que $\alpha_{M}$ é a constante de Madelung da rede, $\epsilon$ a constante dielétrica da estrutura sem defeito e $\Omega$ o volume da supercélula. $\Delta V$ é a correção de alinhamento do potencial formulado por S. Taylor e F. Bruneval [32]:

$$
\Delta V=<v_{K S}^{\text {bulk }}>-<v_{K S}^{\text {defeito }}>
$$

ou seja, é a diferença entre a média do potencial total entre o sistema bulk e o sistema com defeito.

\subsection{Defeitos complexos}

Quando se deseja investigar mais de um defeito numa supercélula, o conceito da energia de ligação se torna muito útil. Nesse contexto, a energia de ligação é uma medida de estabilidade termodinâmica de um complexo contra a dissociação de seus constituintes (sistemas com defeitos isolados). A equação da energia de ligação $E_{l}$ é expressa por:

$$
E_{l}\left[\left(X_{1} X_{2} \ldots X_{N}\right)^{q}\right]=E_{f}\left[\left(X_{1} X_{2} \ldots X_{N}\right)^{q}\right]-\sum_{k=1} E_{f}\left[X_{k}^{q_{k}}\right]
$$

Onde $E_{f}\left[\left(X_{1} X_{2} \ldots X_{N}\right)^{q}\right]$ é a energia de ligação de um defeito complexo $\left(X_{1} X_{2} \ldots X_{N}\right)$ no estado de carga $q=q_{1}+q_{2}+. .+q_{N}$ e $E_{f}\left[X_{k}^{q_{k}}\right]$ é a energia de formação do defeito $X_{k}$ no estado de carga $q_{k}$. Por convenção, foi adotado o valor positivo da energia de ligação como complexos instáveis e negativos como estáveis. Portanto, no caso de um estudo de um defeito complexo de dois elementos, seria possível averiguar se estes defeitos preferem estar ligados ou mais separados um do outro. No primeiro caso se esperaria obter um valor de $E_{l}$ negativo e no último positivo. 


\section{Capítulo 6}

\section{Resultados Experimentais}

\subsection{Cristalinidade dos filmes finos}

\subsubsection{Substrato de Safira-C e Silício (111)}

Todas as amostras apresentadas na tabela 3.1 foram submetidos a análise por difração de raios-X com o principal intuito de verificar o grau de cristalinidade das amostras. Primeiramente foi realizada uma análise qualitativa, identificando os padrões dos principais picos presentes nos difratogramas. Uma vez identificados os picos referentes a estrutura do InN, realizou-se ajustes com funções de Lorentz a fim de estimar a posição angular e o valor de FWHM. A dependência da cristalinidade com a temperatura de deposição e o valor de $R_{a}$ (ver equação 2.14) também foram analisados.

À título comparativo, plotou-se as figuras 6.1 e 6.2 mostrando os difratogramas das amostras de InN sobre Silício e Safira-C, cujos padrões dos picos são praticamente comuns aos respectivos substratos utilizados. 


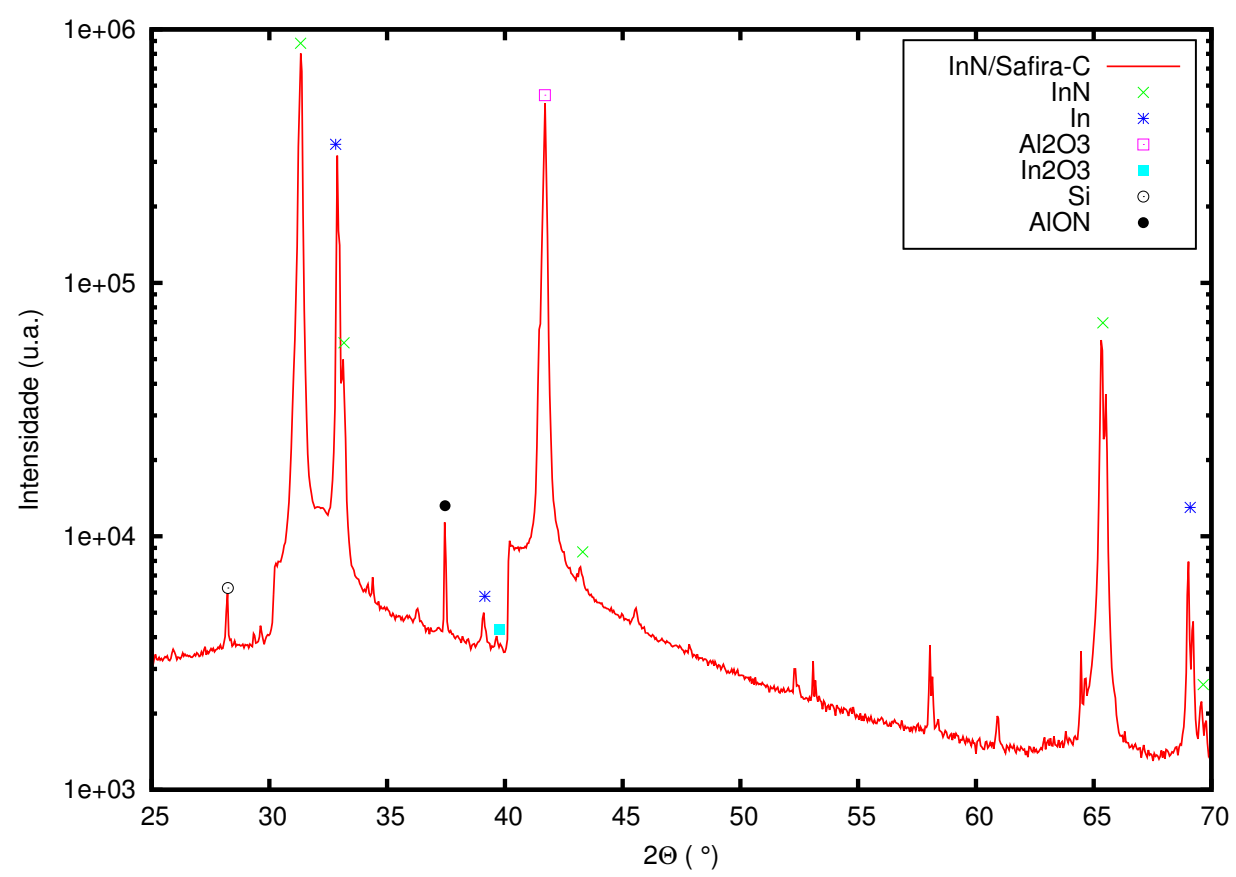

Figura 6.1: Difratograma da amostra F-saf de InN.

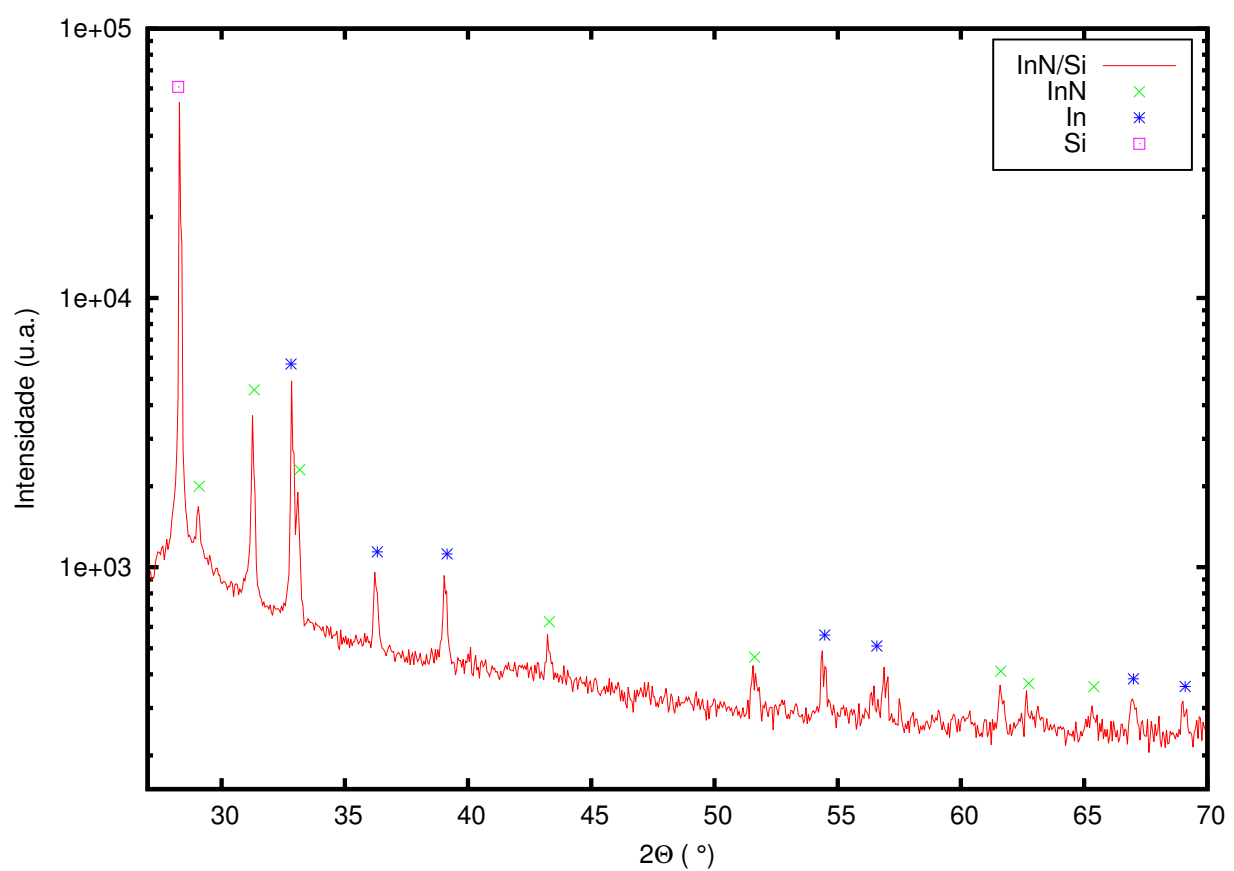

Figura 6.2: Difratograma da amostra C-si de InN.

É de imediato visualizar que os filmes produzidos sobre Safira-C apresentam um grau de cristalinidade muito maior que no silício. Além disso, os filmes formados no substrato de silício são mais policristalinos e é evidente a formação de uma estru- 
tura amorfa, sendo que no de Safira-C houve formação de filmes majoritariamente monocristalinos. Também é importante ressaltar a influência da orientação do substrato da Safira-C (001), induzindo a mesma formação no nitreto de índio. No filme formado sobre o substrato de Safira-C, o pico mais intenso do InN é observado em $2 \theta \approx 31,3^{\circ}$ referente ao plano $(002) ;$ o seu paralelo $(004)$ se situa em $2 \theta \approx 65,3^{\circ}$. Observa-se também o composto numa outra orientação (101) nos angulos $2 \theta \approx 33,15$ ○ (próximo ao pico do In em $2 \theta \approx 32,9^{\circ}$ ) e em $2 \theta \approx 69,6^{\circ}$. Por último há também a formação no plano $(102)$ em $2 \theta \approx 43,3^{\circ}$. Portanto, três fases diferentes estão presentes, sendo claramente a paralela ao plano (001) a mais predominante. É notável uma considerável formação de índio metálico, entretanto esta quantidade excessiva está situada na região da superfície. A pressão de vapor do nitrogênio no InN é extremamente alta, enquanto que a do In é apenas $10^{-6}$ Torr até mesmo a $600^{\circ} \mathrm{C}$, ocasionando então a formação de "gotas" de índio na superfície [33]. Felizmente, é possível contornar essa situação, como já foi realizado pelo grupo de pesquisa do LACIFID $^{1}$ da USP, onde verificou-se que com tratamento químico utilizando ácido clorídrico foi possível reduzir drasticamente o pico referente ao índio metálico. Devido ao atraente resultado dos difratrogramas com InN praticamente monocristalinos obtidos no substrato de Safira-C, focou-se o estudo quantitativo dos filmes formados sobre esse material.

\subsubsection{Temperatura do substrato e o parâmetro $R_{a}$}

A formação de nitreto de índio cristalino não foi observado para temperatura ambiente. Comparando os difratogramas da figura 6.3 observa-se que não há pico de InN no plano (202) no filme formado a $253^{\circ} \mathrm{C}$, além de os picos de outros planos serem menos intensos que em $380^{\circ} \mathrm{C}$. Realizamos também a produção de uma amostra a $480^{\circ} \mathrm{C}$, (figura 6.4) porém não houve formação de $\mathrm{InN}$ devido a baixa temperatura de dissociação na faixa de $550^{\circ} \mathrm{C}$ somado ao bombardeamento por feixes energéticos. Então, diante do melhor grau de cristalinização da amostra B-saf, utilizou-se como referência o valor de temperatura de $380^{\circ} \mathrm{C}$ como sendo razoável para obter alta cristalinidade e um ajuste de Lorentz foi feito no pico mais intenso do InN para

\footnotetext{
${ }^{1}$ link: http://www.dfn.if.usp.br/pagina-dfn/pesquisa/lacifid/
} 
amostras com diferentes valores de $R_{a}$, mas com temperaturas iguais (figura 6.5).

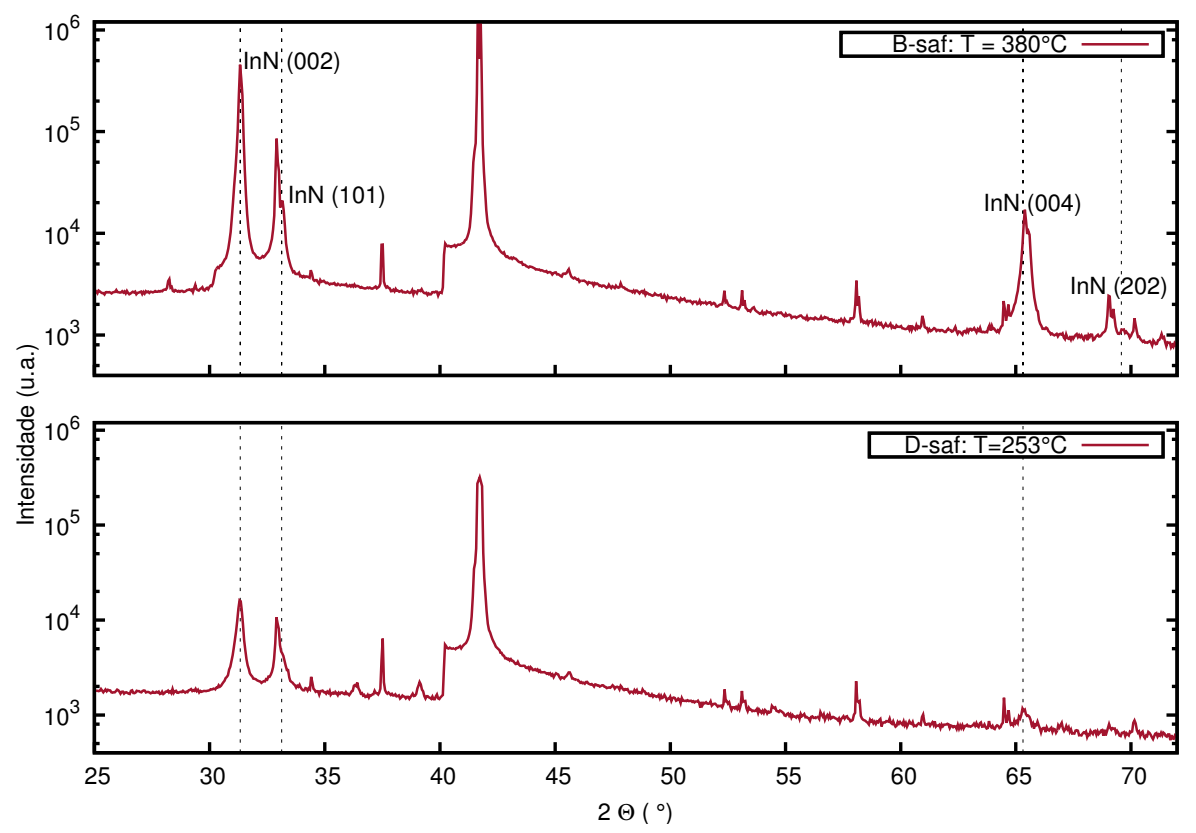

Figura 6.3: Difratogramas de amostras produzidas a $380^{\circ} \mathrm{C}$ e a $253^{\circ} \mathrm{C}$ com valores próximos de $R_{a}$.

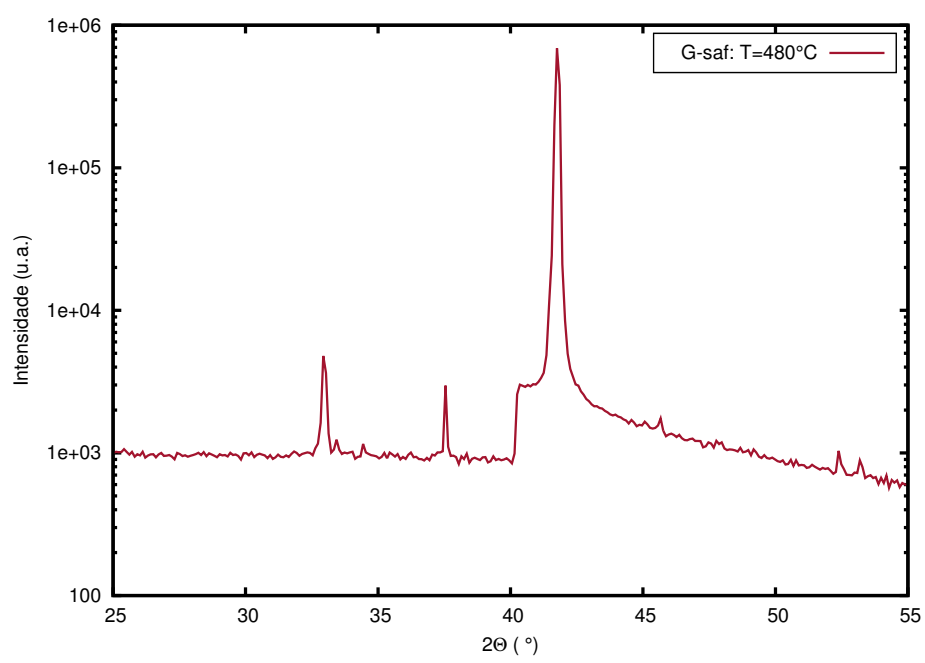

Figura 6.4: Difratograma da amostra G-saf produzida a $480^{\circ} \mathrm{C}$. Não houve a formação de pico referente ao InN.

A figura 6.6 indica que um valor de $R_{a}$ próximo de 2,3 resulta num filme com melhor cristalinidade para temperatura em torno de $T=380^{\circ} \mathrm{C}$. Curiosamente, apenas as amostras B-saf, C-saf e F-saf apresentaram picos cristalinos do InN referente 

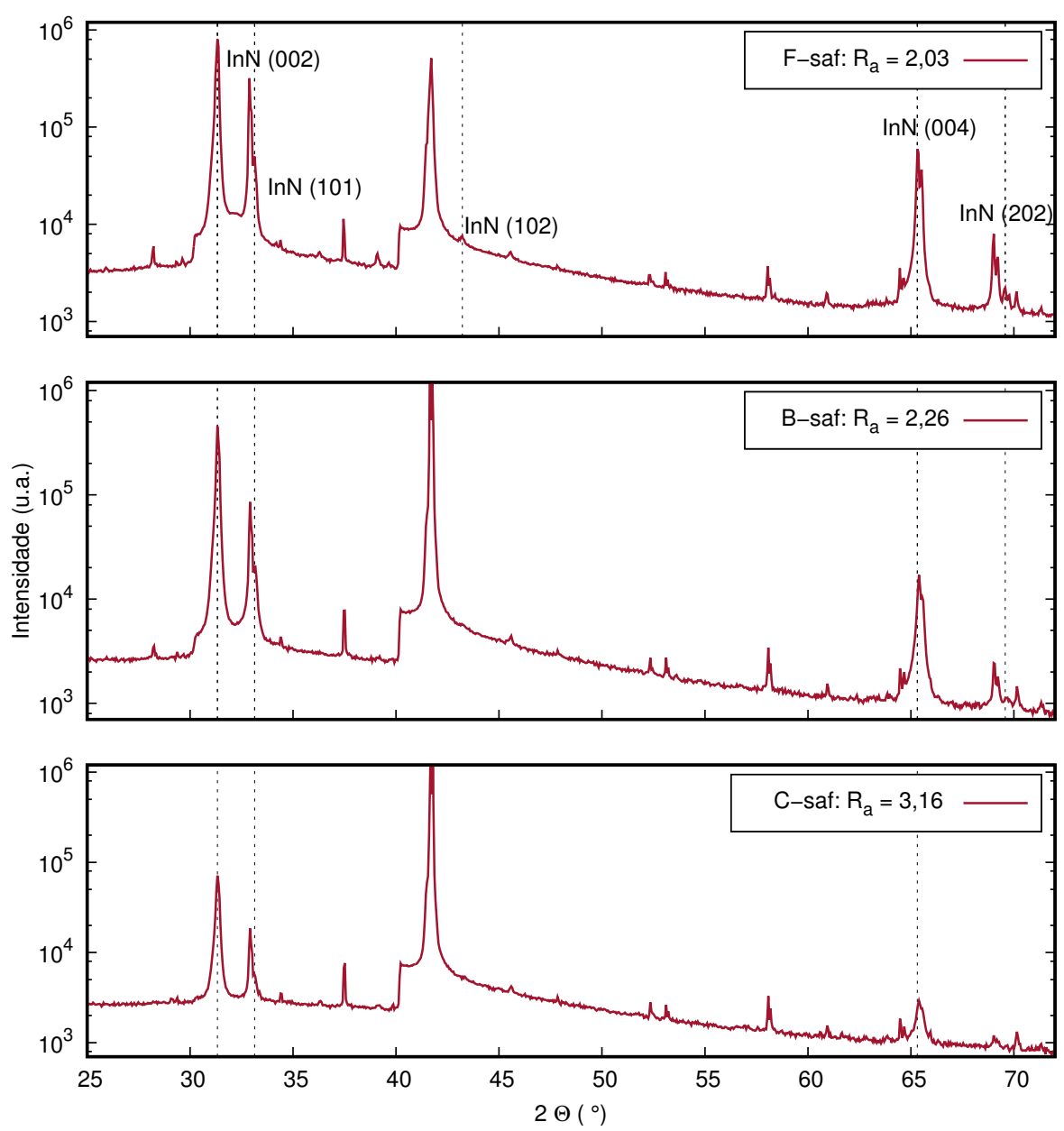

Figura 6.5: Difratogramas de amostras produzidas a $380^{\circ} \mathrm{C}$ com diferentes valores de $R_{a}$.

aos planos (101) e (202) no substrato de Safira-C. Outras amostras ou apresentaram apenas um pequeno "morro" ou era imperceptível devido ao espectro de fundo. Tais amostras são os filmes produzidos à $380^{\circ}$, o que sugere-se, então, que uma maior temperatura induz a formação de domínios cristalinos em outras direções. Por outro lado, tal formação do InN em outra orientação permitiu o cálculo do parâmetro $a$. O parâmetro $c$ foi calculado através do ajuste de Lorentz do pico em $2 \theta \approx 65,3^{\circ}$ pois os picos devido ao $\mathrm{k} \alpha_{1}$ e $\mathrm{k} \alpha_{2}$ estão visíveis, permitindo realizar um duplo ajuste simultâneo e com precisão. A figura 6.7 abaixo ilustra o duplo ajuste que foi realizado em todas as amostras. Para a obtenção do parâmetro $a$, o pico utilizado foi o da posição em $2 \theta \approx 33,15^{\circ}$ e o segundo pico paralelo em $2 \theta \approx 69,6^{\circ}$; escolheu-se obter o parâmetro $a$ a partir do primeiro pico quando o segundo possuia intensidade muito 


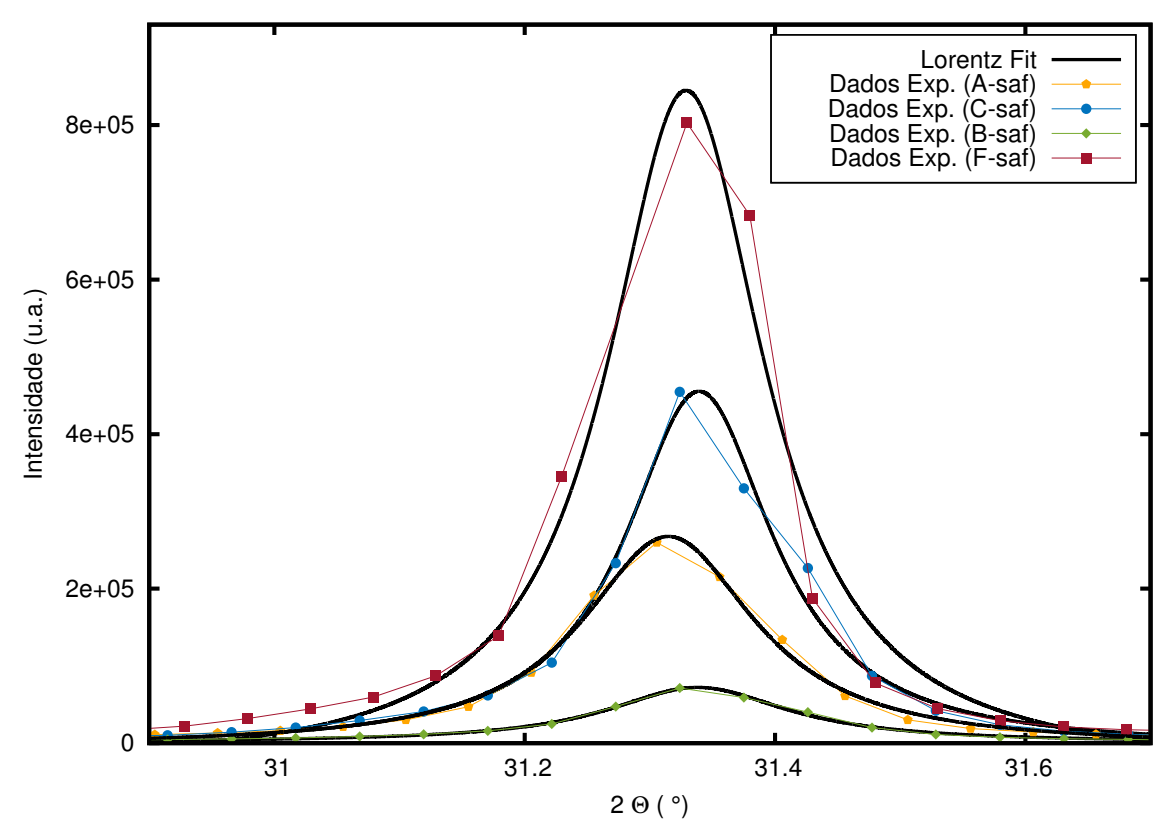

(a)

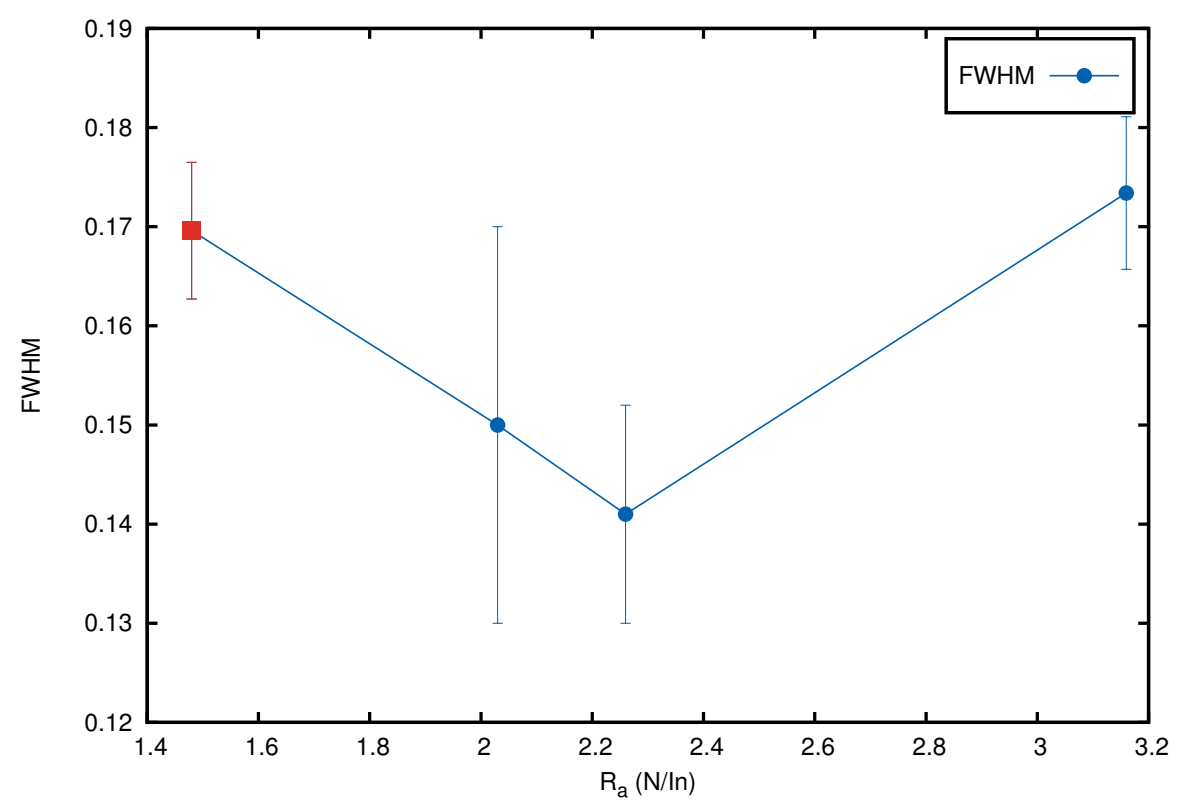

(b)

Figura 6.6: Ajuste de Lorentz no pico de InN para diferentes valores de $R_{a}$ (a) e gráfico de $R_{a}(\mathrm{~N} / \mathrm{In})$ por FHWM (b), onde o dado com o símbolo quadrado se refere a amostra A-saf com condições de produção levemente diferente das outras.

baixa. Os dados estão disponíveis na tabela 6.1 juntamente com valores de outras referências obtidas experimentalmente. 


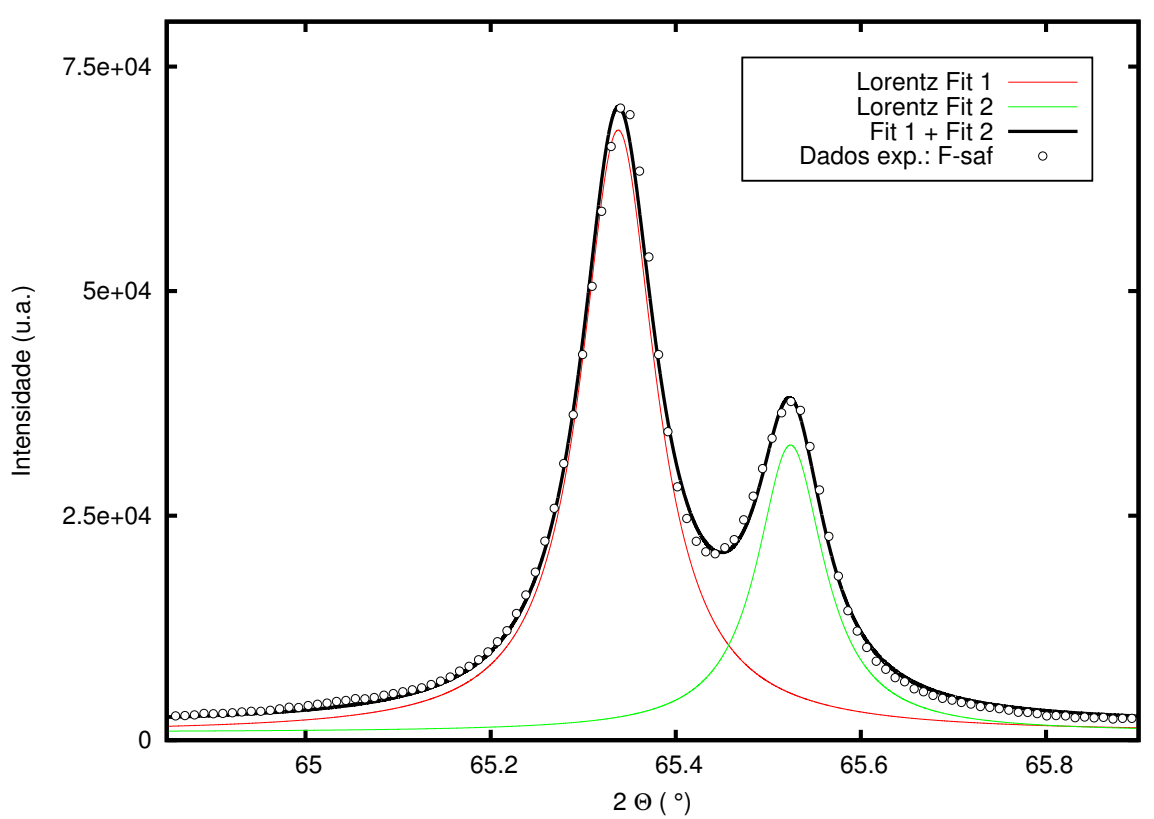

(a) Ajuste de Lorentz no pico referente ao plano (004).

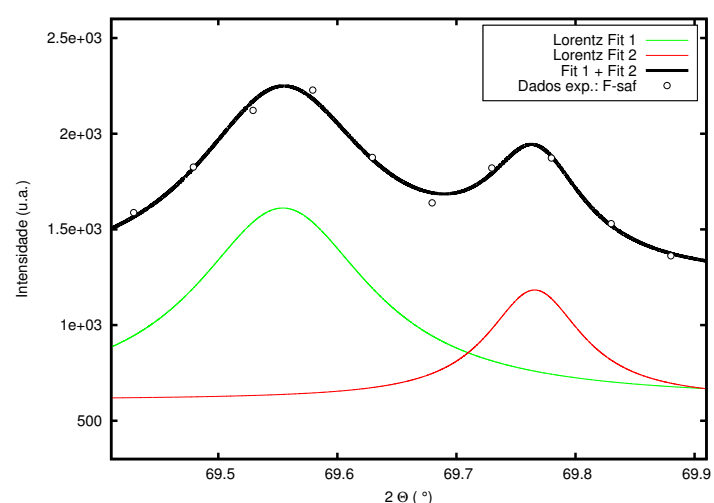

(b) Ajuste de Lorentz no pico referente ao plano (202).

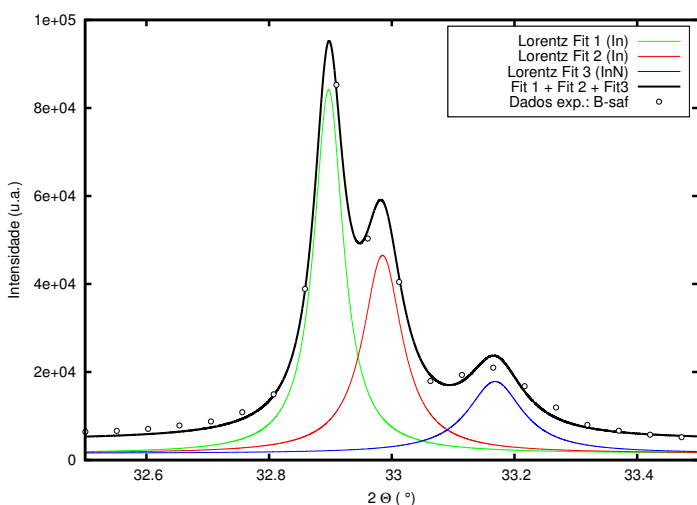

(c) Ajuste de Lorentz no pico referente ao plano (101).

Figura 6.7: Ajustes realizados para obtenção dos parâmetros $c$ (figura A) e $a$ (figura $\mathrm{B}$ e $\mathrm{C})$. 
Tabela 6.1: Parâmetros de rede obtidos do InN, comparando com outros trabalhos.

\begin{tabular}{cccc}
\hline Referências & Método & a(A) & c(A) \\
\hline A-Saf & IBAD & $5,7095(8)$ \\
B-Saf & IBAD & $5,7081(8)$ \\
C-Saf & IBAD & $3,536(4)$ & $5,7061(1)$ \\
D-Saf & IBAD & & $5,7073(4)$ \\
E-Saf & IBAD & & $5,7268(1)$ \\
F-Saf & IBAD & $3,544(1)$ & $5,7081(1)$ \\
K. Kubota et al. [34] & Sputtering & 3,54 & 5,705 \\
V.Y. Davydov et al. [35] & PA-MBE & 3,5365 & 5,7039 \\
Z. G. Qian et al. [36] & ME-MOVPE & & 5,695 \\
S. Yamaguchi et al. [37] & MOVPE & & 5,702 \\
Y. Saito et al. [38] & RF-MBE & & 5,705 \\
R. Juza and H. Hahn [39] & Quimic. sint. (Pó) & 3,54 & 5,704 \\
B. Maleyre et al. [40] & MOVPE (Pó) & 3,539 & 5,7083 \\
A. Svane et al. [41] & GW (Teórico) & 3,543 & 5,721 \\
Nosso trabalho & PBEsol-GGA (Teórico) & 3,531 & 5,749 \\
\hline
\end{tabular}




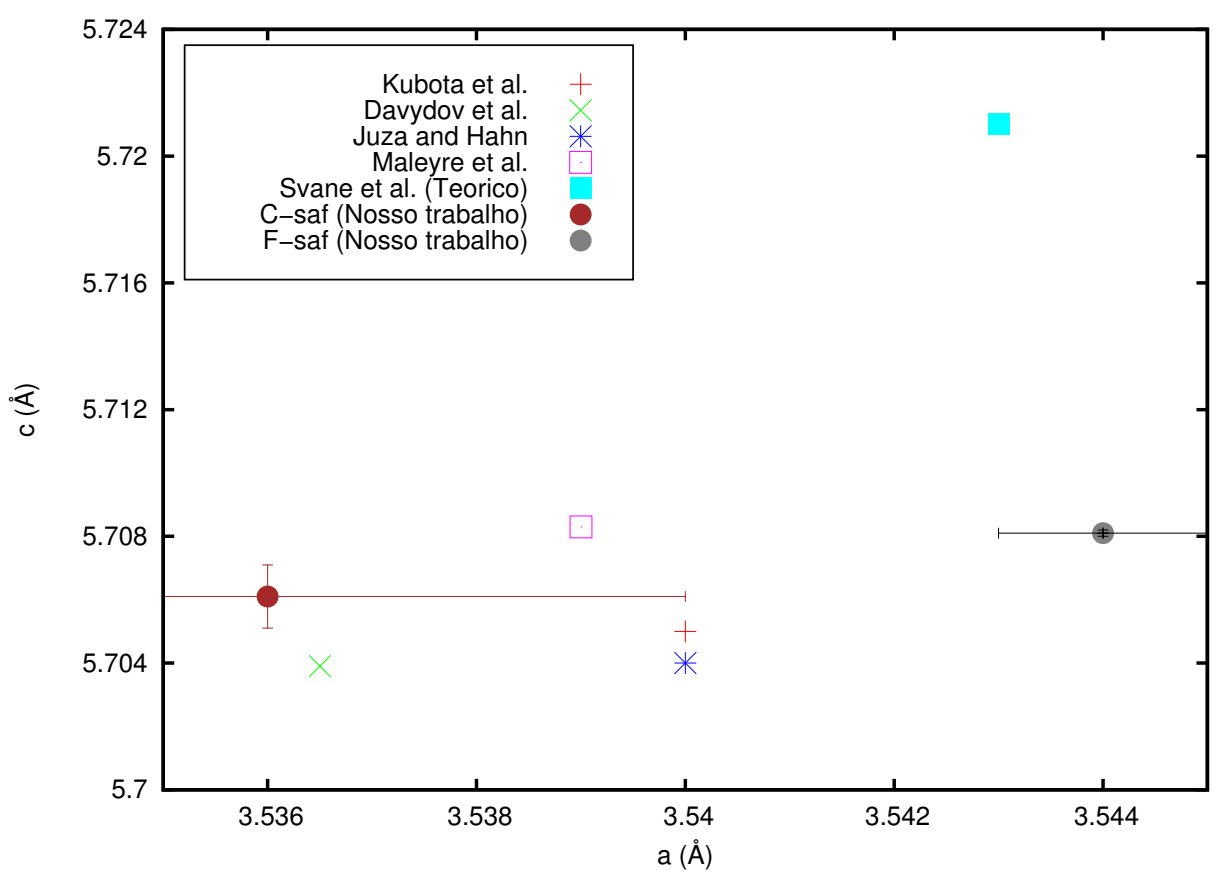

Figura 6.8: Gráfico com parâmetros de rede obtidos pelo nosso grupo e por outros trabalhos listados na tabela 6.1.

\subsubsection{Efeito Gettering}

Para investigar a influência do efeito Gettering, as amostras E-saf e F-saf foram produzidas nas mesmas condições de temperatura, $R_{a}$ e energia do feixe, porém com a excessão de não ter sido realizado a evaporação prévia de titânio no primeiro. Como é possível observar nas figuras 6.9a e 6.9b, há um pequeno deslocamento apenas nos picos referente ao InN, enquanto que o pico do índio metálico se mantém praticamente constante nos dois casos. Será discutido no capítulo 7 que o oxigênio é uma impureza indesejável muito comum no InN, com baixa energia de formação e é energeticamente favorável estes se arranjarem de maneira afastada um dos outros. Além disso, A. Sungthong et al. [42], realizando também medidas de XRD, observaram o deslocamento do pico do InN para ângulos menores conforme se aumentava a concentração de oxigênio na amostra. Portanto, levando em consideração o alto comportamento reativo do titânio com o oxigênio (ver seção 3.2) e que uma distorção uniforme ocasiona em deslocamento de pico (ver figura 3.5), sugere-se que o efeito Gettering diminui o caráter oxinitreto do filme formado. 


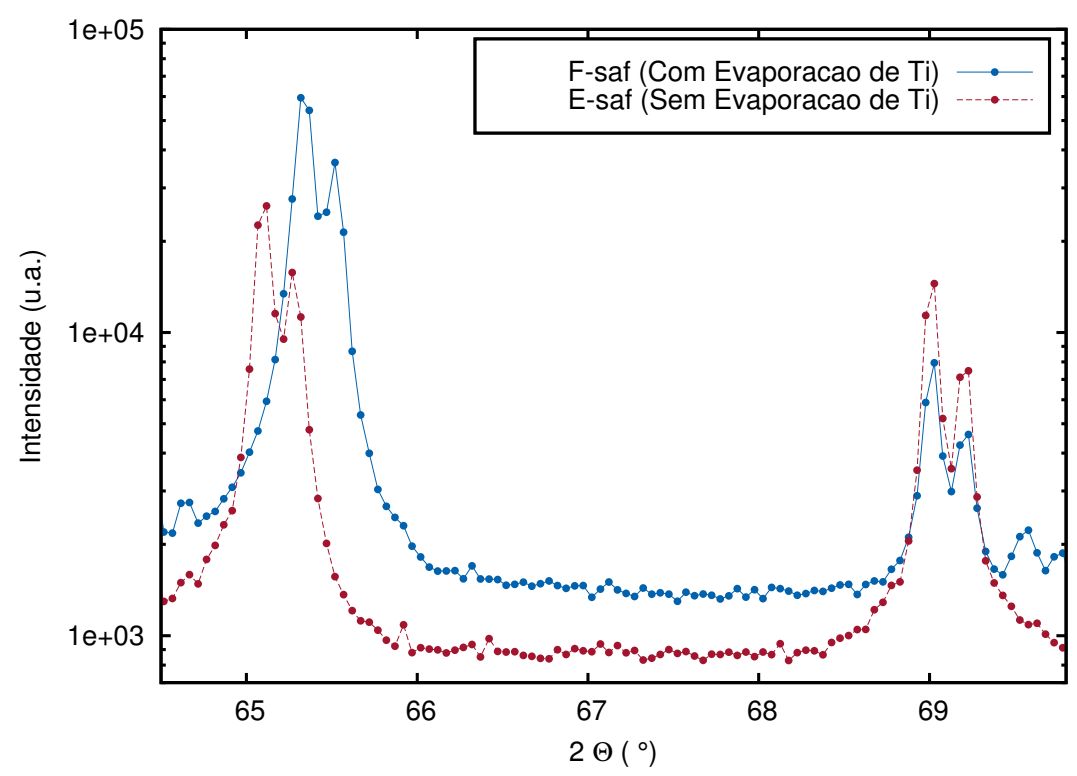

(a)

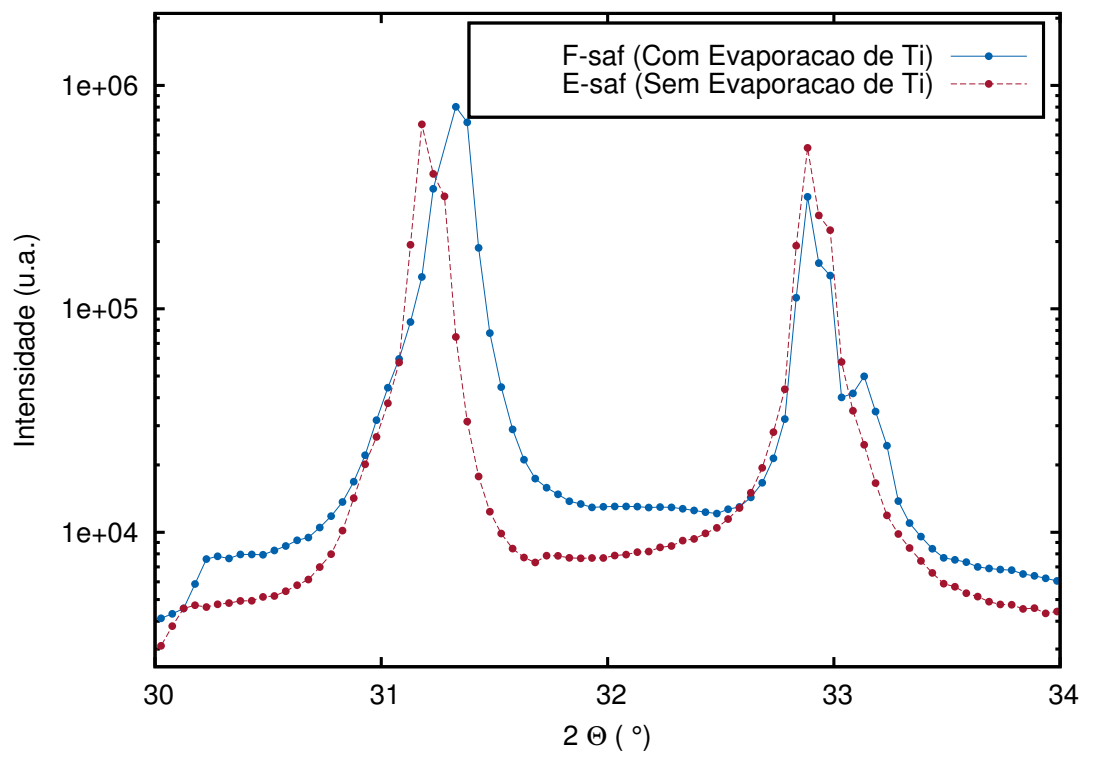

(b)

Figura 6.9: Difratrogramas comparando as amostras E-saf e F-saf, onde foram produzidas sem e com evaporação prévia de titânio, respectivamente. 


\subsection{Perfil dos filmes formados.}

A figura 6.10 mostra o resultado dos ajustes realizados pelo programa SIMNRA ${ }^{2}$ para três amostras para investigar o perfil de composição dos filmes formados. É de imediato notar que não é possível observar picos bem definidos do nitrogênio e os pontos devido ao substrato apresentam um comportamento irregular com pequenas saliências. O pico do índio, devido a sua maior massa, é facilmente visível à direita do gráfico. Essa característica indica ser reflexo do uso de feixes energéticos na deposição dos filmes, ocasionando num gradiente de composição e mistura com elementos do substrato. De fato, em um material comum com interfaces bem definidas, o número de camadas virtuais a ser criado para o ajuste teórico é comparável com o número de elementos. Nos espectros ajustados das amostras B-saf,D-saf e D-si foram necessários de 25 a 30 camadas.

Com o SIMNRA é possível obter o perfil de profundidade com as camadas virtualmente criadas no ajuste teórico. Este programa oferece informações das camadas em unidades de número de átomos por centímetro quadrado. Assim, estimou-se a espessura das camadas realizando uma média ponderada dos compostos formados em cada uma, dividindo-se o número de átomos por centímetro ao quadrado pela respectiva densidade atômica. Nessa estimativa, foram consideradas a formação de In, $\mathrm{Al}_{2} \mathrm{O}_{3}, \mathrm{InO}_{x} \mathrm{~N}_{1-x}$ e Si. Primeiramente, é notório, observando as figuras 6.11, 6.12 e 6.13, a expressiva presença dos elementos do substrato com o índio e nitrogênio. Em especial, o uso do substrato de silício, ocasiona um maior acúmulo desse elemento ao longo da superfície do que com o uso do sustrato de Safira-C. Esse comportamento é efeito dos resultados mostrados pelo programa SRIM (ver figura 3.3), onde o uso do substrato de silício ocasionou num maior alcance dos íons e maior número de vacâncias por íon, ou seja, mais átomos de silício do alvo acabam sendo recuados em direção a superfície. Como era esperado, os gráficos da figura 6.11, 6.12 e 6.13 indicam um maior acúmulo de índio metálico na superfície.

\footnotetext{
${ }^{2}$ link: http://home.rzg.mpg.de/ mam/
} 


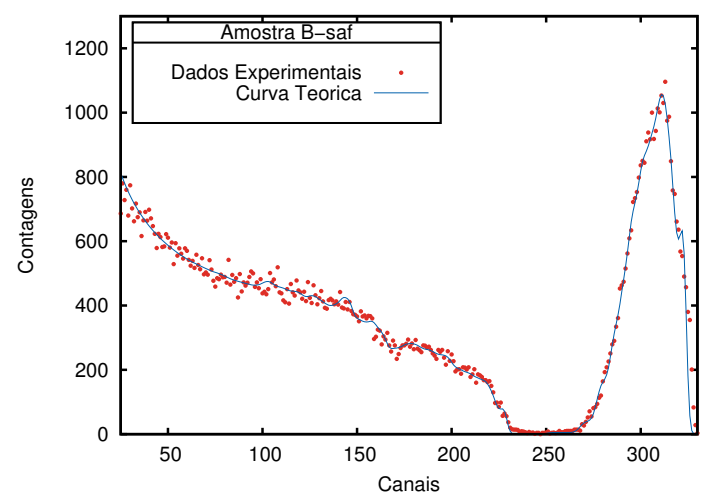

(a)

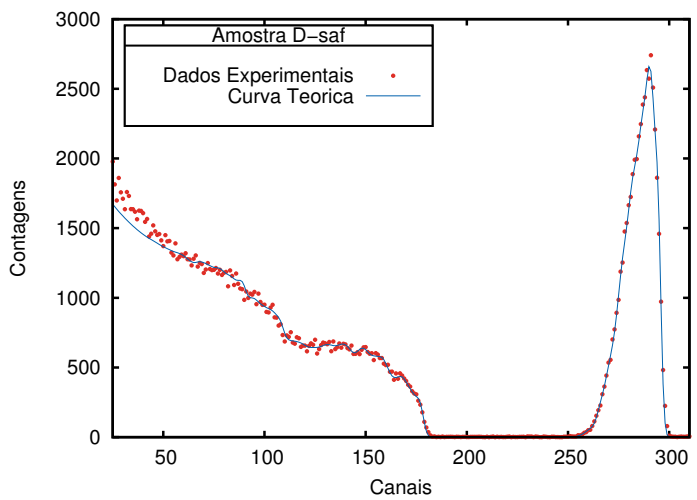

(b)

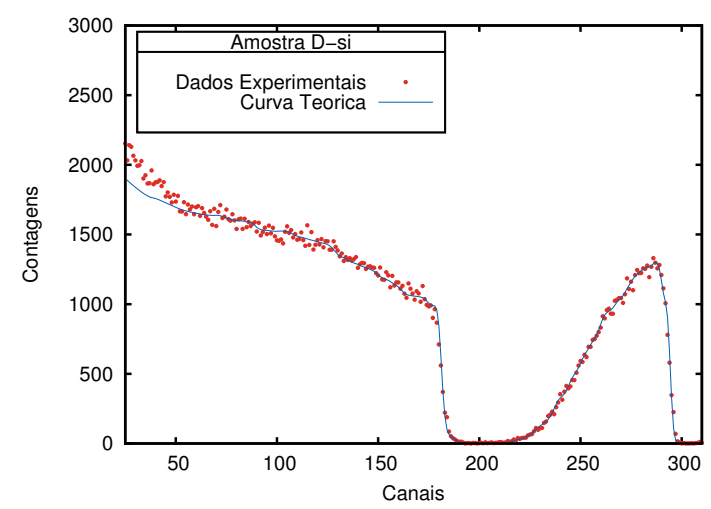

(c)

Figura 6.10: Dados experimentais obtidos por RBS e a curva teórica ajustada das amostras C-saf (a), D-saf (b) e D-si (c).

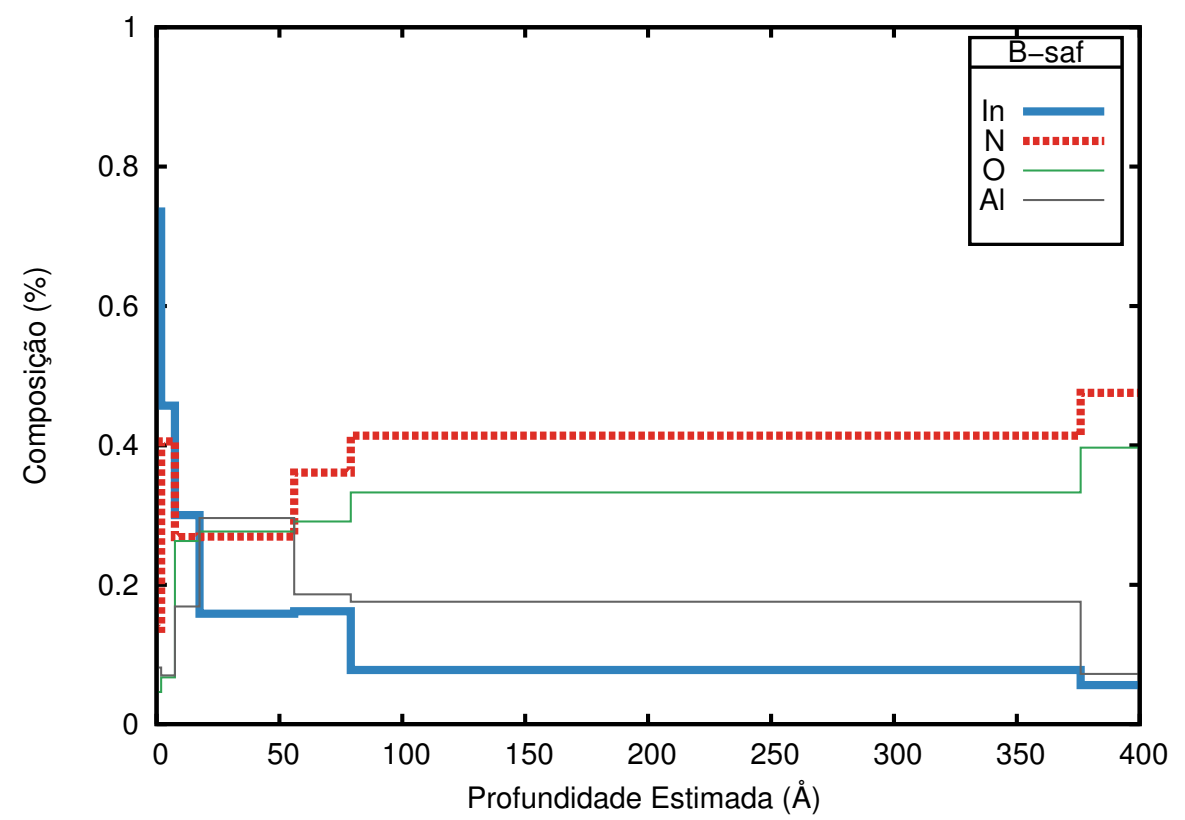

Figura 6.11: Perfil de composição em função da profundidade estimada da amostra B-saf. 


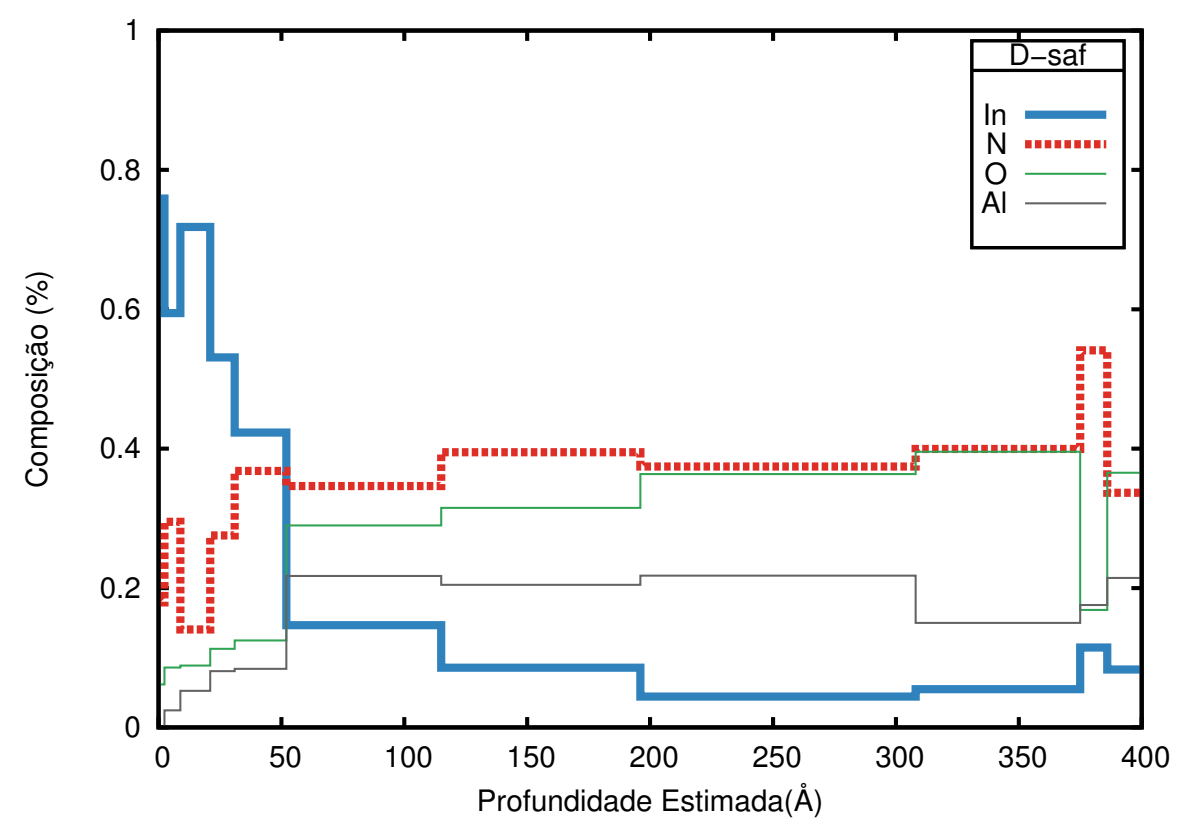

Figura 6.12: Perfil de composição em função da profundidade estimada da amostra D-saf.

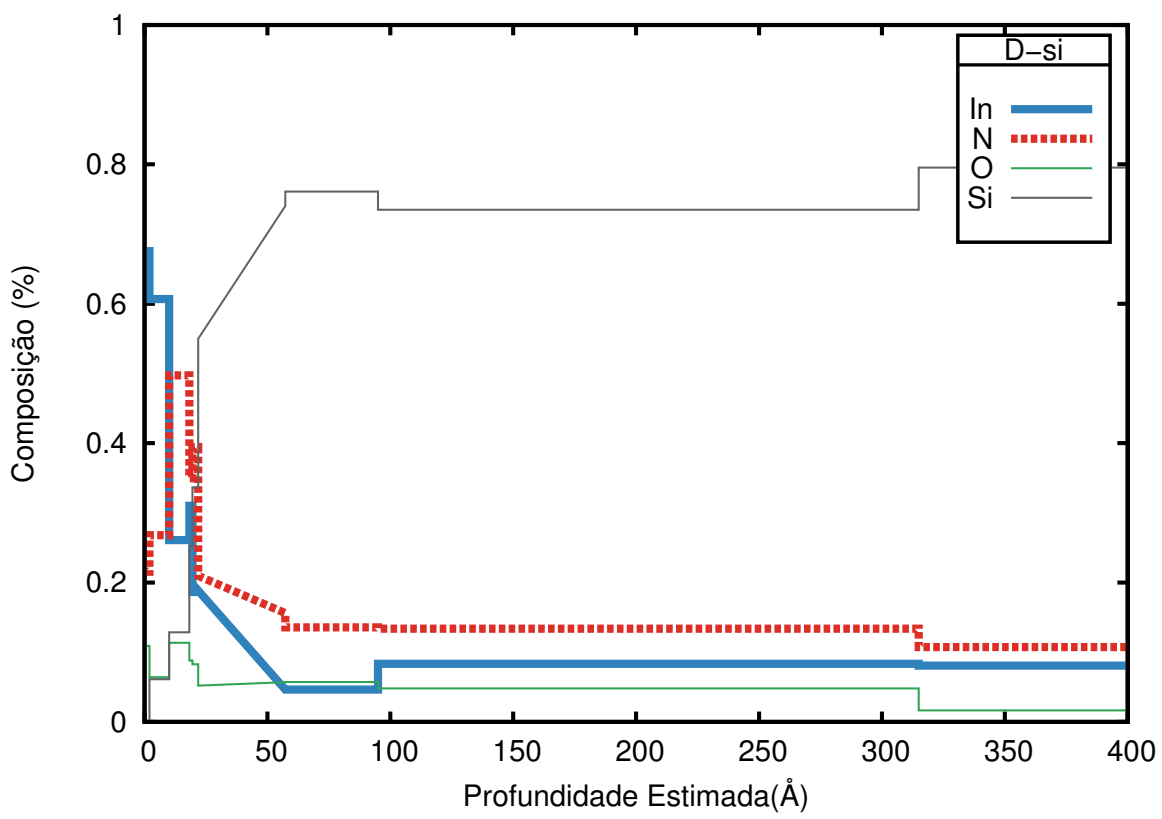

Figura 6.13: Perfil de composição em função da profundidade estimada da amostra D-si. 


\section{Capítulo 7}

\section{Resultados Teóricos: InN e $\mathrm{InO}_{x} \mathrm{~N}_{1-x}$}

\section{$7.1 \quad \operatorname{InN}$}

O cálculo do InN e vários outros compostos semicondutores, utilizando métodos comuns para o tratamento do potencial de troca e correlação como LDA e GGA, são bem conhecidos por subestimar o valor do band gap. Entretanto, outras propriedades óticas e parâmetros estuturais, apresentam boa exatidão se comparadas com resultados experimentais.

Os cálculos ab initio foram realizados utilizando o esquema de ondas planas aumentadas + orbitais locais $(\mathrm{APW}+\mathrm{lo})$ baseado na Teoria do Funcional da Densidade (DFT) incorporado no programa Wien2k. A Wurtzita é a estrutura hexagonal estável do InN e por isso foi escolhida para o presente estudo, cujo grupo espacial é o $P 6{ }_{3} m c$; a célula unitária pode ser visualizado na figura 7.1.

No átomo de índio os estados $4 p^{6} 4 d^{10} 5 s^{2} 5 p^{1}$ foram tratados como estados de valência e $2 s^{2} 2 p^{3}$ para o nitrogênio. Para o tratamento do potencial de troca e correlação foi utlizado o funcional PBEsol-GGA [20], cujo método mostrou-se superior ao LDA em vários aspectos, principalmente na obtenção dos parâmetros de rede. 


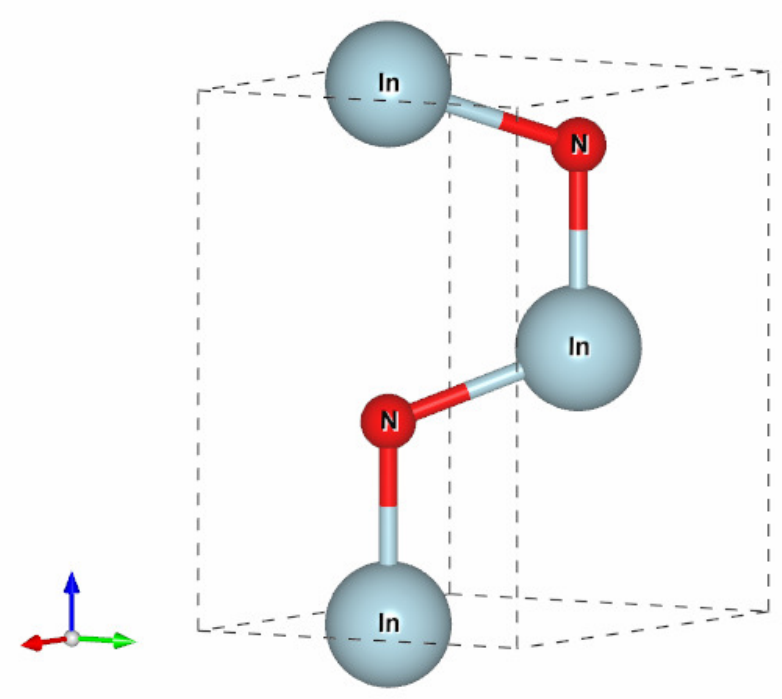

Figura 7.1: Célula unitária da estrutura Wurtzita do InN.

Variou-se o número de pontos k e o valor $R_{M T}$. $K_{\max }$ a fim de obter parâmetros cuja energia esteja com um grau de convergência que julgou-se ser razoável, considerando também o custo computacional. Os valores ótimos escolhidos foram 700 pontos k e $R_{M T} . K_{\max }=7$, onde utilizou-se $R_{M T}^{N}=1,55$ u.a. e $R_{M T}^{I n}=2,20$ u.a..

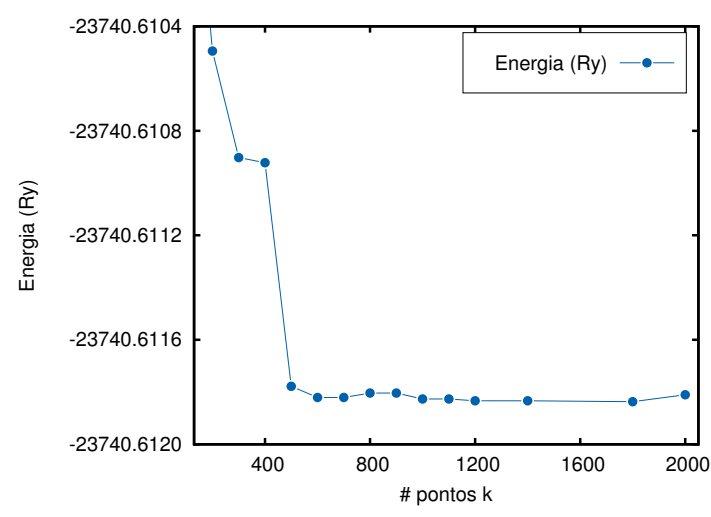

(a)

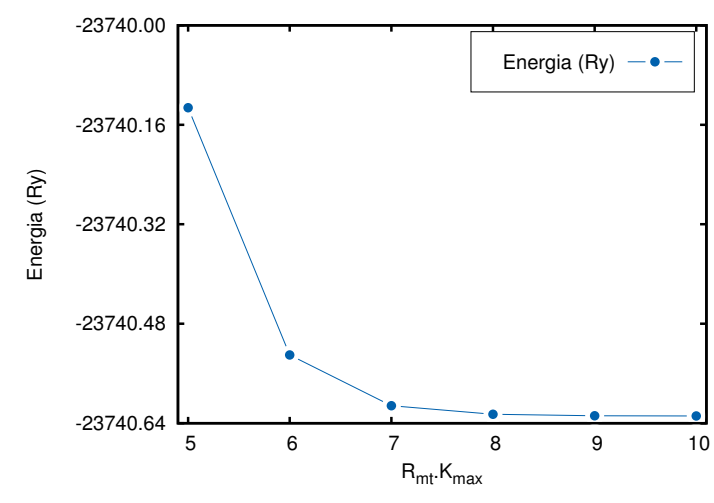

(b)

Figura 7.2: Gráficos de energia em função do número de pontos k (a) e energia em função do valor de $R_{m t} . K_{\max }(\mathrm{b})$. 


\subsubsection{Otimização da estrutura}

Para otimização dos parâmetros estruturais do InN foram realizados cálculos da energia total para inúmeros valores de volume e razão $c / a$. É comum observar na literatura, a otimização variando apenas os parâmetros de rede sem otimizar a posição atômica, porém optou-se neste trabalho em otimizar a posição atômica para cada variação do volume e $c / a$ até que as forças em cada átomos fossem menores que $1 \mathrm{mRy} /$ u.a.. Em seguida, realizou-se um ajuste polinomial de ordem 3 (figura 7.3) para obter o valor ideal dos parâmetros $c$ e $a$. Apenas por comparação, adotouse também o método LDA, além do PBEsol-GGA. Os resultados estão listados na tabela 7.1.

Tabela 7.1: Valores dos parâmetros de rede otimizados para cada método e resultados de outros trabalhos.

\begin{tabular}{ccc}
\hline Método & $\mathbf{a}(\AA)$ & $\mathbf{c}(\AA)$ \\
\hline LDA & 3,509 & 5,671 \\
PBEsol-GGA & 3,533 & 5,752 \\
GW (A. Svane et al. [41]) & 3,543 & 5,721 \\
Exp. (B. Maleyre et al. [40]) & 3,539 & 5,7083 \\
\hline
\end{tabular}




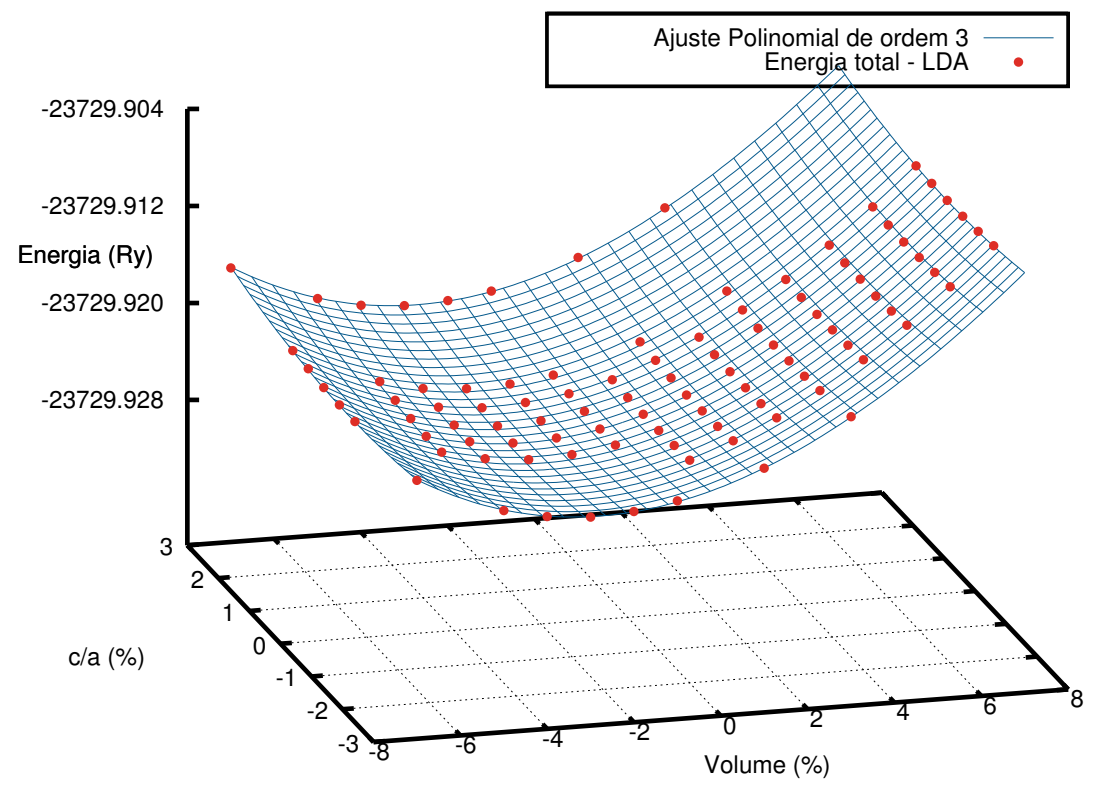

(a)

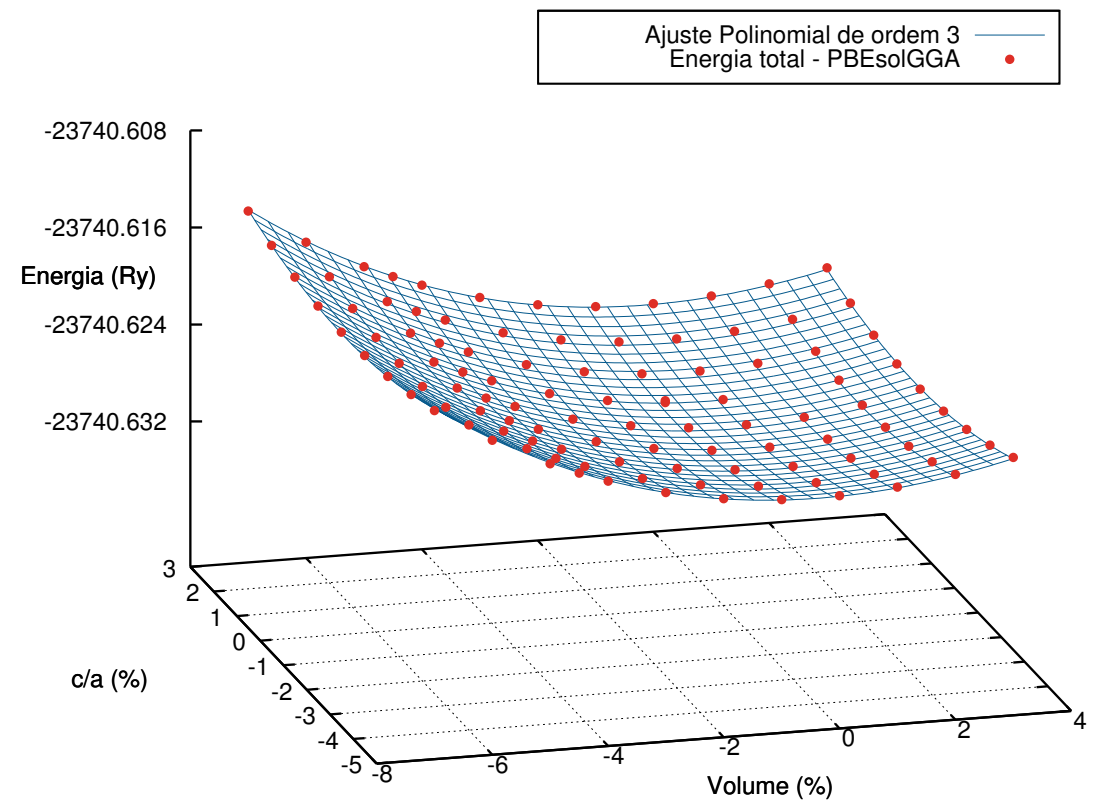

(b)

Figura 7.3: Ajuste polinomial de ordem 3 da energia total em função do volume (\%) e c/a(\%) utilizando o funcional LDA (a) e PbesolGGA (b). 
Como esperado, os parâmetros obtidos com LDA apresentam um desvio maior se comparados com os resultados de outros grupos apresentados na tabela, porém uma maior concordância foi obtida com o funcional PBEsol-GGA. É relevante ressaltar que o esquema GW é um sofisticado método, porém computacionalmente custoso, baseado na teoria de muitos corpos o qual permite obter parâmetros estruturais e propriedades óticas com alta exatidão; o sistema de produção MOVPE é capaz de produzir compostos monocristalinos e é amplamente utilizado, principalmente na indústria, para produção de filmes finos de alta qualidade.

\subsubsection{Propriedades óticas e inclusão do método TB-mBJ}

A figura 7.4 apresenta um gráfico comparativo dos métodos com e sem a implementação do método TB-mBJ. Nota-se que os estados do In e N são deslocados para níveis de maior energia na banda de condução, causando então o real alargamento do band gap, o que reflete na estrutura de banda apresentado na figura 7.6. Além disso, com a inserção do potencial há um alargamento entre as bandas de valência próximo da energia de Fermi e as bandas concentradas na região de aproximadamente $-12 \mathrm{eV}$. Da figura 7.5 observa-se que a banda de valência mais próxima da energia de Fermi é majoritariamente devido aos estados do nitrogênio s e p. Medidas de espectroscopia por perda de energia de elétrons [43] indicam a presença da banda $4 \mathrm{~d}$ do In em 15, $5 \pm 0,5 \mathrm{eV}$ abaixo da energia de Fermi e um pico de transição entre estados de valência e condução de $6,2 \pm 0,1 \mathrm{eV}$. O primeiro pode ser claramente observado no gráfico da densidade de estados onde há um intenso pico em $-15,3$ eV. O segundo indica ser a transição se considerarmos a região do pico em cerca de $-1,2 \mathrm{eV}$ e o início da região do platô em aproximadamente $4,4 \mathrm{eV}$. 


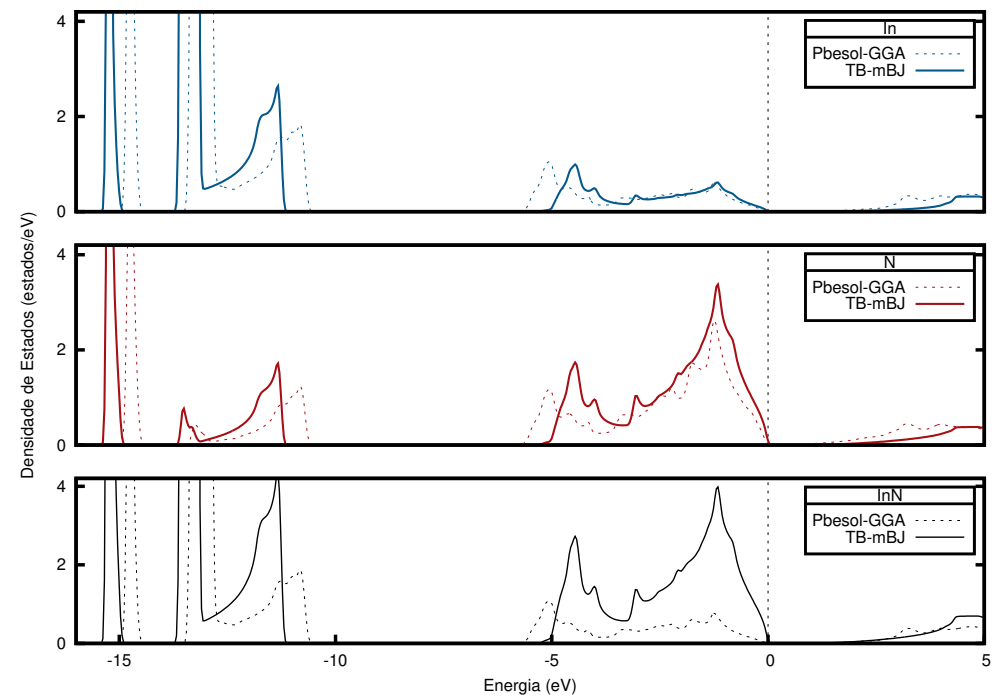

Figura 7.4: Densidade de estados comparando com a implementação do método TB-mBJ.

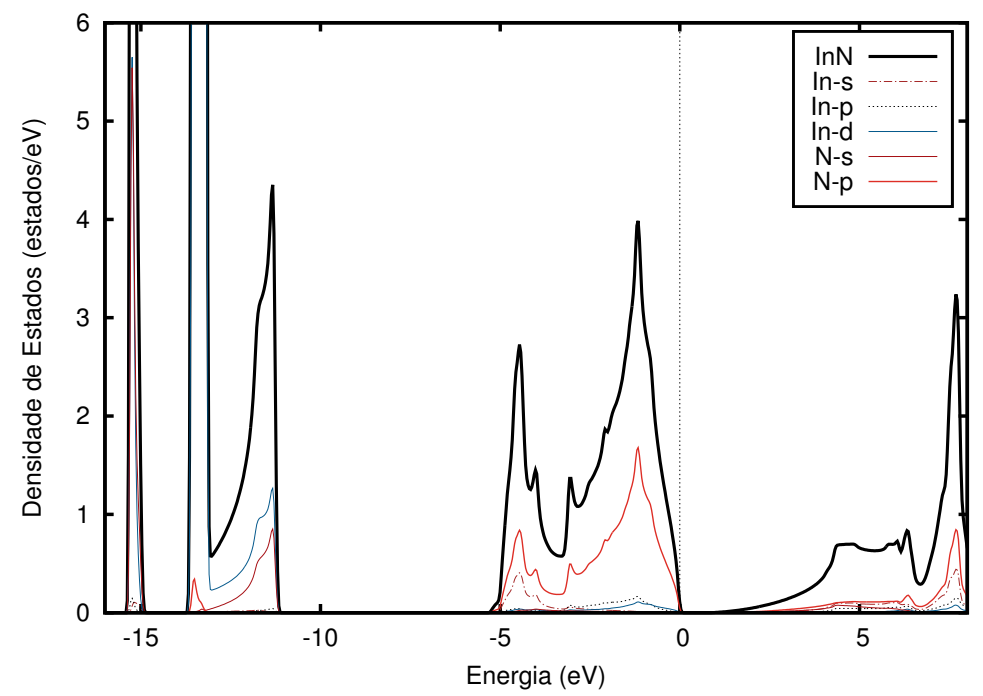

Figura 7.5: Densidade de estados com a contribuição de cada orbital do InN. 


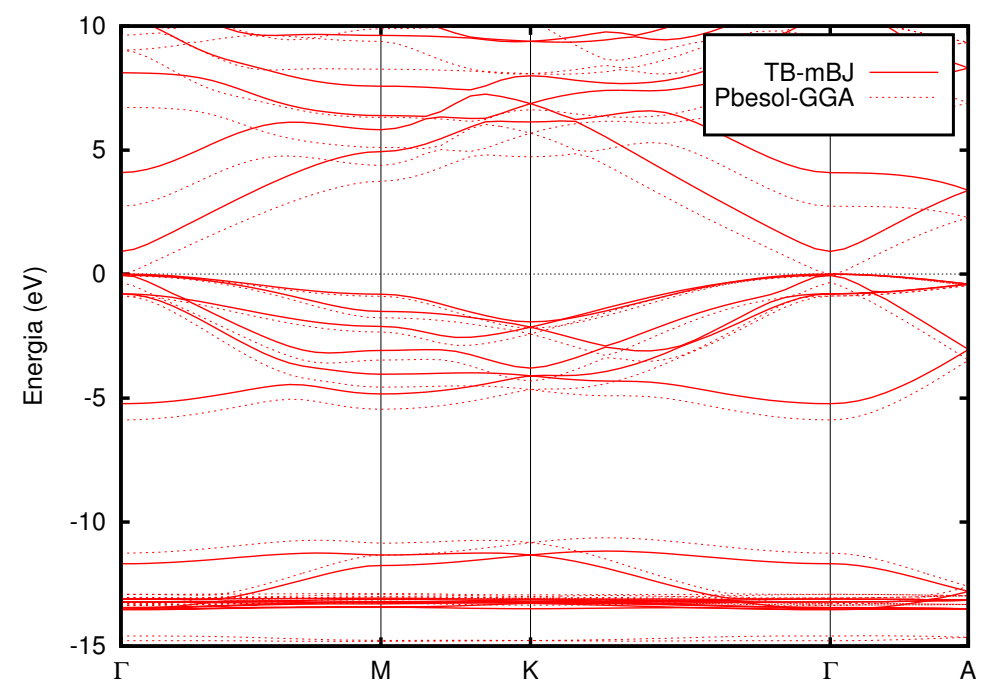

Figura 7.6: Estrutura de banda com e sem a implementação do método TB-mBJ.

Da figura 7.6 obteve-se o valor do band gap fundamental $E_{g}=0,89 \mathrm{eV}$ e a partir da equação 4.28 calculou-se o espectro de absorção $\alpha$ e com a equação 4.29 estimou-se o valor do band gap ótico, tal que $E_{g}^{o p t}=0,98 \mathrm{eV}$. O valor do band gap experimental mais aceito atualmente é de $\sim 0,7 \mathrm{eV}$.

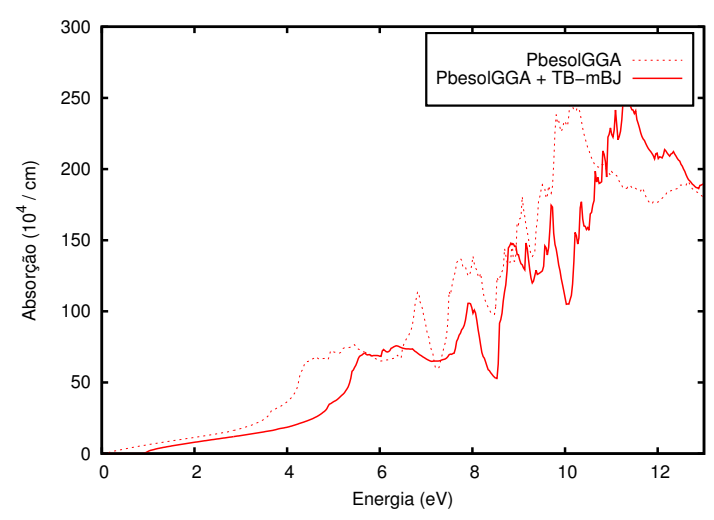

(a)

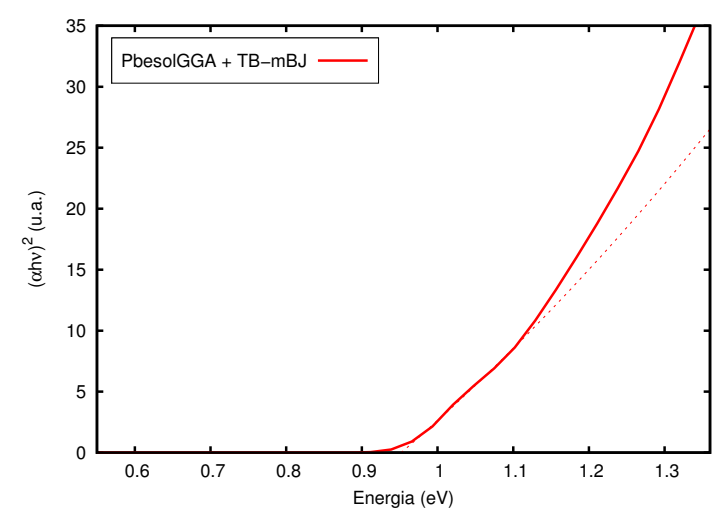

(b)

Figura 7.7: Gráficos de absorção por energia com e sem inserção do método TB-mBJ (a) e estimativa do valor do band gap ótico (b), utilizando a equação 4.29. 


\section{$7.2 \quad \operatorname{InO}_{x} \mathrm{~N}_{1-x}$}

Para a investigação da influência do oxigênio no InN, criou-se uma supercélula 3x3x2 correspondendo a 72 átomos (36 N e 36 In) como está ilustrado na figura 7.8. Para este cálculo utilizou-se um valor menor de $R_{M T} \cdot K_{\max }=6$ devido ao alto custo computacional; utilizou-se $R_{M T}^{O}=1,60$ u.a. para o átomo de oxigênio. É importante ressaltar que para o cálculo da energia de formação, tomou-se a cautela de utilizar o mesmo tamanho da base e o número de pontos $\mathrm{k}$.

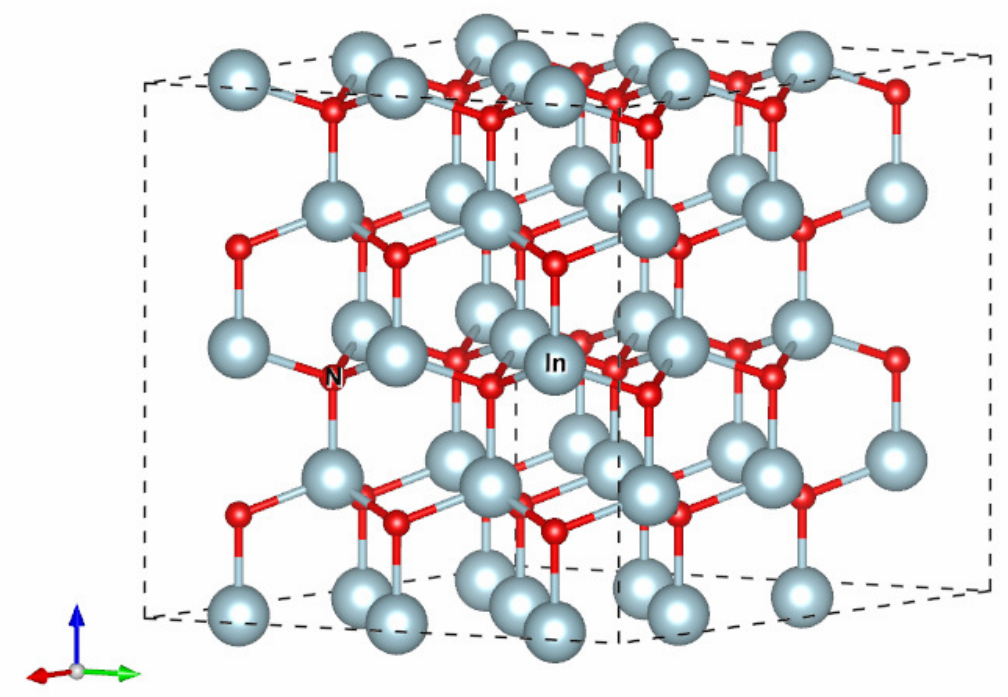

Figura 7.8: Supercélula com 72 átomos (36 N e 36 In).

\subsubsection{Defeito de um único oxigênio}

O átomo de oxigênio possui apenas um número atômico a mais que o nitrogênio e o raio atômico é bem menor que do índio, então é esperado que se comporte como doador substituindo o nitrogênio no InN. Em outro trabalho, Stampfl et. al. [44] realizou um estudo das impurezas e outros defeitos nativos utilizando a aproximação LDA no InN e seu grupo reportou que o oxigênio se comporta como doador, com energia de formação significativamente menor que outros defeitos como vacância de nitrogênio $V_{N}$ e de índio $V_{I n}$. Além dos dois últimos casos, os defeitos substitucionais $\mathrm{In}_{N}, \mathrm{~N}_{\text {In }}$ e $\mathrm{V}_{\text {In }}$ apresentaram energia de formação positiva. No presente trabalho, 


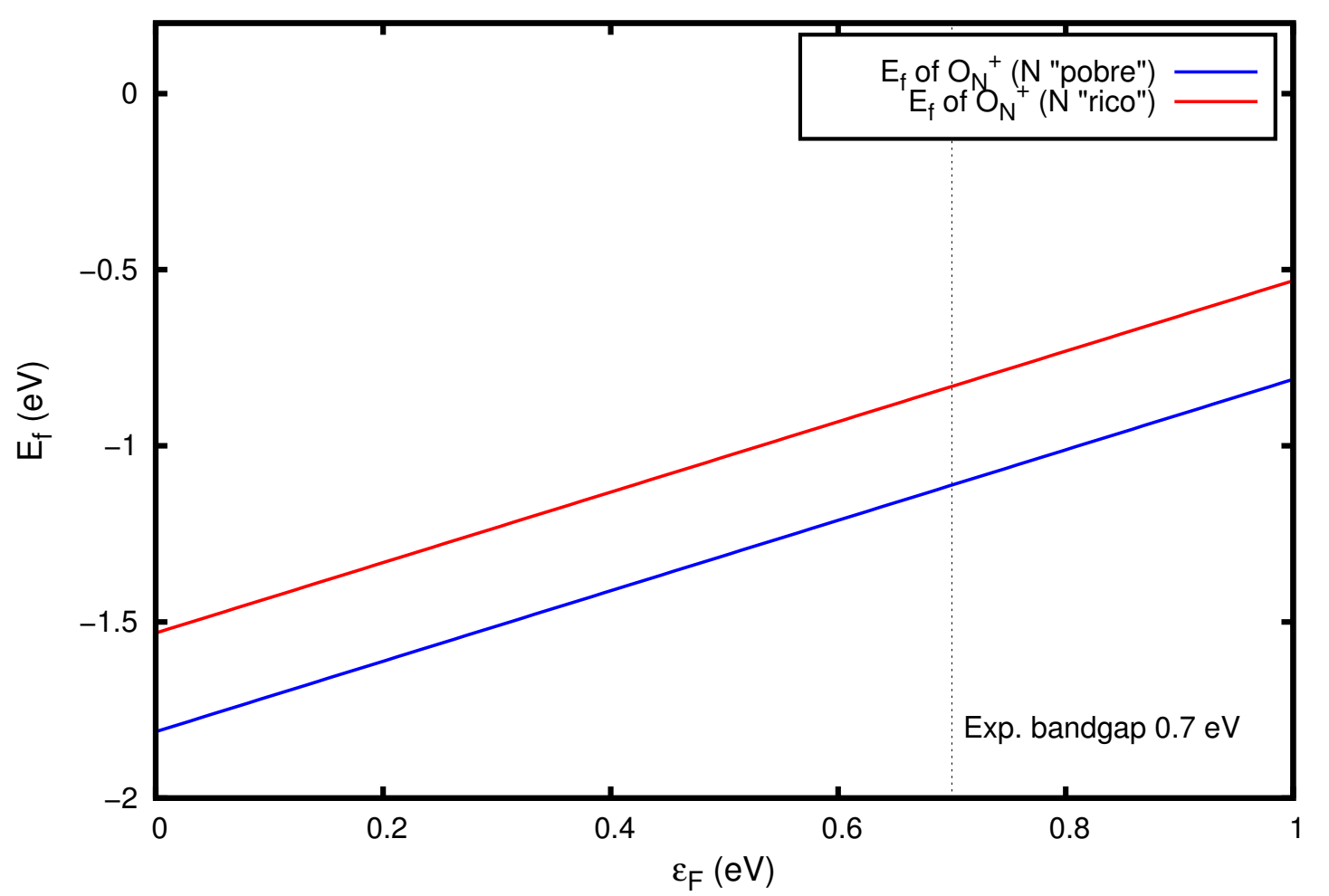

Figura 7.9: Energia de Formação por nível de Fermi de um oxigênio isolado utilizando condições "rico" e "pobre" de N.

também foi realizado o cálculo da energia de formação do oxigênio substituindo o nitrogênio $\mathrm{O}_{N}$, nos estados de carga 0 e $1+$. O gráfico da figura 7.13 mostra que $\mathrm{O}_{N}$ tem tendências de se comportar como doador. É interessante notar que a energia de formação do $\mathrm{O}_{N}$ é um pouco menor que no caso do GaN como está apresentado em [45].

\subsubsection{Defeitos complexos}

Com o objetivo de obter as propriedades óticas do composto $\operatorname{InO}_{x} \mathrm{~N}_{1-x}$, primeiramente realizou-se uma estudo a respeito da distribuição mais provável para pequenos valores de $x$. Assim, diferentes situações foram investigados distribuindo as impurezas de maneira uniforme ou agrupando-os em uma região de uma supercélula de 72 átomos.

É importante ressaltar que nesse primeiro estágio, todas as impurezas foram tra- 
tadas no estado de carga neutro. Para cada sistema, a posição atômica foi otimizado até que forças sentidas em cada átomo ficassem menores que $2 \mathrm{mRy} /$ u.a. Até o sistema com $x=8,33 \%$ (3 átomos) a menor energia obtida foi na situação em que os átomos estavam distribuídos uniformemente, enquanto que para $x=11,11 \%$ (4 átomos) a menor energia obtida foi a do tipo Cluster1 (7.10a). Nesse último caso, os 4 átomos de oxigênio tendem a cercar o índio, substituindo os 4 átomos de nitrogênio. Para esse número de impurezas, uma situação em que pares de átomos de oxigênio estão uniformemente distribuídos (7.10b) também foi considerado, o qual será denotado por Cluster2. Na supercélula com $x=22,22 \%$ (8 átomos), considerou-se dois casos em que 4 átomos de oxigênio se agrupam em torno do índio e esses agrupamentos estão ou mais próximos (Cluster2), ou estão mais separados (Cluster1). Finalmente, uma supercélula com $x=33,33 \%$ (12 átomos) foi construído, onde três situações foram considerados: impurezas uniformemente distribuídos (distribuição uniforme), agrupamentos de 4 oxigênios onde cada um está, dentro das limitações da supercélula, mais separados um do outro (Cluster1) e por último, uma distribuição onde os agrupamentos estão concentrados numa região (Cluster2). Dentre os três casos mencionados, a distribuição Cluster1 resultou no sistema com menor energia. Resumindo, observa-se uma tendência de transição de uma distribuição atômica uniforme para uma distribuição uniforme de agrupamentos de 4 átomos de oxigênio rodeando um único índio. A energia total obtida em cada caso está apresentada na tabela 7.2. 


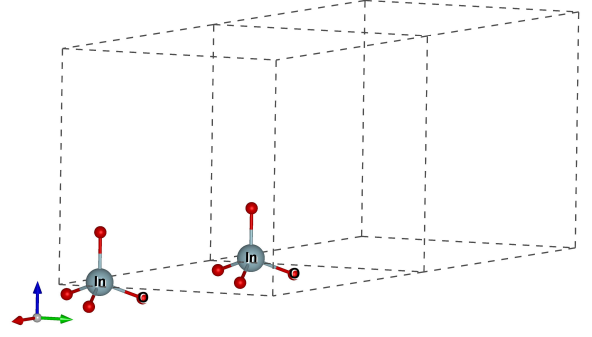

(a) Distribuição Cluster1.

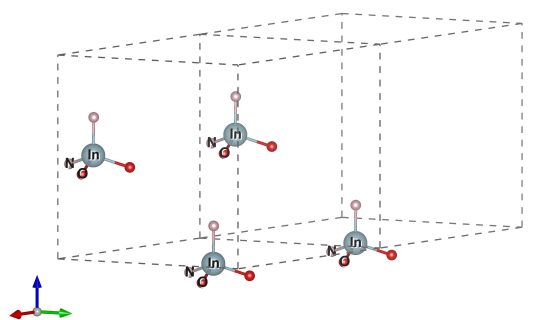

(b) Distribuição Cluster2.

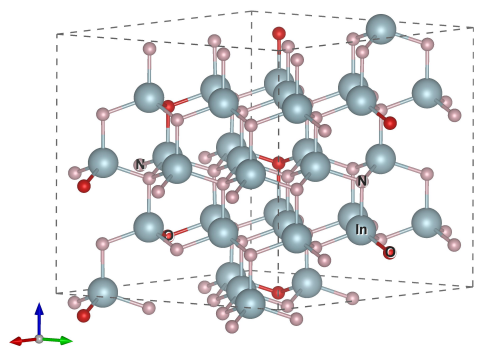

(c) Distribuição Uniforme.

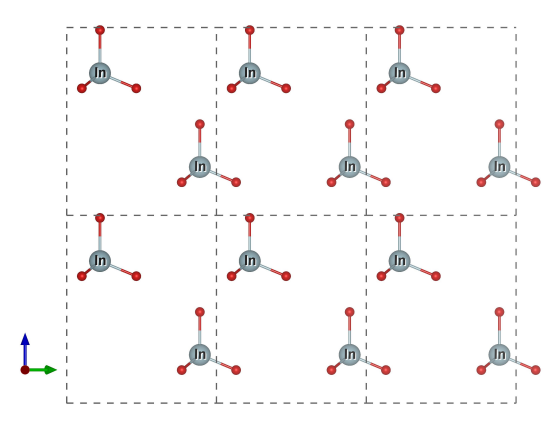

(d) Distribuição Cluster1.

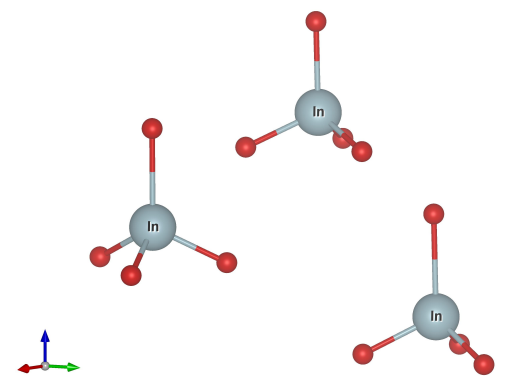

(f) Distribuição Cluster1.

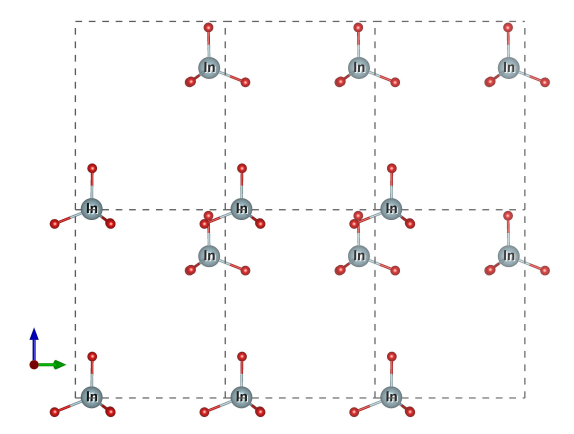

(e) Distribuição Cluster2.

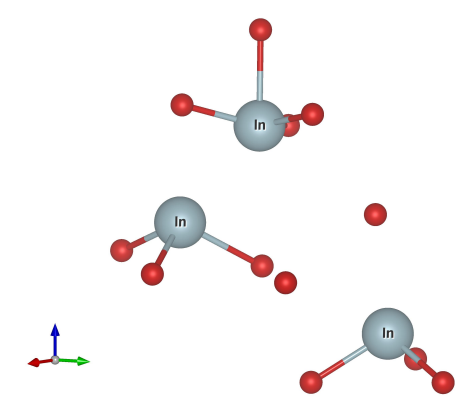

(g) Distribuição Cluster2.

Figura 7.10: Tipos de distribuição para uma supercélula (linhas pontilhadas representam as fronteiras) de 72 átomos e 4 (a,b,c), 8 (d,e) e 12 (f,g) oxigênios substitucionais. Alguns átomos foram omitidos para facilitar a compreensão. 
Tabela 7.2: Energia da supercélula para cada tipo de distribuição atômica.

\begin{tabular}{c|c|c|c} 
\# Oxigênio & Uniforme (Ry) & Cluster1 (Ry) & Cluster2 (Ry) \\
\hline 1 & $\mathbf{- 4 2 7 3 7 1 , 7 5 2}$ & & \\
\hline 2 & $\mathbf{- 4 2 7 4 1 2 , 6 8 6}$ & $-427412,678$ & \\
\hline 3 & $\mathbf{- 4 2 7 4 4 5 , 4 2 2}$ & $-427445,419$ & \\
\hline 4 & $-427494,625$ & $\mathbf{- 4 2 7 4 9 4 , 6 5 0}$ & $-427494,632$ \\
\hline 8 & $-427658,222$ & $\mathbf{- 4 2 7 6 5 8 , 3 2 2}$ & $-427658,309$ \\
\hline 12 & $-427821,833$ & $\mathbf{- 4 2 7 8 2 2 , 0 1 0}$ & $-427821,951$
\end{tabular}

Diante desses resultados, focou-se o estudo na supercélula de 4 átomos de oxigênio na distribuição Cluster1 considerando os estados de carga $1+, 2+, 3+$ e $4+$, onde calculou-se a energia de ligação $E_{b}$ (ver equação 5.9) para cada caso. Os resultados apresentados na tabela 7.3 indicam que todos os casos são sistemas instáveis. Além disso, a instabilidade é maior conforme o aumento do estado da carga, indicando ser energeticamente favorável os oxigênios de carga $1+$ se arranjarem isoladamente. Esse resultado está coerente com trabalhos experimentais de outros grupos [46, 47] onde não há formação de $\operatorname{In}_{2} \mathrm{O}_{3}$ mesmo com alta concentração de oxigênio.

Tabela 7.3: Energia de ligação para cada estado de carga do defeito complexo.

\begin{tabular}{c|c} 
Estado de Carga & Energia de Ligação por átomo $(\mathrm{eV})$ \\
\hline $1+$ & - \\
$2+$ & 0,296 \\
$3+$ & 0,558 \\
$4+$ & 0,727
\end{tabular}

\subsubsection{Propriedades óticas}

Para obtenção das propriedades óticas do composto $\operatorname{InO}_{x} \mathrm{~N}_{1-x}$, realizou-se os cálculos com DFT em supercélulas com presença de 2,76, 8,32, 11,11 e 22,22\% de oxigênio no estado de carga $1+$, distribuídos uniformemente no espaço. Como é possível observar na figura 7.11 a borda de absorção diminui conforme se aumenta 
a concentração de oxigênio, apesar de ainda ser maior que o valor do bulk de InN. Esse efeito é devido a redução da diferença entre o mínimo da banda de condução e o máximo da banda de valência. Portanto, há uma competição entre o efeito de Moss-Burstein e a interação entre os elétrons da banda de condução e as impurezas na qual resulta numa compensação parcial. Os resultados obtidos nesse trabalho utilizando o método TB-mBJ no esquema FP-(L)APW+lo não estão de acordo com o trabalho experimental de Yoshimoto et al. [48], onde reportaram o aumento do band gap com o aumento da presença de oxigênio. Entretanto, Wintreber et al. [49] não encontrou tal relação, apesar de o band gap ser próximo de 1,4 eV . Porém, esse último grupo produziu filmes monocristalinos enquanto que o primeiro produziu filmes policristalinos com baixa mobilidade eletrônica de $10 \frac{\mathrm{cm}^{2}}{V \cdot s}$ e não havia informação a respeito do tamanho do nanogrão. Portanto, não é possível descartar os efeitos de tamanho quântico, já que é muito comum em estruturas policristalinas e podem afetar fortemente o espectro de absorção. No trabalho de Lan et al. [50], eles obtiveram um band gap por fotoluminescência de 1,9 e $0,77 \mathrm{eV}$ para nanoestruturas com formato cilíndrico, ou também conhecido como nano-bastões, de diâmetro 30-50 nm e maiores que $50 \mathrm{~nm}$, respectivamente. C. Chao et al. [51] também observaram esse comportamento, porém para diâmetros variando entre 5 e $40 \mathrm{~nm}$. Infelizmente, a comparação com resultados experimentais não é possível, uma vez que há vários outros fatores que fortemente influenciam nas propriedades óticas do InN como o efeito de tamanho quântico, presença de outras impurezas, como é amplamente discutido em Butcher et al [52].

Tabela 7.4: Valores de $E_{g}^{o p t}$ e $\Delta E_{M B C-M B V}$ extraídos dafigura 7.11 and 7.12, respectivamente.

\begin{tabular}{c|c|c} 
Oxigênio (\%) & $E_{g}^{o p t}(\mathrm{eV})$ & $\Delta E_{M B C-M B V}(\mathrm{eV})$ \\
\hline 2,76 & 1,501 & 0,909 \\
8,32 & 1,321 & 0,795 \\
11,11 & 1,262 & 0,733 \\
22,22 & 1,273 & 0,615
\end{tabular}

Observa-se então que devido a doação dos elétrons pelo oxigênio, estes influ- 


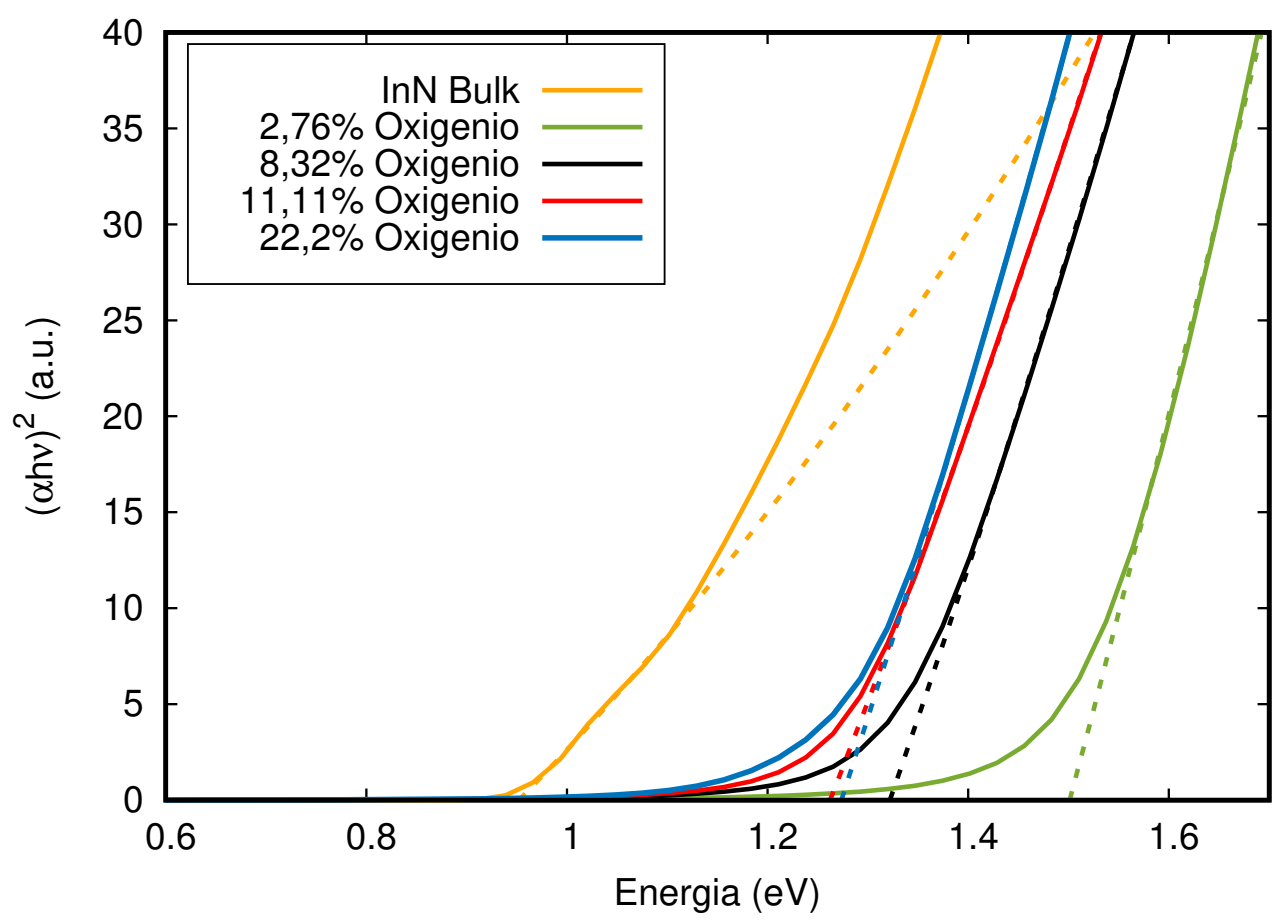

Figura 7.11: Determinação do band gap ótico do $\operatorname{InO}_{x} \mathrm{~N}_{1-x}$ utilizando o método TB-mBJ.

enciam na variação da borda de absorção. Portanto, a fim de aprofundar o estudo nessa direção calculou-se o espectro de absorção do InN com diferentes concentrações de transportadores de carga (figura 7.13) utilizando apenas o método Pbesol-GGA. Para cada concentração, aplicou-se novamente a equação 4.29 para obtenção do band gap ótico. A comparação com resultados experimentais utilizando métodos de produção MBE e MOCVD também estão exibidos a título de comparação. Devido a subestimação dos métodos GGA, a curva foi deslocada para se adequar aos dados experimentais em baixas concentrações de transportadores. O gráfico da figura 7.13 mostra que os resultados de Sugita et al. [53] estão em boa concordância com a curva teórica, porém os resultados de Walukiewicz et al. [54] revelam uma notável discrepância para altas concentrações, onde o primeiro grupo utilizou o método MOCVD e o segundo MBE. Isto pode ser devido a alta mobilidade eletrônica de $730 \frac{\mathrm{cm}^{2}}{V \cdot s}$ pelo primeiro autor e de $615 \frac{\mathrm{cm}^{2}}{V \cdot s}$ para o segundo autor. Como o cálculo realizado com o InN é de um sistema puro e sem defeitos, é coerente haver uma melhor concordância com os resultados experimentais de uma estrutura com menor número de defeitos compensadores. 


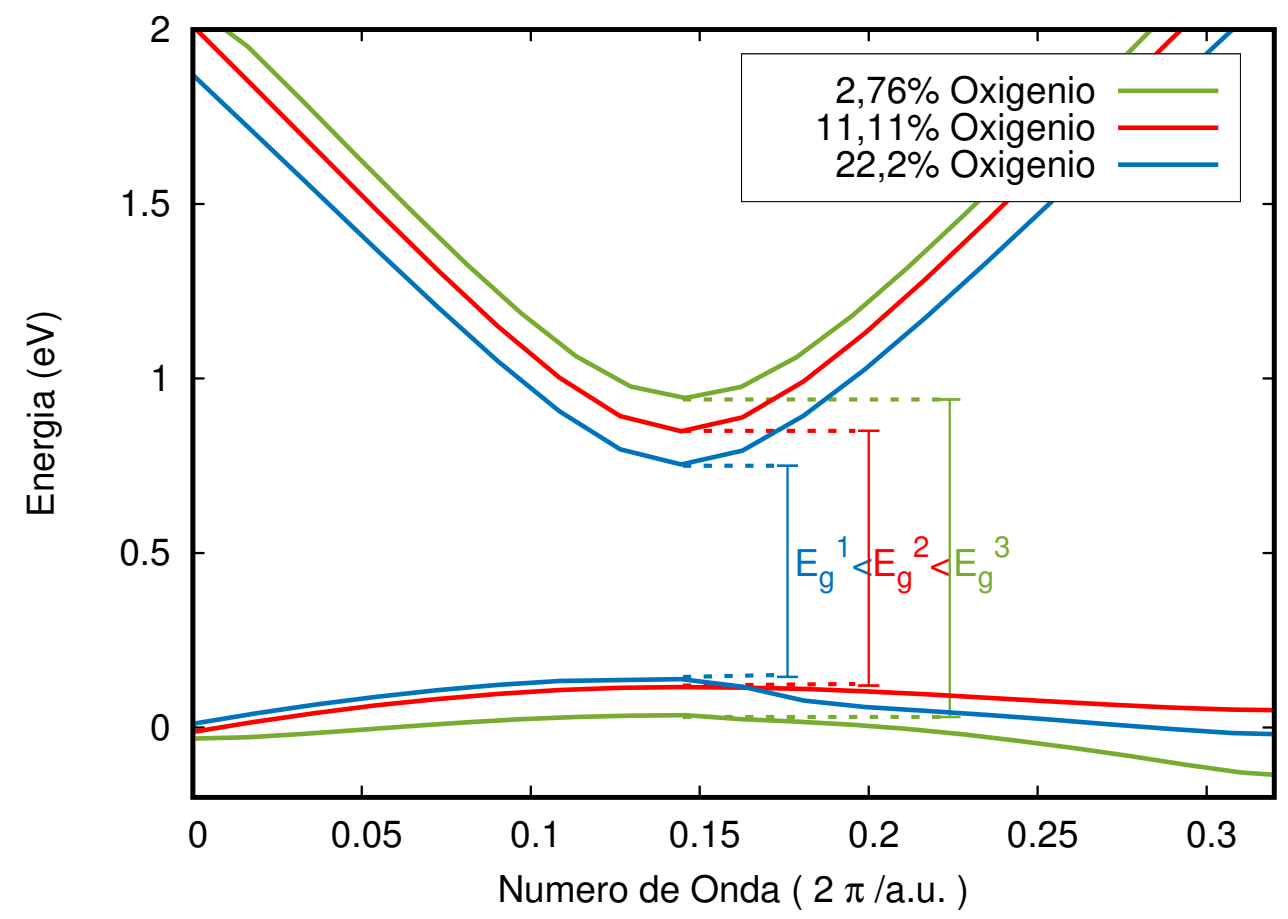

Figura 7.12: $\mathrm{MBC}$ e MBV do $\mathrm{InO}_{x} \mathrm{~N}_{1-x}$ calculado a partir do método TB-mBJ.

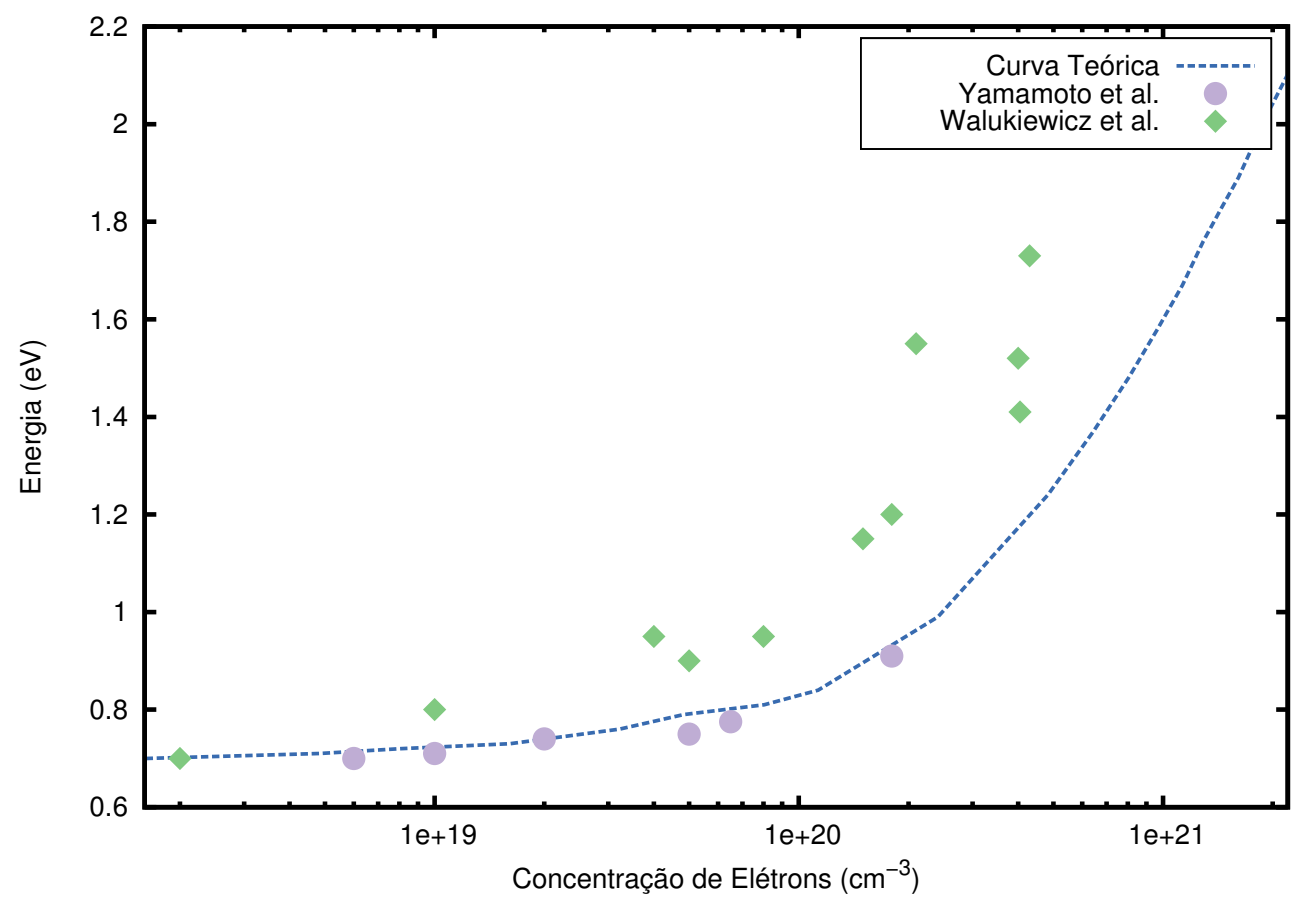

Figura 7.13: Curva teórica da variação do band gap ótico em função de transportadores de carga. 


\section{Capítulo 8}

\section{Conclusões}

A utilização do sistema IBAD para produção de filmes finos de InN se mostrou bastante promissor diante dos resultados de alta cristalinidade obtidos pelo XRD. As amostras depositadas à temperatura ambiente e acima da temperatura de $\mathrm{T}=480^{\circ} \mathrm{C}$ não apresentaram formação de $\mathrm{InN}$, no último devido a baixa temperatura de dissociação do InN somado ao bombardeamento de íons energéticos. O uso de $R_{a}$ próximo de 2,3 possibilitou um maior grau de cristalinidade, o qual descresce conforme se diverge desse valor. A utilização do efeito Gettering permitiu a redução de impurezas no filme fino, principalmente de oxigênio.

As medidas obtidas por RBS indicam uma forte mistura dos elementos do substrato com o InN, mesmo próximos da superfície. Verificou-se também uma maior concentração de índio na superfície, devido a alta pressão de vapor do nitrogênio no InN e ao sputtering preferencial.

Os cálculos ab initio baseados no DFT utilizando o funcional PBEsolGGA na energia de troca e correlação, possibilitou a obtenção de parâmetros de rede próximos de resultados experimentais. A aplicação do método TB-mBJ permitiu a abertura do band gap, cujo valor obtido foi de $E_{g}=0,89 \mathrm{eV}$, próximo do valor experimental de cerca de $0,7 \mathrm{eV}$. O estudo realizado da formação dos defeitos mostrou que o oxigênio pode ser facilmente incorporado no InN e ter a função de doador. Os resultados obtidos com o cálculo da energia de ligação indicam que é energeticamente 
favorável estes se distribuírem de forma carregada e isolada na estrutura. Devido a doação dos elétrons pelo oxigênio, o efeito de Moss-Burstein aumenta o band gap ótico aparente, entretanto, a interação dos elétrons de condução com as impurezas resulta também numa diminuição da MBC e MBV. Apesar desse último efeito, o band gap ótico efetivo continua a ser maior do que do bulk de InN. 


\section{Referências}

[1] H. J. Hovel e J. J. Cuomo. Electrical and optical properties of rf sputtered gan and inn. Applied Physics Letters, 20(2), 1972.

[2] T.L. Tansley e C.P. Foley. Optical band gap of indium nitride. Journal of Applied Physics, 59:3241-3244, 1986.

[3] H. Lu, W.J. Schaff, e L.F. Eastman. Mater. Res. Soc. Symp. Proc., 693:9, 2002.

[4] H. Lu, W.J. Schaff, e L.F. Eastman. Surface chemical modification of inn for sensor applications. Journal of Applied Physics, 95:3577, 2004.

[5] B.J. Neudecker e R.A. Zuhr. Intercalation compounds for battery materials. Electrochem. Soc. Proc., 99-24:295, 2000.

[6] Q. Guo e A. Yoshida. Temperature dependence of band gap change in inn and aln. Jpn. Journal of Applied Physics, 33:2453, 1994.

[7] J. Wu, W. Walukiewicz, K. M. Yu, J. W. Ager, E. E. Haller, H. Lu, W. J. Schaff, Y. Saito, e Y. Nanishi. Unusual properties of the fundamental bandgap of inn. Applied Physics Leter, 80:3967-3969, 2002.

[8] Elias Burstein. Physical Review, 93:632-633, 1954.

[9] T.S. Moss. Proc. Phys. Soc., B67:775, 1954.

[10] D. Van Vechten, G. K. Hubler, E. P. Donovan, e F. D. Correll. Fundamentals of ion beam assisted deposition. i. model of process and reproducibility of film composition. Journal of Vacuum Science Technology A, 8(2), 1990.

[11] P.W. Atkins. Physical Chemistry. W.H. Freeman Compann, 1982. 
[12] G. K. Hubler, D. Van Vechten, E. P. Donovan, e C. A. Carosella. Fundamentals of ion beam assisted deposition. ii. absolute calibration of ion and evaporant fluxes. Journal of Vacuum Science Technology A, 8(2), 1990.

[13] D. Van Vechten, G.K. Hubler, e E.P. Donovan. Characterization of a $3 \mathrm{~cm}$ kaufman ion source with nitrogen feed gas. Vacuum, 36(11-12):841 - 845, 1986.

[14] M. R. Flannery, P. C. Cosby, e T. F. Moran. Molecular charge transfer: Experimental and theoretical investigation of the role of incidention vibrational states in $\mathrm{n} 2+-\mathrm{n} 2$ and co +- co collisions. The Journal of Chemical Physics, 59(10), 1973.

[15] Ashraful Ghani Bhuiyan, Akihiro Hashimoto, e Akio Yamamoto. Indium nitride (inn): A review on growth, characterization, and properties. Journal of Applied Physics, 94(5), 2003.

[16] F. Agulló-Rueda, E.E. Mendez, B. Bojarczuk, e S. Guha. Raman spectroscopy of wurtzite inn films grown on si. Solid State Communications, 115(1):19 - 21, 2000 .

[17] B. D Cullity. Elements Of X Ray Diffraction. Addison-Wesley, 1956.

[18] P. Hohenberg e W. Kohn. Physical Review, 136(3B):864, 1964.

[19] W. Kohn e L. J. Sham. Self-consistent equations including exchange and correlation effects. Physical Review, 140:A1133-A1138, 1965.

[20] John P. Perdew, Adrienn Ruzsinszky, Gábor I. Csonka, Oleg A. Vydrov, Gustavo E. Scuseria, Lucian A. Constantin, Xiaolan Zhou, e Kieron Burke. Restoring the density-gradient expansion for exchange in solids and surfaces. Physics Review Letters, 100:136406, 2008.

[21] J. Kuneš, V. I. Anisimov, S. L. Skornyakov, A. V. Lukoyanov, e D. Vollhardt. Nio: Correlated band structure of a charge-transfer insulator. Physics Review Letters, 99:156404, 2007. 
[22] F. Bechstedt, F. Fuchs, e G. Kresse. Ab-initio theory of semiconductor band structures: New developments and progress. Physica Status Solidi (b), 246(8):1877-1892, 2009.

[23] Axel D. Becke e Erin R. Johnson. A simple effective potential for exchange. The Journal of Chemical Physics, 124(22), 2006.

[24] Peter Blaha Fabien Tran e Karlheinz Schwarz. Band gap calculations with becke-johnson exchange potential. Journal of Physics: Condensed Matter, 19(19):196208, 2007.

[25] Fabien Tran e Peter Blaha. Accurate band gaps of semiconductors and insulators with a semilocal exchange-correlation potential. Physics Review Letters, 102:226401, 2009 .

[26] David Koller, Fabien Tran, e Peter Blaha. Merits and limits of the modified becke-johnson exchange potential. Physical Review B, 83:195134, 2011.

[27] Claudia Ambrosch-Draxl e Jorge O. Sofo. Linear optical properties of solids within the full-potential linearized augmented planewave method. Computer Physics Communications, 175(1):1 - 14, 2006.

[28] W.A. Harrison. Electronic structure and the properties of solids. Dover Publication, 1989.

[29] C. Kittel. Introduction to Solid State Physics. John Wiley and Sons, 1996.

[30] S. B. Zhang e John E. Northrup. Chemical potential dependence of defect formation energies in gaas: Application to ga self-diffusion. Physics Review Letters, 67:2339-2342, 1991.

[31] M Leslie e N J Gillan. The energy and elastic dipole tensor of defects in ionic crystals calculated by the supercell method. Journal of Physics C: Solid State Physics, 18(5):973, 1985.

[32] Samuel E. Taylor e Fabien Bruneval. Understanding and correcting the spurious interactions in charged supercells. Physical Review B, 84:075155, 2011. 
[33] F. Stokker-Cheregi, A. Nedelcea, F. M. Voicu, D. M. Marin, R. Birjega, e M. Dinescu. Strucuture and morphology of indium nitride thin films grown by plasma assisted pld: The impact of nitrogen flow and substrate temperature. Romanian Reports in Physics, 65(1):213 - 218, 2013.

[34] K. Kubota, Y. Kobayashi, e K. Fujimoto. Preparation and properties of iii v nitride thin films. Journal of Applied Physics, 66(7), 1989.

[35] V.Yu. Davydov, A.A. Klochikhin, R.P. Seisyan, V.V. Emtsev, S.V. Ivanov, F. Bechstedt, J. Furthmüller, H. Harima, A.V. Mudryi, J. Aderhold, O. Semchinova, e J. Graul. Absorption and emission of hexagonal inn. evidence of narrow fundamental band gap. Physica Status Solidi (b), 229(3):r1-r3, 2002.

[36] Z.G. Qian, G. Yu, W.Z. Shen, H. Ogawa, e Q.X. Guo. Growth-dependent phonon characteristics in inn thin films. Physica B: Condensed Matter, $318(2-3): 180-187,2002$.

[37] Nitta S. Takeuchi T. Wetzel C. Amano H. Akasaki I. Yamaguchi S., Kariya M. Structural properties of inn on gan grown by metalorganic vapor-phase epitaxy. Journal of Applied Physics, 85(11):7682-7688, 1999.

[38] Y. Saito, T. Yamaguchi, H. Kanazawa, K. Kano, T. Araki, Y. Nanishi, N. Teraguchi, e A. Suzuki. Growth of high-quality inn using low-temperature intermediate layers by rf mbe. Journal of Crystal Growth, 237-239, Part 2:1017 $1021,2002$.

[39] H. Hahn R. Juza. Anorg. Allg. Chem., 239(282):7682-7688, 1938.

[40] B. Maleyre, S. Ruffenach, O. Briot, e A. van der Lee. Lattice parameters of relaxed wurtzite indium nitride powder obtained by mocvd. Superlattices and Microstructures, 36(4-6):527 - 535, 2004.

[41] A. Svane, N. E. Christensen, I. Gorczyca, M. van Schilfgaarde, A. N. Chantis, e T. Kotani. Quasiparticle self-consistent gw theory of iii-v nitride semiconductors: Bands, gap bowing, and effective masses. Physical Review B, 82:115102, 2010. 
[42] A. Sungthong, S. Porntheeraphat, A. Poyai, e J. Nukeaw. An extreme change in structural and optical properties of indium oxynitride deposited by reactive gas-timing $\{\mathrm{RF}\}$ magnetron sputtering. Applied Surface Science, 254(23):7950 $-7954,2008$.

[43] K. A. Mkhoyan, J. Silcox, E. S. Alldredge, N. W. Ashcroft, H. Lu, W. J. Schaff, e L. F. Eastman. Measuring electronic structure of wurtzite inn using electron energy loss spectroscopy. Journal of Applied Physics, 82, 2003.

[44] C. Stampfl, C. G. Van de Walle, D. Vogel, P. Krüger, e J. Pollmann. Native defects and impurities in inn: First-principles studies using the local-density approximation and self-interaction and relaxation-corrected pseudopotentials. Physical Review B, 61:R7846-R7849, 2000.

[45] A. F. Wright. Substitutional and interstitial oxygen in wurtzite gan. Applied Physics, 98, 2005.

[46] A. Sungthong, S. Porntheeraphat, A. Poyai, e J. Nukeaw. An extreme change in structural and optical properties of indium oxynitride deposited by reactive gas-timing $\{\mathrm{RF}\}$ magnetron sputtering. Applied Surface Science, 254(23):7950 $-7954,2008$.

[47] Elaissa Trybus, Gon Namkoong, Walter Henderson, Shawn Burnham, W. Alan Doolittle, Maurice Cheung, e Alexander Cartwright. Inn: A material with photovoltaic promise and challenges. Journal of Crystal Growth, 288(2):218 $224,2006$.

[48] Masahiro Yoshimoto, Hiroaki Yamamoto, Wei Huang, Hiroshi Harima, Junji Saraie, Akiyoshi Chayahara, e Yuji Horino. Widening of optical bandgap of polycrystalline inn with a few percent incorporation of oxygen. Applied Physics Letters, 83(17), 2003.

[49] M. Wintrebert-Fouquet, K.Scott A Butcher, e P.P.-T Chen. Inn grown by remote plasma-enhanced chemical vapor deposition. Journal of Crystal Growth, 269(1):134 - 138, 2004. 
[50] Z.H Lan, W.M Wang, C.L Sun, S.C Shi, C.W Hsu, T.T Chen, K.H Chen, C.C Chen, Y.F Chen, e L.C Chen. Growth mechanism, structure and $\{\mathrm{IR}\}$ photoluminescence studies of indium nitride nanorods. Journal of Crystal Growth, $269(1): 87-94,2004$.

[51] Chih-Kang Chao, Hsiang-Szu Chang, Tzu-Min Hsu, Chien-Nan Hsiao, ChiChung Kei, Shou-Yi Kuo, e Jen-Inn Chyi. Optical properties of indium nitride nanorods prepared by chemical-beam epitaxy. Nanotechnology, 17(15):3930, 2006.

[52] K. S. A. Butcher e T. L. Tansley. InN, latest development and a review of the band-gap controversy. Superlattices and Microstructures, 38:1-37, 2005.

[53] K. Sugita, H. Takatsuka, A. Hashimoto, e A. Yamamoto. Photoluminescence and optical absorption edge for movpe-grown inn. Physica Status Solidi (b), 240(2):421-424, 2003.

[54] W. Walukiewicz, S.X Li, J Wu, K.M Yu, J.W Ager III, E.E Haller, Hai Lu, e William J Schaff. Optical properties and electronic structure of inn and in-rich group iii-nitride alloys. Journal of Crystal Growth, 269(1):119 - 127, 2004. 